THE IMPACT OF DEFECTS ON TENSILE STRENGTH AND MODULUS OF 3D PRINTED PARTS MANUFACTURED BY FUSED DEPOSITION MODELING

by

Mobina Movahedi

Bachelor of Engineering, Ryerson University (2015)

\author{
A project \\ presented to Ryerson University \\ in partial fulfilment of the \\ requirements for the degree of \\ Master of Engineering \\ in the program of Aerospace Engineering
}

Toronto, Ontario, Canada, 2019

(C) Mobina Movahedi, 2019 


\section{AUTHOR'S DECLARATION FOR ELECTRONIC SUBMISSION OF A PROJECT}

I hereby declare that I am the sole author of this project. This is a true copy of the project, including any required final revisions.

I authorize Ryerson University to lend this project to other institutions or individuals for the purpose of scholarly research.

I further authorize Ryerson University to reproduce this project by photocopying or by other means, in total or in part, at the request of other institutions or individuals for the purpose of scholarly research.

I understand that my project may be made electronically available to the public. 


\section{ACKNOWLEDGEMENTS}

I would first like to thank my thesis advisor Dr. Kazem Fayazbakhsh of Aerospace Engineering at Ryerson University. The door to his office was always open whenever I ran into a trouble or had questions about any aspects of my research. He consistently allowed this paper to be my own work, but directed me in the right the direction whenever he thought I needed it.

I would also like to acknowledge Jordan Kalman of Ryerson University, undergraduate studies at Aerospace Engineering for his great support throughout this project to capture high quality imaging.

Finally, I must express my profound gratitude to my parents for providing me with unfailing support and continuous encouragement throughout my years of study. This accomplishment would not have been possible without them.

Thank you. 


\title{
The Impact of Defects on Tensile Strength and Modulus of 3D Printed Parts Manufactured by Fused Deposition Modeling
}

\author{
Mobina Movahedi \\ Master of Engineering, Aerospace Engineering, Ryerson University, Toronto (2019)
}

\begin{abstract}
Additive manufacturing (AM), 3D printing, is defined as a process of depositing materials layer by layer to create three-dimensional printed models, as opposed to subtractive manufacturing methodologies. It has the potential of revolutionizing field of manufacturing, which allows us to create more complex geometries with lower cost and faster speed in comparison to injection molding, compression forming, and forging. Therefore, 3D printing can shorten the designmanufacturing cycle, reduce the production cost, and increase the competitiveness. Due to the improvements of processes and advancements of modeling and design, Fused Deposition Modeling (FDM) technologies, a common 3D printing technique, have been involved in wide various applications in the past three decades and numerous studies have been gathered. This research work studies directional properties of FDM 3D printed thermoplastic parts per ASTM D638. Tensile strength and modulus of the coupons along and perpendicular to the printing direction are evaluated. It is observed that FDM 3D printing introduces anisotropic behavior to the manufactured part, e.g. tensile strength of 57.7 and $30.8 \mathrm{MPa}$ for loading along and perpendicular to the printing direction, respectively. FDM 3D printers are not ideal and introduce defects into the manufactured parts, e.g. in the form of missing material, gap. This study investigates the impact of gaps on tensile strength and modulus of 3D printed parts. A maximum reduction of $20 \%$ in strength is found for a gap (missing bead) along the loading direction.
\end{abstract}




\section{TABLE OF CONTENTS}

AUTHOR'S DECLARATION FOR ELECTRONIC SUBMISSION OF A PROJECT ............................ii

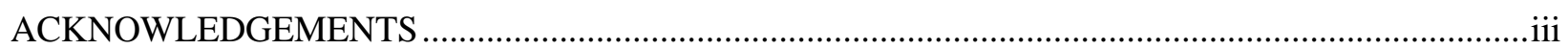

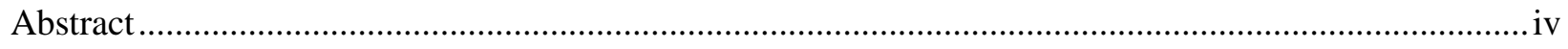

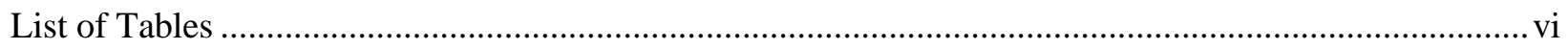

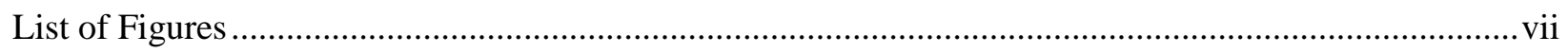

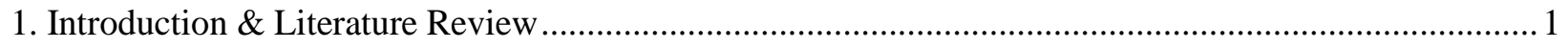

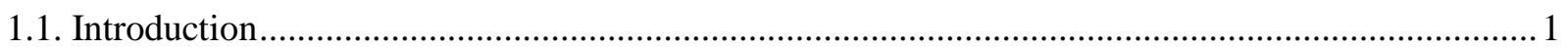

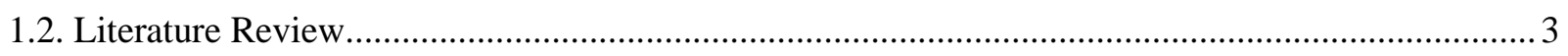

1.2.1. Impact of build orientation and raster angle on tensile strength and modulus.......................... 4

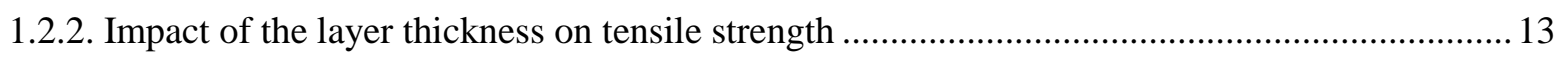

1.2.3 Impact of air gap and infill percentage on the tensile strength ............................................... 14

1.2.4 Impact of fiber reinforced filaments on tensile strength ..................................................... 16

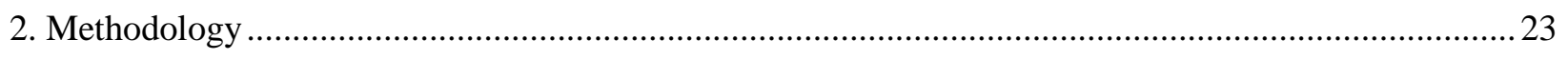

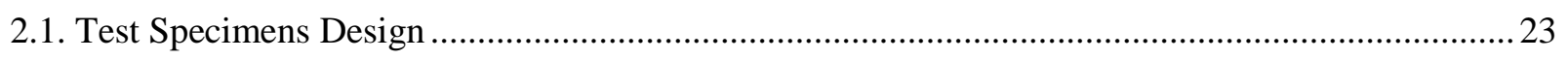

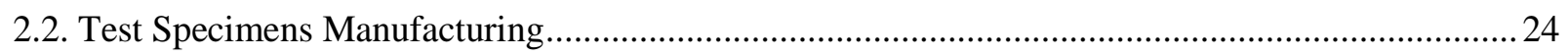

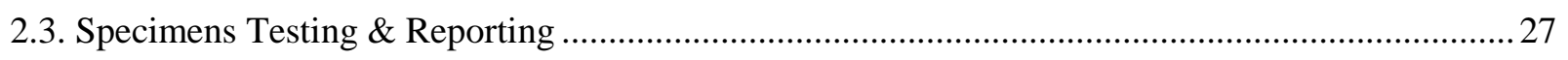

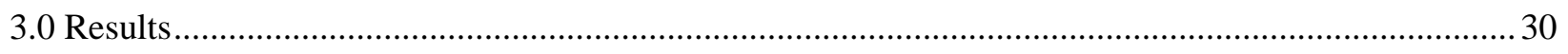

3.1. Mechanical characterization of 3D printed parts without defects .............................................. 30

3.2. Mechanical characterization of 3D printed parts with defects ................................................... 36

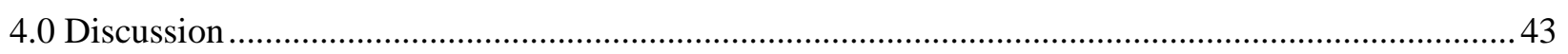

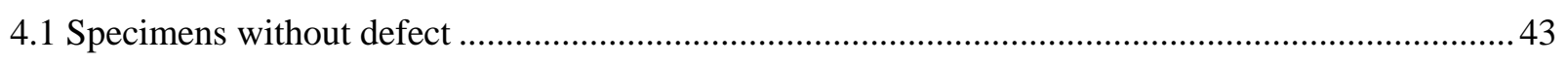

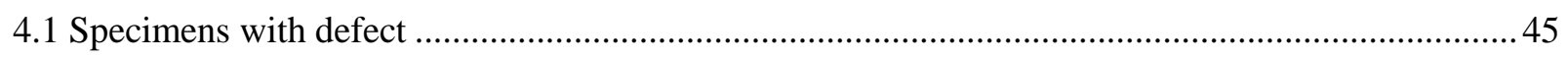

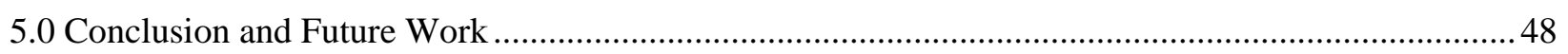

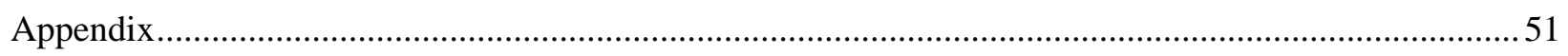

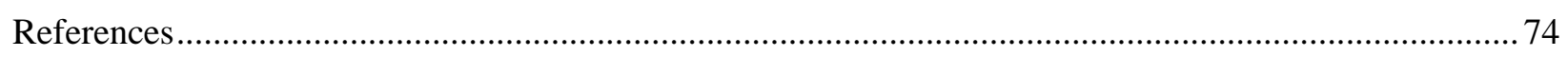




\section{LIST OF TABLES}

Table 1: Printing parameters and their levels considered (7) ..................................... 5

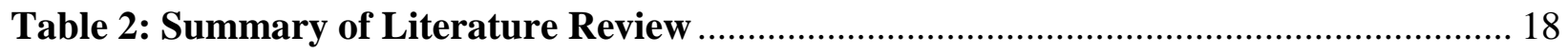

Table 3: Specimen Design Parameters ..................................................................... 25

Table 4: FDM Tensile coupons without defects print mechanical properties.................... 30

Table 5: Coupon A Tensile Test Experimental Results.............................................. 34

Table 6: Coupon B Tensile Test Experimental Results/............................................ 34

Table 7: Coupon C Tensile Test Experimental Results............................................ 35

Table 8: FDM Tensile coupons with defects mechanical properties ............................... 36

Table 9: Coupon D Tensile Test Experimental Results............................................. 41

Table 10: Coupon E Tensile Test Experimental Results ........................................... 41

Table 11: Coupon F Tensile Test Experimental Results ............................................. 41

Table 12: Tensile strength and Modulus of specimens without defect ............................ 43

Table 13: Tensile strength and Modulus of specimens with defect ............................... 45

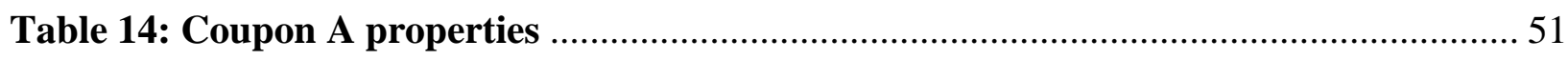

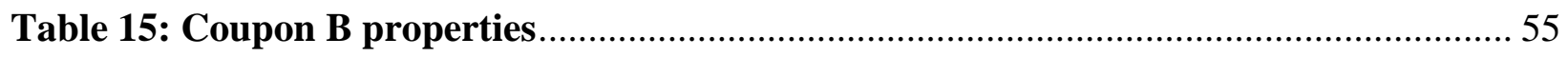

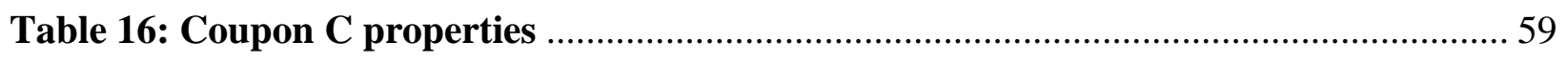

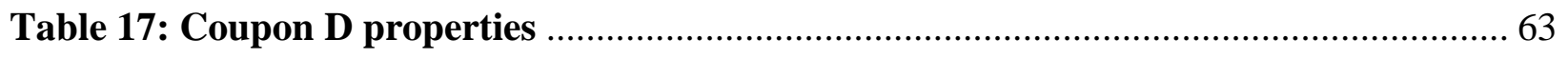

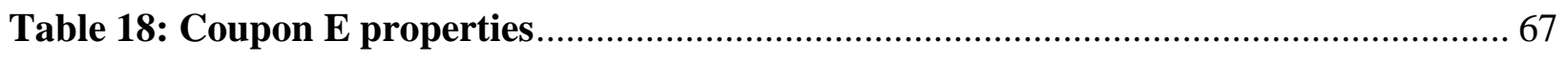

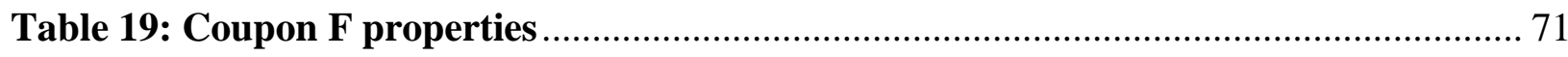




\section{LIST OF FIGURES}

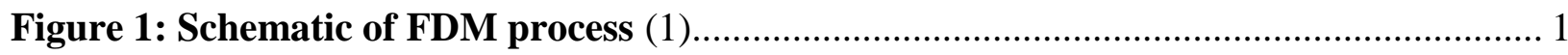

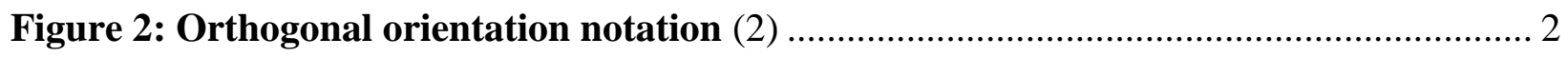

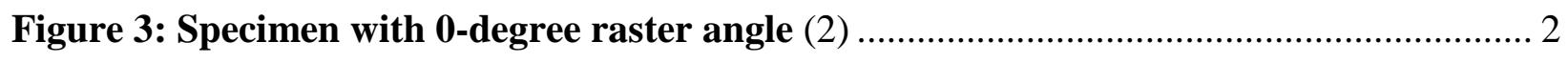

Figure 4: Specimen with 45-degree raster angle (2) …............................................. 2

Figure 5: Specimen with 90-degree raster angle (2) .............................................. 3

Figure 6: Specimen with +/- 45-degree raster angle $(2)$............................................ 3

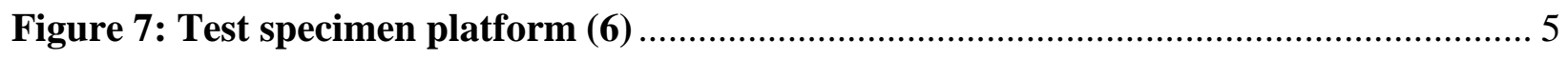

Figure 8: 3D views of specimen setup on the printer (7) .......................................... 5

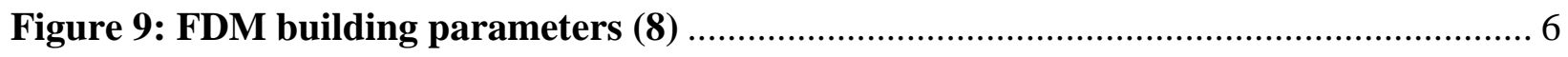

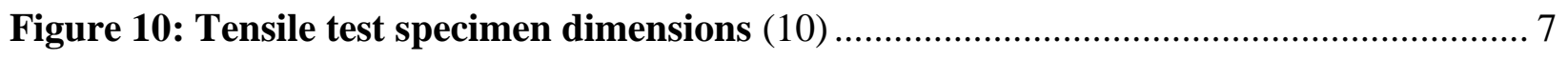

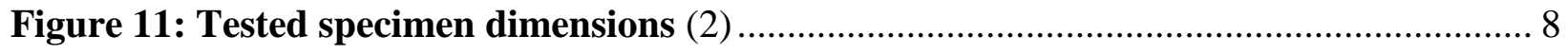

Figure 12: Build orientation: (a) Up-right (XZY), (b) Face-up (XYZ), and (c) Edge-up (ZYX) (11)

Figure 13: Boundary conditions and relative raster angle between infill and loading line (12)

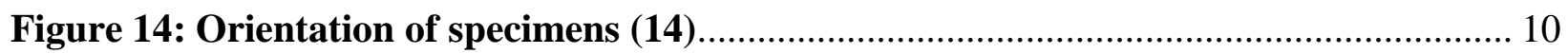

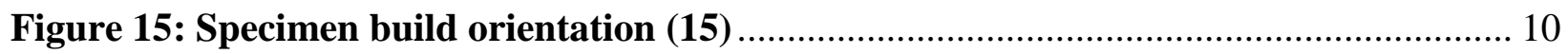

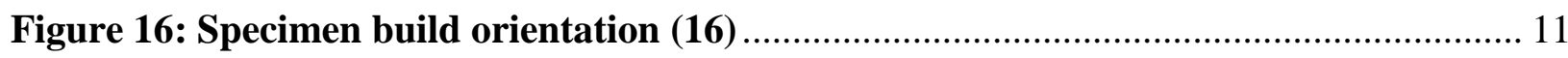

Figure 17: The element orientation in the working area according to direction of print head

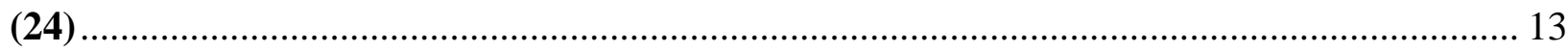

Figure 18: Stress-Strain curve for specimen build at $\mathbf{0 / 9 0}$ degree with different layer

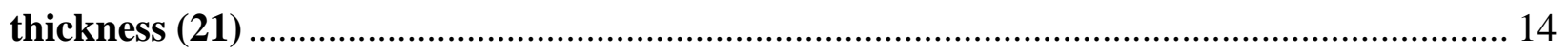

Figure 19: Specimen model for the tensile strength test (28) ....................................... 15

Figure 20: ASTM D638-02a Type I tensile strength test specimen (29) .......................... 16 


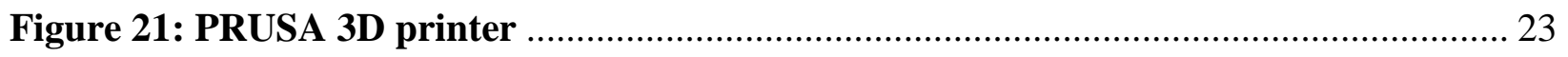

Figure 22: Specimen Dimensions for thickness T (36) ................................................. 24

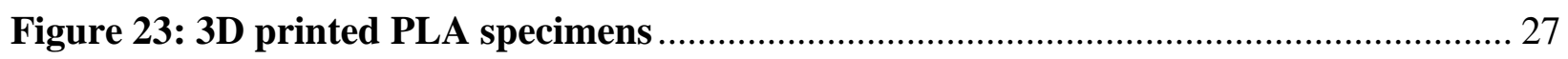

Figure 24: Coupon with defect on 0-degree raster angle ..................................................... 27

Figure 25Coupon with defect on 90-degree raster angle .................................................... 27

Figure 26: Coupon with defect on both 0 and 90-degree raster angle ................................. 27

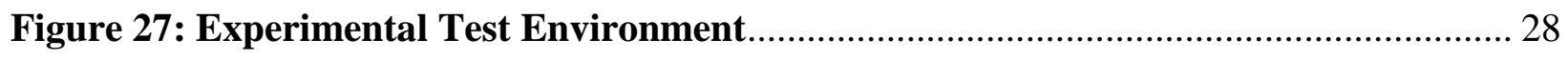

Figure 28: Stress - Strain Curves for Coupon A-1 ………............................................... 31

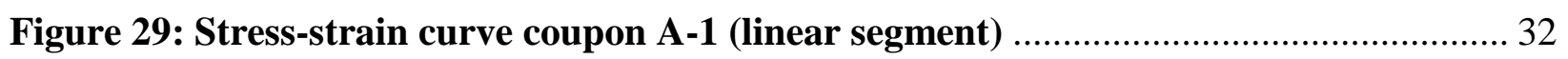

Figure 30: Stress - Strain Curves for Coupon B-1 ………………...................................... 32

Figure 31: Stress - Strain Curves for Coupon B-1 (linear segment) ..................................... 33

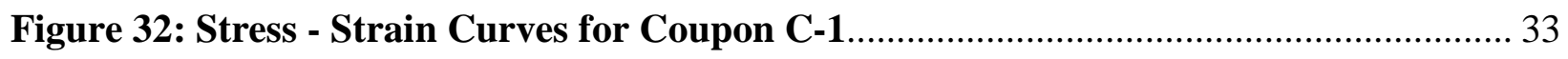

Figure 33: Stress-strain curve coupon C-1 (linear segment) …………………………....... 34

Figure 34. Coupon A SEM image of fracture surface (15x zoom) ………........................ 35

Figure 35. Coupon B SEM image of fracture surface (15x zoom) …………....................... 36

Figure 36. Coupon C SEM image of fracture surface (15x zoom) ……………………....... 36

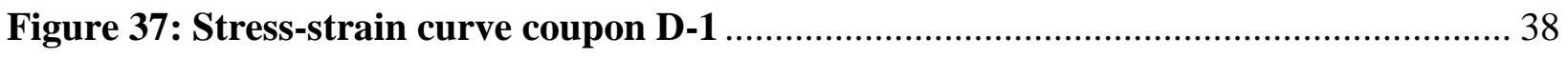

Figure 38: Stress-strain curve coupon D-1 (linear segment) ……………………............... 38

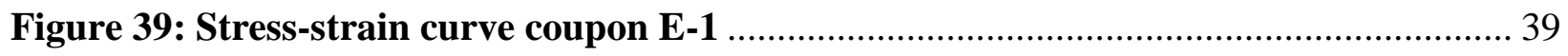

Figure 40: Stress-strain curve coupon E-1 (linear segment) ................................................ 39

Figure 41: Stress-strain curve coupon F-1_.................................................................... 40

Figure 42: Stress-strain curve coupon F-1 (linear segment) ……………………................. 40

Figure 43. Coupon D SEM image of fracture surface (15x zoom) ………………............ 42 


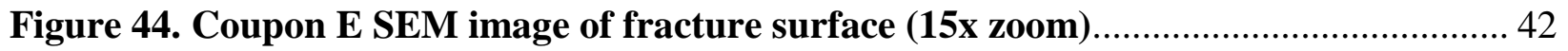

Figure 45. Coupon F SEM image of fracture surface $(15 \mathrm{x} \mathrm{zoom)}$................................. 42

Figure 46: Tensile Strength of specimens without defects ............................................. 44

Figure 47: Modulus of specimens without defects ........................................................ 44

Figure 48. Failure strain of specimens without defects ........................................... 45

Figure 49: Tensile Strength of specimens with defects compared with the baseline (Coupon

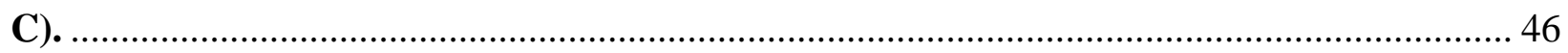

Figure 50: Modulus of specimens with defects compared with the baseline (Coupon C).... 47

Figure 51. Failure strain of specimens with defects compared with the baseline (Coupon C).

Figure 52: Stress - Strain Curves for Coupon A-2 .................................................... 51

Figure 53: Stress-strain curve coupon A-2 (linear segment) ....................................... 52

Figure 54: Stress - Strain Curves for Coupon A-3 .................................................. 52

Figure 55: Stress-strain curve coupon A-3 (linear segment) ......................................... 53

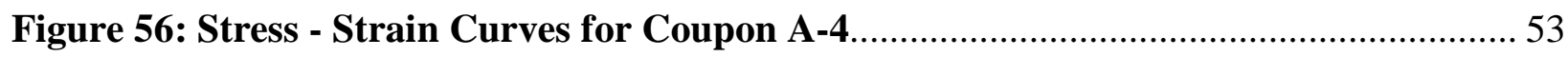

Figure 57: Stress-strain curve coupon A-4 (linear segment) ........................................ 54

Figure 58: Stress - Strain Curves for Coupon A-5 ................................................. 54

Figure 59: Stress-strain curve coupon A-5 (linear segment) ...................................... 55

Figure 60: Stress - Strain Curves for Coupon B-2 ...................................................... 56

Figure 61: Stress - Strain Curves for Coupon B-2 (linear segment) ................................56

Figure 62: Stress - Strain Curves for Coupon B-3 ..................................................... 57

Figure 63: Stress - Strain Curves for Coupon B-3 (linear segment) ............................... 57

Figure 64: Stress - Strain Curves for Coupon B-4 ................................................. 58

Figure 65: Stress - Strain Curves for Coupon B-4 (linear segment) .............................. 58 


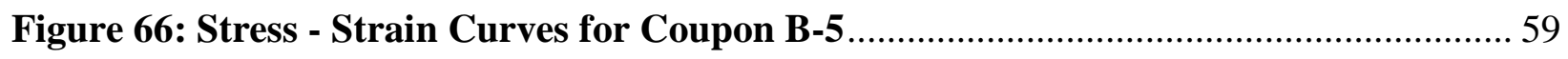

Figure 67: Stress - Strain Curves for Coupon B-5 (linear segment) ................................. 59

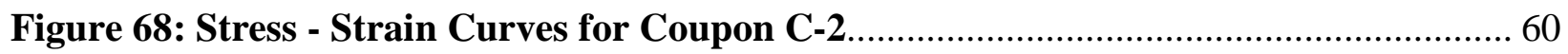

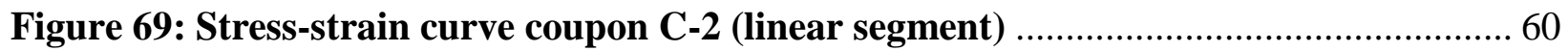

Figure 70: Figure 1: Stress - Strain Curves for Coupon C-3 ...................................... 61

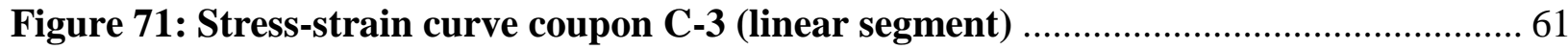

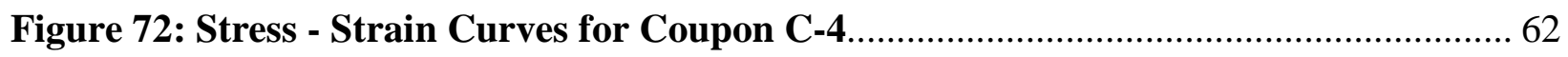

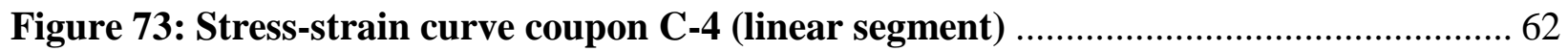

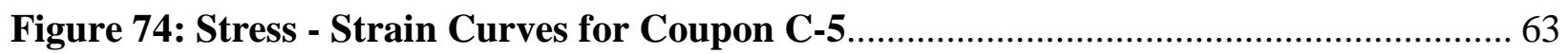

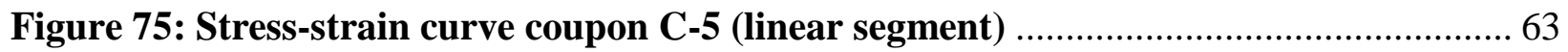

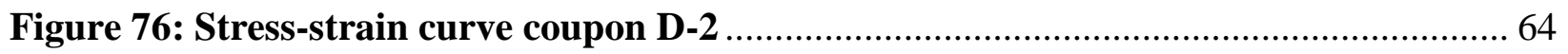

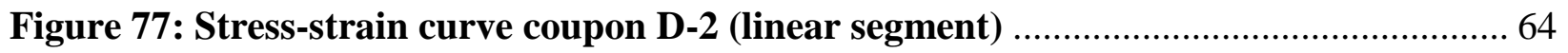

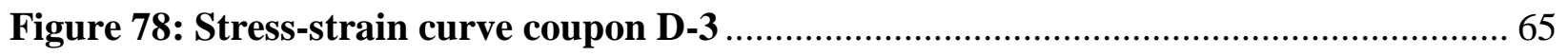

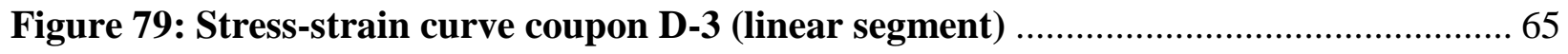

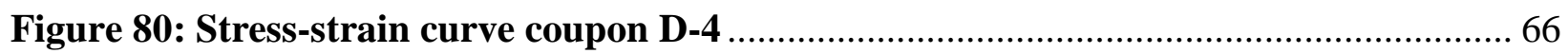

Figure 81: Stress-strain curve coupon D-4 (linear segment) ...................................... 66

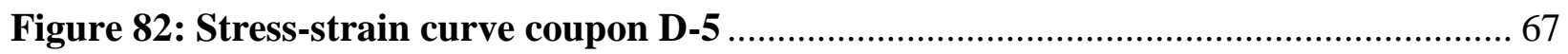

Figure 83: Stress-strain curve coupon D-5 (linear segment) ..................................... 67

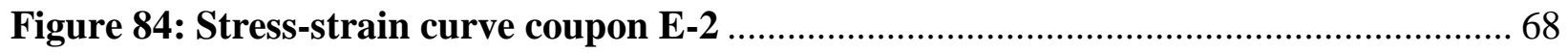

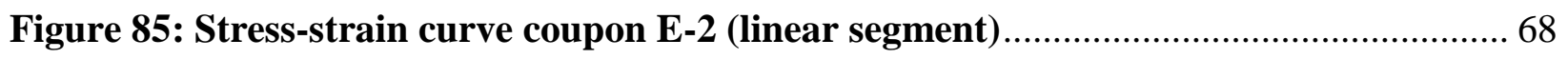

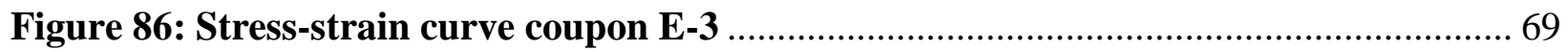

Figure 87: Stress-strain curve coupon E-3 (linear segment) ..................................... 69

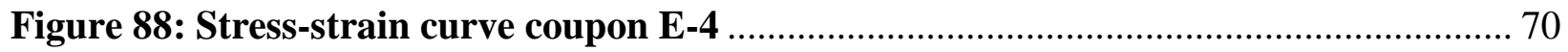


Figure 89: Stress-strain curve coupon E-4 (linear segment).

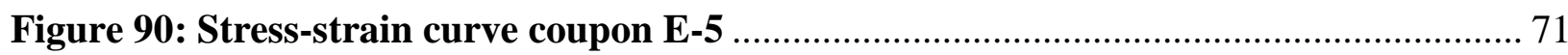

Figure 91: Stress-strain curve coupon E-5 (linear segment) .............................................. 71

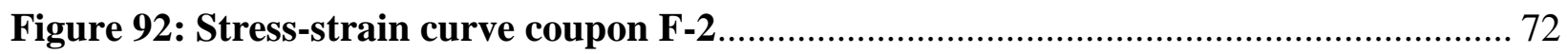

Figure 93: Stress-strain curve coupon F-2 (linear segment) …………………………....... 72

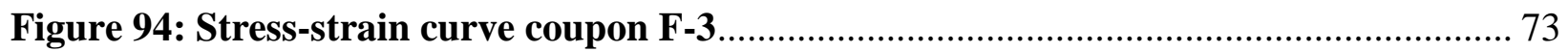

Figure 95: Stress-strain curve coupon F-3 (linear segment) …………………………...... 73

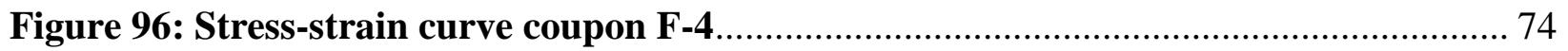

Figure 97: Stress-strain curve coupon F-4 (linear segment) ............................................. 74 


\section{INTRODUCTION \& LITERATURE REVIEW}

\subsection{INTRODUCTION}

In recent years, in the world of manufacturing Rapid Prototyping also known as Additive Manufacturing (AM) has become the focus. Fused deposition modeling (FDM) is one of the most common additive manufacturing techniques to fabricate complex three-dimensional components to a near-net shape. Throughout this manufacturing process, generally one material is being used for model, which is known as filament, and in some cases support material is required and being used in printing as well. This material is generally being deposited through a different nozzle than the filament. A very fine extrusion nozzle moving in the plane of build, mostly X and Y directions for depositing the material layer by layer. Upon the completion of one layer, the build platform is lowered and/or nozzle goes up based on the model to allow the next layer to be added. The support structure might be required depending on the positioning of the part. The support material can be removed easily once the prototyping process is complete and the part is out of the build chamber. Figure 1 below, depicts a schematic of FDM process.

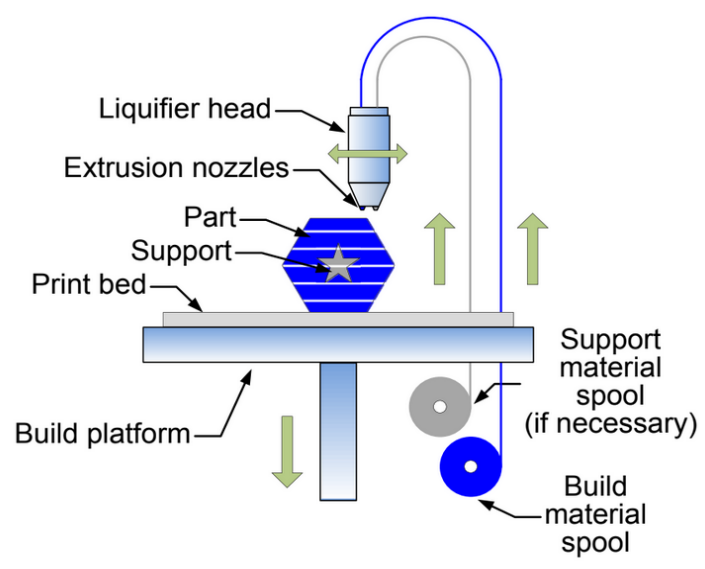

Figure 1: Schematic of FDM process (1)

To produce FDM parts aside from the material selection the process control parameters are likely to affect the properties of the FDM parts. The build parameters that most affecting the mechanical behavior of 3D printed parts are as follows: 
- Build Orientation - The orientation of which the model is printed. Figure 2, shows the orthogonal orientation notation per ISO/ASTM 52921:2013(E).

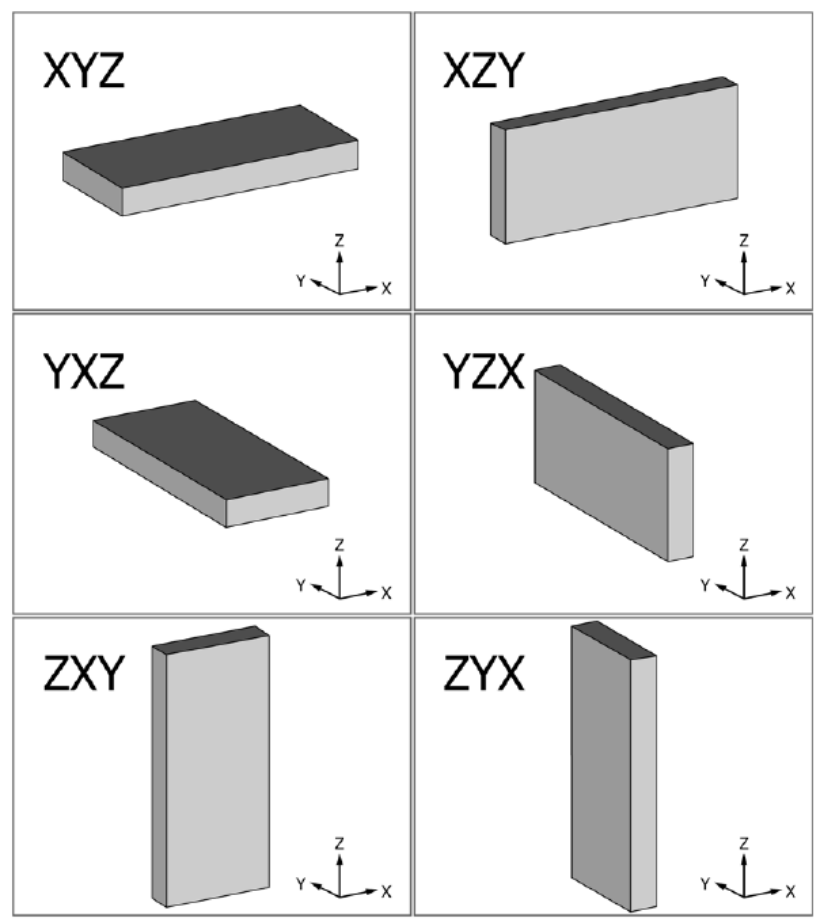

Figure 2: Orthogonal orientation notation (2)

- Raster Angle (orientation): this refers to the direction of the beads of material based on the loading of the part in the machine, principle direction. Figure 3 to Figure 6 below represent basic raster angles of 0, 45, 90 and +/- 45 degree.

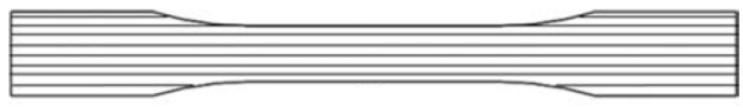

Figure 3: Specimen with 0-degree raster angle (2)

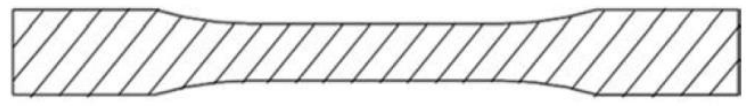

Figure 4: Specimen with 45-degree raster angle (2) 


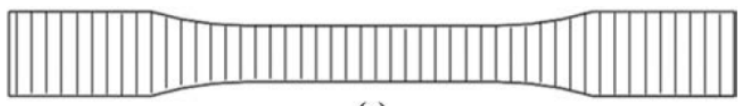

(c)

Figure 5: Specimen with 90-degree raster angle (2)

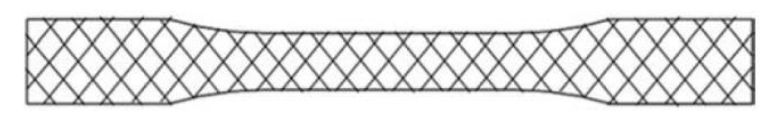

Figure 6: Specimen with +/- 45-degree raster angle (2)

- Layer Thickness: also known as slice height, is the thickness of each layer measured in Zdirection.

- Air Gap: the space between the beads of FDM 3D printed material is called air gap. The default is zero where, beads just touch and can be modified to have positive gap, which means that there is space between beads and they do not touch. The air gap can also be set to have a negative value, where the beads overlap or in other words partially occupy same space.

- Nozzle Temperature: the temperature of the nozzle at which filament material is being deposited has a critical impact on material bonding. The increase of the nozzle temperature to a certain limit during printing results in better interlayer bonding between the newly extruded polymer chains.

- Bed Temperature: In 3D printing, heated beds are commonly being used as they are well known for improving the print quality by preserving the extruded filament elevated temperature and therefore preventing warping.

\subsection{LITERATURE REVIEW}

Literature review was gathered to study the effect of above printing (build) parameters, i.e. build orientation, raster angle, layer thickness, and air gap, on the mechanical properties of 3D printed parts, e.g. tensile strength and modulus. The following subsections present a summary of studies 
gathered on various build parameters and their impact starting with orientation and raster angle followed by layer thickness, and air gap (or infill percentage).

\subsubsection{IMPACT OF BUILD ORIENTATION AND RASTER ANGLE ON TENSILE STRENGTH AND MODULUS}

Vast majority of journals and conference papers reviewed has focused on the impact of raster angle and build orientation on the mechanical behavior of 3D printed dog bone coupons as per ASTM D638 standard. Cetinkaya and Ryan (3) studied the ultimate tensile strength and modulus of the reinforced carbon fiber of 5-15 weight percentage (wt\%) considering the build orientation. The results of this study showed $44.1 \%$ increase in ultimate tensile stress (from 46.0 to $66.3 \mathrm{MPa}$ ) and a $42.7 \%$ increase in modulus (from 2.84 to $4.05 \mathrm{GPa}$ ) with carbon fibers aligned along the tensile axis. Carneiro et al. (4) Studied the raster angle of FDM parts by testing samples in various orientations of +/- 45, 0, and 90 degrees with layer thickness of $0.2 \mathrm{~mm}$ and infill degree of $100 \%$. It was observed that the 0-degree orientation samples have the highest, while the 45-degree samples have the lowest tensile strength. As a result of mechanical testing on various thicknesses, it was concluded that higher layer thickness value presents higher tensile strength.

Torrado el al. (5) presented an analysis on the effect of build orientation on the failure mode. The specimen XYZ orientation was recommended in comparison with ZXY orientation due to its simplicity, higher accuracy, and higher reliability of printing. Chacon et al. (6) studied the effect of build orientation on the mechanical performance of 3D printed PLA specimens using tensile testing. Figure 7 represents the coupon type and build orientation used for printing and testing based on ASTM638 standards. It was observed that the upright build orientation (ZXY) has 37\% to $78 \%$ lower tensile strength than flat (XYZ) and on-edge (XZY) orientation, respectively, which had similar value. 

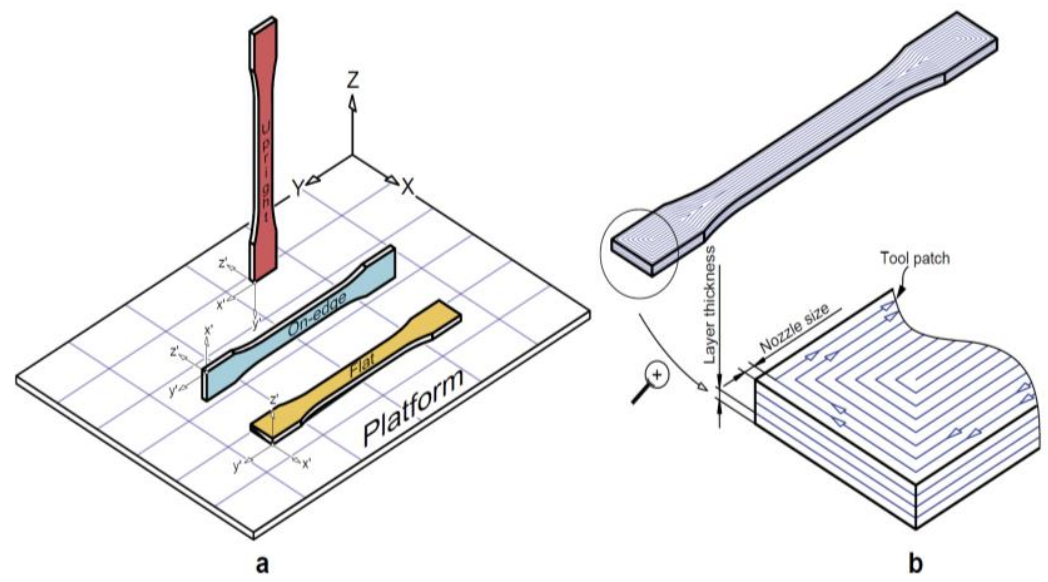

Figure 7: Test specimen platform (6)

Uddin et al. (7) compared mechanical performance of 3D printed parts with injection molding products. Table 1 and Figure 8 summaries the printing parameters and orientations considered here.

Table 1: Printing parameters and their levels considered (7)

\begin{tabular}{|c|c|c|c|}
\hline Parameters & \multicolumn{3}{|c|}{ Levels } \\
\hline Layer thickness $(\mathbf{m m})$ & 0.09 & 0.19 & 0.39 \\
\hline Printing Plane & $\mathrm{XY}$ & YZ & $\mathrm{ZX}$ \\
\hline Printing orientation & $\mathrm{H}(0$ degree $)$ & $\mathrm{D}(45$ degree $)$ & $\mathrm{V}(90$ degree $)$ \\
\hline
\end{tabular}

Figure 8 depicts the printing orientation considered in this study.

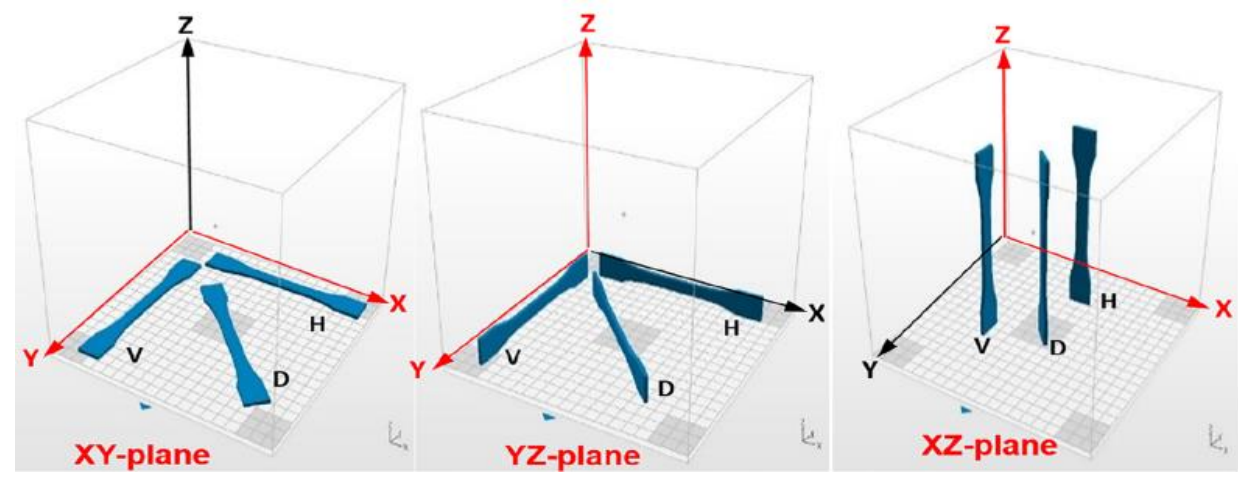

Figure 8: 3D views of specimen setup on the printer (7) 
3D printed specimens with layer thickness of $0.09 \mathrm{~mm}$ and $\mathrm{XYZ}$ build orientation had the highest Young's modulus of $1.5 \mathrm{GPa}$, while injection molding specimen were 1.22 times stiffer. The XYZ specimens with layer thickness of $0.09 \mathrm{~mm}$ show the highest yield strength of $39 \mathrm{MPa}$ among all printed specimens. While injection-molded parts had the highest yield strength, ductility of the printed specimens was 1.45 times larger than that of injection-molded parts. YZ-V with layer thickness of $0.19 \mathrm{~mm}$ had the highest failure strength of $30 \mathrm{MPa}$, which is two-fold increase of that of injection-molded parts.

Hossain et al. (8) studied the improvement of mechanical properties such as tensile strength of FDM parts through variation of build parameters. The build parameters considered in this study were: raster angle (RA), contour width $(\mathrm{CW})$, raster width $(\mathrm{RW})$, and raster-to-raster air gap (RRAG) parameters shown in Figure 9. Three build orientations of XYZ, XZY and ZXY each with raster angles of [0 90], [30 -60] and [45 -45] degree were tested. The XYZ build orientation presented the highest Ultimate Tensile Strength (UTS) of $44.76 \mathrm{MPa}$ to $53.22 \mathrm{MPa}$ observed at [0 90] and [45 -45] degree, respectively compared with [30 -60] degree. For the XZY orientation, the highest UTS of $62.84 \mathrm{MPa}$ was generated by a [0 90] degree raster angle. The ZXY orientation highest UTS of 35.27 MPa was at [30 -60] degree.

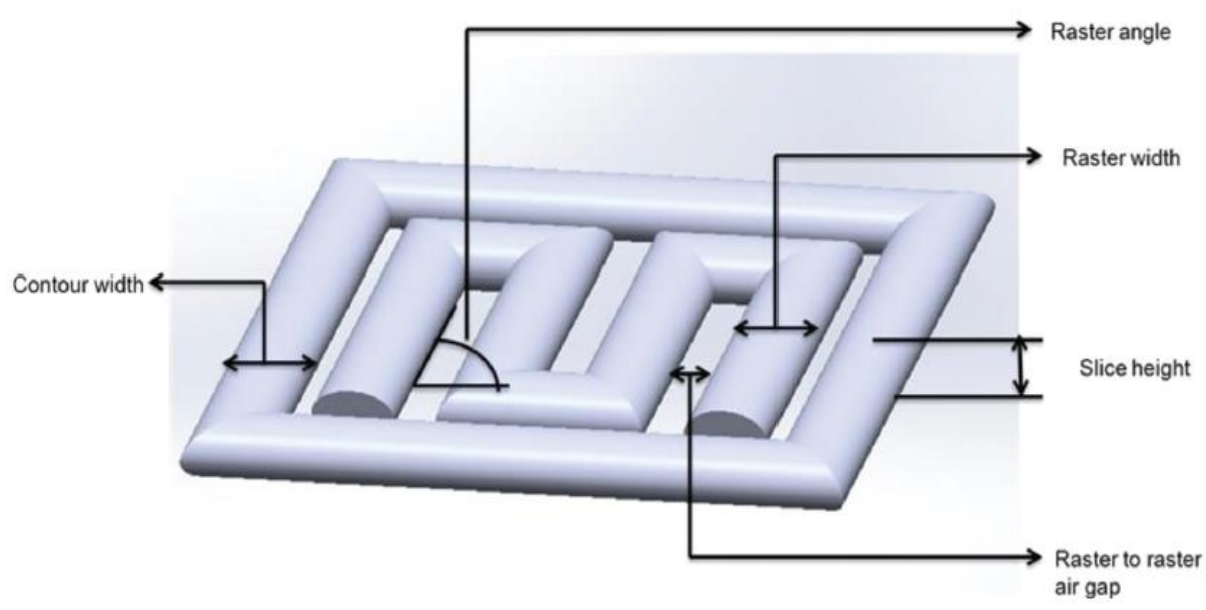

Figure 9: FDM building parameters (8)

Zaldivar et al. (9) showed FDM part's strength ranged from $46 \%$ to $85 \%$ of with the injectionmolded parts. The sample dimensions were $165 \mathrm{~mm}$ in length, $3.2 \mathrm{~mm}$ in thickness, and $13 \mathrm{~mm}$ in 
width. All samples tested with $10 \mathrm{KN}$ load cell and constant crosshead displacement of $5 \mathrm{~mm} / \mathrm{min}$. The X-flat oriented specimens (XYZ) showed tensile strength of $42.97 \mathrm{MPa}$ at 45-degree raster angle and 46.83 MPa at 0 degree. Similarly, X-edge (XZY) specimens showed tensile strength of 47.52MPa at 45-degree raster angle and 71.03 $\mathrm{MPa}$ at 0-degree raster. Gajdos and Slota (10) studied the mechanical properties of 3D printed parts by modifying the print parameters. In their work, the following three different specimens were tested with slice height of $0.127 \mathrm{~mm}$ :

- Sample A: raster width of 0.3408mm and [45 90] degree raster angle

- Sample B: raster width of $0.4032 \mathrm{~mm}$ and [0 0 ] degree raster angle

- Sample C: raster width of $0.4032 \mathrm{~mm}$ and [45 90] degree raster angle

Sample A, B, and C had tensile strength of 29.06 MPa, 23.08 MPa, and 35.25 MPa, respectively. Increasing the raster width by $16 \%$ from $0.3408 \mathrm{~mm}$ (sample A) to $0.4032 \mathrm{~mm}$ (sample C) caused a $21 \%$ increase in tensile strength. The tensile strength of sample B is $29 \%$ lower compared with sample A due to internal structure of sample (10).

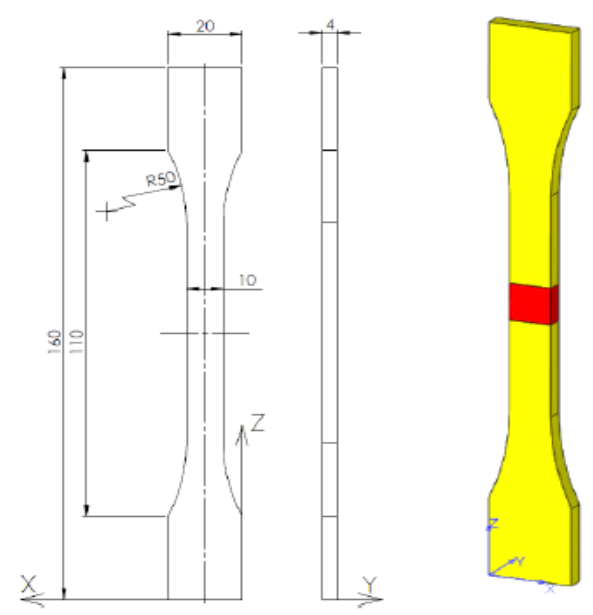

Figure 10: Tensile test specimen dimensions (10)

Ziemain and Okwara (2) aimed at defining the tensile and fatigue behavior of layered Acrylonitrile Butadiene Styrene (ABS) components fabricated by FDM. Tensile tests were performed on dogbone specimens with four different raster orientations according to ASTM D638. The highest ultimate and yield strengths of 25.15 $\mathrm{MPa}$ and 24.18MPa, respectively, were obtained at $0^{\circ}$ raster. The lowest ultimate and yield strength of $9.16 \mathrm{MPa}$ and $8.55 \mathrm{MPa}$, respectively, were obtained at $90^{\circ}$ raster. The mean UTS of the $90^{\circ}$ specimens $(9.16 \mathrm{MPa})$ showed only $36.4 \%$ of that of the $0^{\circ}$ 
raster specimens $(25.15 \mathrm{MPa})$, followed by the $45^{\circ}$ specimens $(10.11 \mathrm{MPa})$ at $40.2 \%$ and the $45 / 45^{\circ}$ specimens $(16.90 \mathrm{MPa})$ at $67.2 \%$ of the $0^{\circ}$ specimens $(2)$.

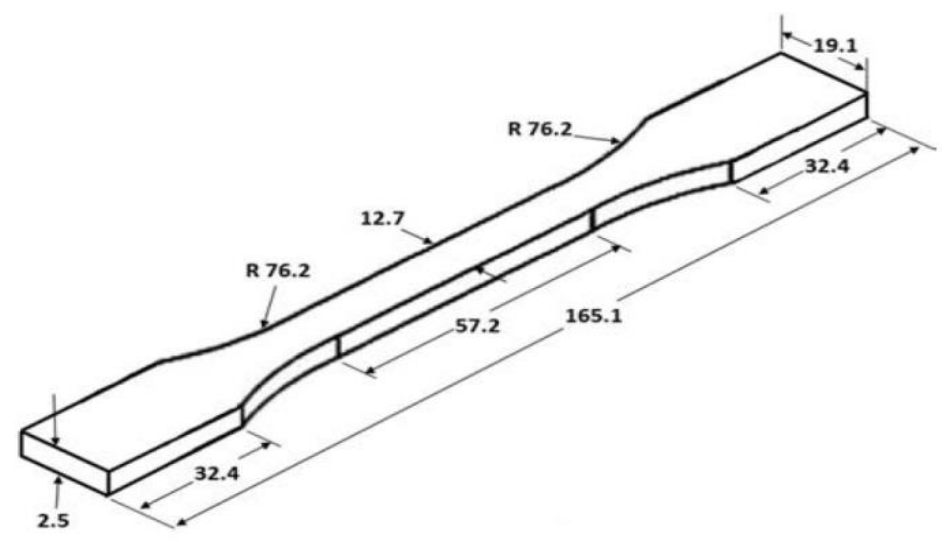

Figure 11: Tested specimen dimensions (2)

Smith and Dean (11) have performed a study on structural characteristics of 3D printed components using polycarbonate material. Tested specimens were manufactured according to type I of ASTM D638 standard with layer thickness of $0.254 \mathrm{~mm}$. Results obtained showed that the ultimate tensile strength and elastic modulus varied between $30 \%$ and $53 \%$ comparing specimens with the lowest and highest value. Results obtained on Edge-up (ZYX), Face-up (XYZ) and Upright (XZY) showed tensile strength of 29.6MPa, 35.70 MPa and 20.60 MPa, respectively, with Modulus of 1.18GPa, 1.58GPa and $1.37 \mathrm{Gpa}$, respectively.

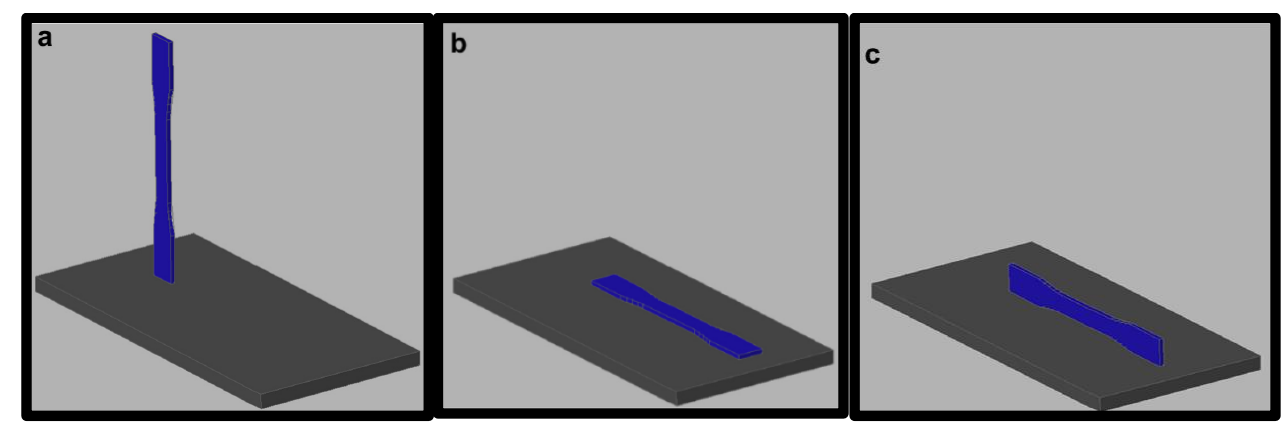

Figure 12: Build orientation: (a) Up-right (XZY), (b) Face-up (XYZ), and (c) Edge-up (ZYX) (11)

Lanzotti et al. (12) studied the ultimate tensile strength and strain of 3D printed parts made from Poly Lactic Acid (PLA) with a Replicating Rapid prototype. Specimens were printed by varying three important process parameters: layer thickness, infill orientation, and the number of shell perimeters. A Computer-Aided Design (CAD) of tensile coupons was created according to the ASTMD638 standard, and a set of 60 specimens were printed with various print parameters 
combination. As a result, specimens with 0-degree raster angle had the highest UTS of 53.59 MPa and 90-degree specimen had the lowest value of 43.39 MPa. Layer thickness of $0.10 \mathrm{~mm}$ showed UTS of 49.29 MPa, while 0.20 mm samples reached 48.49Mpa in UTS.

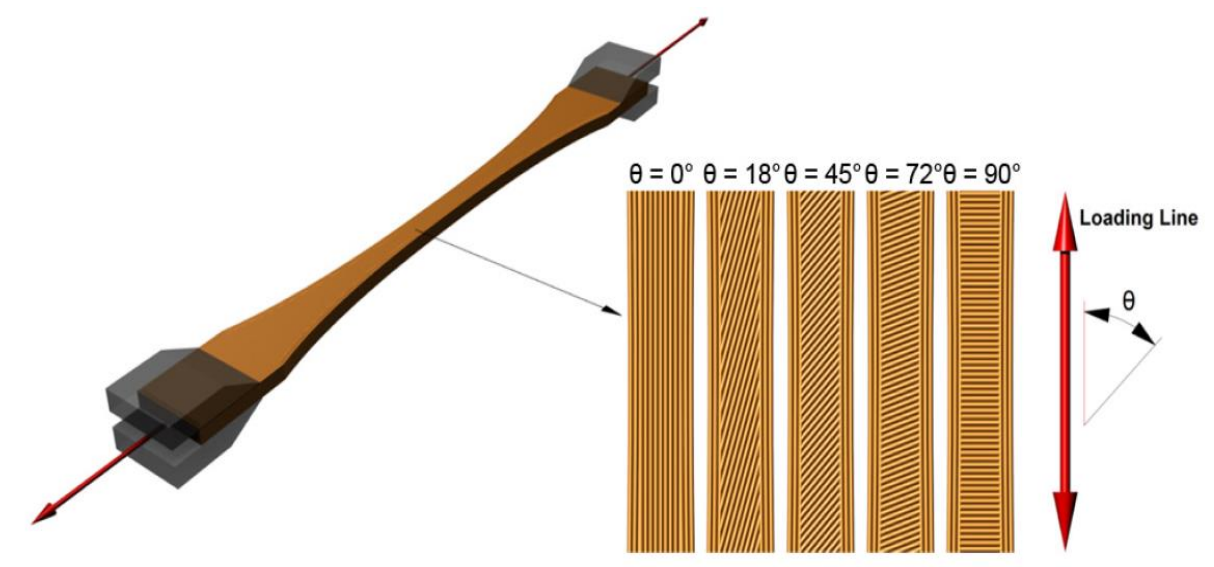

Figure 13: Boundary conditions and relative raster angle between infill and loading line (12)

Hill and Haghi (13) published deposition direction-dependent failure criteria for FDM polycarbonate with the purpose of exploring the failure criteria based on build parameters for FDM components. The properties of this material were found to be highly orientation dependent. Tensile tests were performed on specimens prepared according to the ASTM D638 Type-I standards with layer thickness of $0.27 \mathrm{~mm}$. Six set of specimens were tested with a total of 42 tests. Results showed the highest tensile strength of $59.8 \mathrm{MPa}$ at 90 degree and lowest tensile strength of 18.00 MPa at 15-degree raster angle. Ackermann and Safka (14) studied the influence of part orientation of 3D printed with use of FDM method. First, set of test specimens were printed with raster angles of $0^{\circ}, 45^{\circ}$, and $90^{\circ}$ shown in Figure 14 . To verify repeatability of tensile test for each raster angle, five specimens were tested. The specimens built in $45^{\circ}$ (YXZ) and $90^{\circ}$ (YZX) positions showed distinct necking of the cross-section. These samples also showed highest value of tensile strength of $55 \mathrm{MPa}$ compared to $0^{\circ}$ (YXZ) positioned specimens with $49 \mathrm{MPa}$. They concluded that the mechanical performance of the material is strongly dependent on the model orientation. 


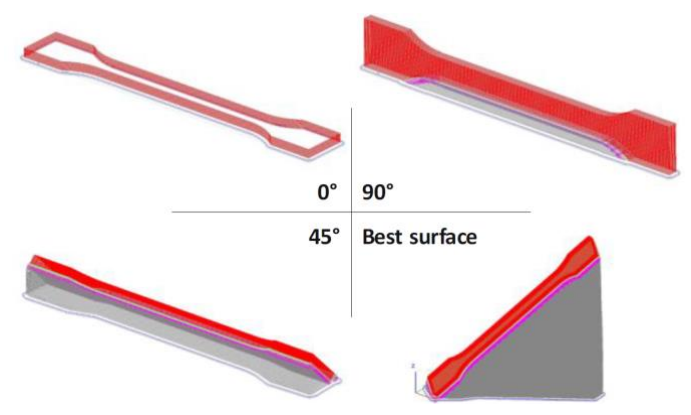

Figure 14: Orientation of specimens (14)

Riddick and Haile (15) studied the material characterization of ABS-M30 by testing specimens manufactured at various build orientation and raster angle as followed:

- Raster angle: $\pm 45,0,0 / 90$, and 90 degrees

- Build orientation: side (YZX), horizontal (YXZ), and vertical (ZXY) build.

The YZX build orientation specimens presented the highest tensile strength for all raster angles. The results for tensile strength obtained are as follows: 0 degree (34.17 MPa), \pm 45 degree (29.62 $\mathrm{MPa}), 0$ / 90 degree (29.1 MPa), and 90 degree (24.24 MPa). In general, the ZXY build direction specimens display relatively low tensile strength of $12.42 \mathrm{MPa}$ to $19.80 \mathrm{MPa}$.

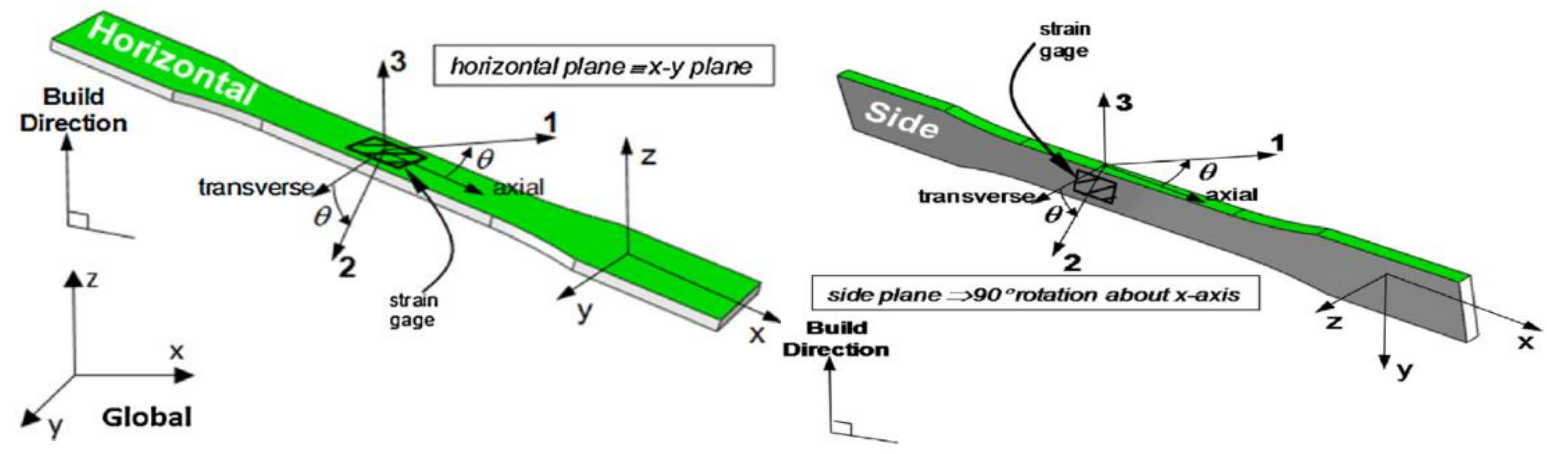

Figure 15: Specimen build orientation (15)

Ficher (16) studied the mechanical behavior of FDM Parts Manufactured with Ultem 9085 per ASTM638 with different build orientations of YZX (on its edge), YXZ (flat), and ZYX (upright) . The tensile test was performed to obtain tensile strength and strain with a test speed of $5 \mathrm{~mm} / \mathrm{min}$. Specimens with YZX orientation had the highest tensile strength of $32 \mathrm{MPa}$ with $6.5 \%$ elongation at break in comparison with YXZ (27 MPa, 5.5\%) and ZYX (15 MPa, 2.3\%). 
It is interesting that both Riddick (15) and Ficher (16) showed that manufacturing on the edge gives higher strength compared with the flat case.

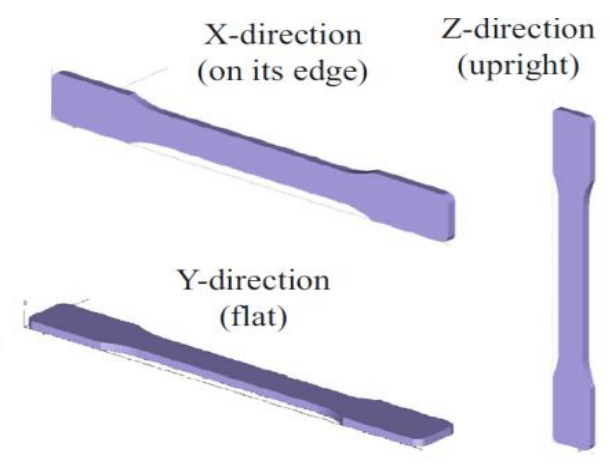

Figure 16: Specimen build orientation (16)

Bellini and Guceri (17) performed tensile test experiment on FDM dog bone specimens fabricated with various build orientations of XYZ, XZY, and ZXY at raster angle of 0, 90, +45, and -45 degrees. Tensile test results obtained shows that the samples with XZY orientation have highest tensile strength of $15.99 \mathrm{MPa}$ in comparison with XYZ (11.70 MPa) and ZXY (7.61 MPa). Similarly, the elastic modulus of $1.07 \mathrm{GPa}$ obtained from XZY specimens were higher than all other samples (17). Dan Odel (18) studied the tensile behavior of ABS P400 parts fabricated by FDM. Throughout the experiments, specimens were fabricated with $0.3 \mathrm{~mm}$ thickness and various raster angles of 0, +/-45, 90 and 0/90 degrees. Specimens with 0-degree raster angle had the highest tensile strength of $22 \mathrm{MPa}$ and 90-degree raster angle had the lowest tensile strength of 7.0 MPa. Torrado (19) studied mechanical behavior of ABS and ABS 5\% Jute Fiber composite material (19). Coupons printed using ABS material exhibits a ductile fracture by sharp ridges, which are characteristic of craze cracking. Specimens printed in both the horizontal (XYZ) and vertical $(\mathrm{ZYX})$ directions were tested to obtain both ultimate tensile strength and percent elongation. Results obtained were $33.96 \mathrm{MPa}$ with $8.64 \%$ and $17.73 \mathrm{MPa}$ with $2.08 \%$, respectively. For ABS $5 \%$ Jute Fiber composite, tensile strength and percent elongation obtained were $24.25 \mathrm{MPa}$ with $4.25 \%$ and $8.63 \mathrm{MPa}$ with $1.55 \%$ for specimens oriented in XYZ and ZXY directions, respectively. From the results gathered by Vidakis and Vairis (20), it can be concluded that the parts built with larger layer thickness showed lower tensile strength. In addition, for specimens with ABS material, it was observed that 90 degrees build angle and $0.25 \mathrm{~mm}$ layer thickness produced significantly lower tensile strength of $8 \mathrm{MPa}$ in comparison with raster angle of 0 and 45 degrees. They also found that the ABS plus parts had a maximum tensile strength of $20 \%$ higher than ABS (20). Garg 
and Bhattacharya (21) investigated failure of FDM parts under tensile loading including $0^{\circ}, 90^{\circ}$, $0^{\circ} / 90^{\circ}$ raster angles. They concluded that specimens with $0 / 90$ degree raster angle present a higher tensile strength. Halil et al. (22) studied the mechanical properties of short fiber (0.2-0.4 mm) reinforced Acrylonitrile-Butadiene-Styrene (ABS) composites (fiber loading from $0 \%$ to $40 \%$ by weight). In comparison with traditional molding with $0 \%$ fiber loading, it was observed that the tensile strength and modulus of elasticity of 3D printed samples with $40 \%$ fiber loading increased by $115 \%$ (from 30.0 to $67.8 \mathrm{MPa}$ ) and $700 \%$ (from 2.0 to $14.0 \mathrm{GPa}$ ), respectively. Chockalingam et al. (23) performed an experimental study on mechanical tensile strength of ABS FDM parts per ASTM D638 standard (23). Throughout this study, 31 unique specimens were tested with a total thickness of $4 \mathrm{~mm}$ with varying build orientation and raster angle. The following process parameters were used for FDM parts:

- Build orientation: horizontal (XYZ), vertical (ZXY), and perpendicular (YZX)

- Raster Angle: 0, 30, and 60 degrees

Specimens with XYZ orientation and 0-degree raster angle presented highest tensile strength of 36.7 $\mathrm{MPa}$ and specimens with YZX orientation and 60-degree raster angle showed the lowest tensile strength of $25.37 \mathrm{MPa}$.

Zelený and Safka (24) investigated the impact of build orientation on the mechanical characteristics of 3D printed ABS parts using tensile testing. The test specimens were manufactured and tested according to DIN EN ISO 527-2. ABS parts were manufactured using FDM technology using SST 768 3D printer with layer thickness of $0.25 \mathrm{~mm}$ and $0.33 \mathrm{~mm}$. The lowest tensile strength of $20.82 \mathrm{MPa}$ was obtained with the orientation longitudinally on the surface (XYZ) and the highest tensile strength of $24.89 \mathrm{MPa}$ is obtained with the orientation perpendicularly on the side (XZY). Figure 17 represents both the computer aided model and the actual printed specimens. 


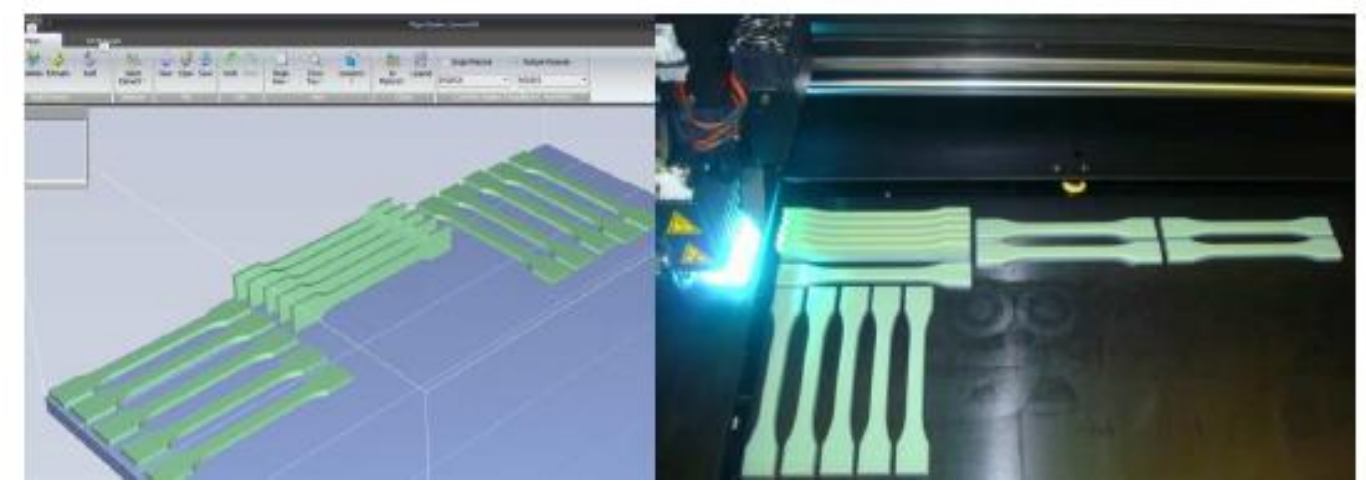

Figure 17: The element orientation in the working area according to direction of print head (24)

In addition to the build orientation and the raster angle, several research papers investigated the impact of the layer thickness on mechanical performance of 3D printed specimens. A summary of these studies are provided in Section 1.2.1.

\subsubsection{IMPACT OF THE LAYER THICKNESS ON TENSILE STRENGTH}

Anton et al. (25) focused on the study of elastic modulus, tensile strength, and fracture toughness of $\mathrm{ABS}$ and $\mathrm{ABS}$ reinforced by $5 \%$ weight Carbon Nano Tube (CNT) with various layer thicknesses. It was observed that an increase in specimen layer thickness resulted in a decrease in tensile strength and modulus. Chacon et al. (6) also studied the impact of layer thickness of 3D printed PLA specimens using tensile testing. They investigated three values of $0.12,0.18$, and 0.24 $\mathrm{mm}$ for the layer thickness It was concluded that a lower layer thickness results in an increase in both strength and stiffness, which was confirmed by Garg and Bhattacharya (21) as well. Stressstrain graph of specimens with raster angle of $0^{\circ} / 90^{\circ}$ and different layer thicknesses can be seen in Figure 18 (21). Specimens with $0.178 \mathrm{~mm}$ layer thickness had the highest tensile strength of 32 MPa compared with specimens with layer thicknesses of 0.254 and $0.33 \mathrm{~mm}$ that had tensile strength of $23 \mathrm{MPa}$ and $27 \mathrm{MPa}$, respectively. 


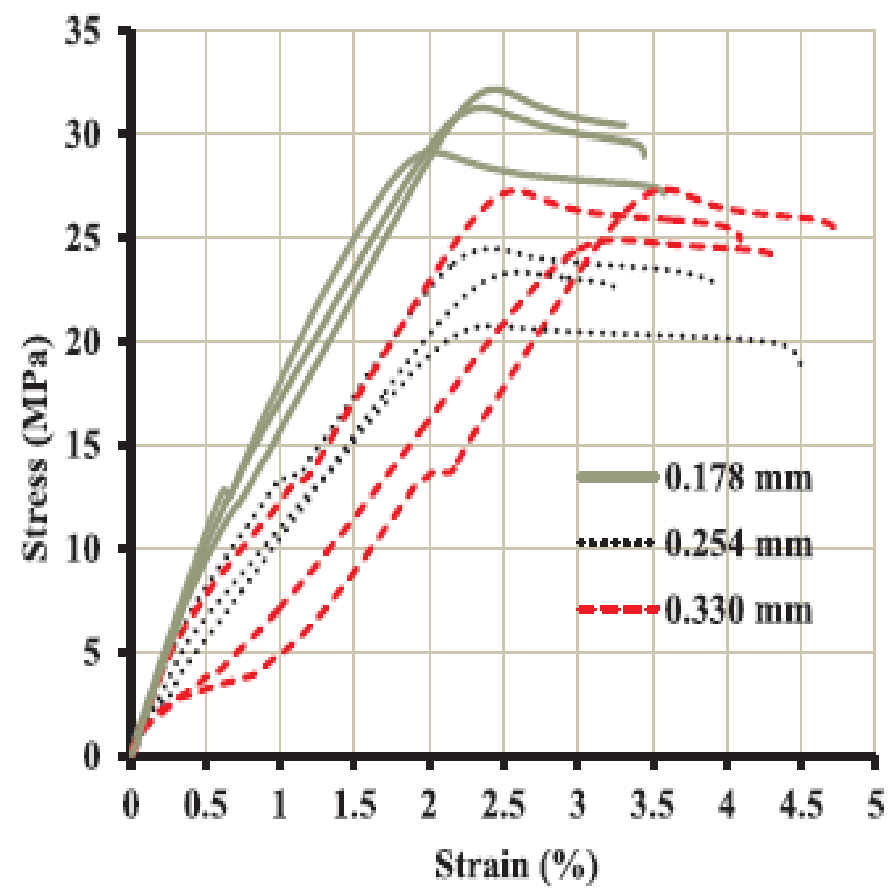

Figure 18: Stress-Strain curve for specimen build at $0 / 90$ degree with different layer thickness (21)

Kumar et al. (26) investigated the influence of various process parameters such as layer thickness, raster angle, and air gap on tensile, flexural, and impact strength of FDM printed. The mechanical behaviors at breaking point was determined based on the following standards: ISO R527:1966, ISO R178:1975, and ISO R179:1982. Throughout this experimental study, 32 samples were tested with a layer thickness of $0.127,0.178$, and $0.254 \mathrm{~mm}$, and raster angles of 0,30 , and 60 degrees. It was found that the specimen with the lowest layer thickness with 60-degree raster angle, and no air gap presented the highest tensile strength of $18.1 \mathrm{MPa}$ and Flexural strength of $39.2 \mathrm{MPa}$.

Aside from the build orientation, raster angle, and layer thickness, air gap and infill percentage influences the tensile strength of 3D printed specimens. A summary of research papers considering air gap and infill percentage is provided in Section 1.2.3.

\subsubsection{IMPACT OF AIR GAP AND INFILL PERCENTAGE ON THE TENSILE STRENGTH}

In mechanical behavior study of ABS material completed by Michael Dawoud et al. (27), the raster angle and air gap were varied to investigate the tensile strength. It was concluded that with a proper selection of build parameters in FDM the mechanical behavior comparable to those parts with 
injection molded can be reached. A negative raster gap was shown to be one of the most significant factors in improving mechanical behavior of FDM parts. Results showed negative air gap with raster angle of $-45^{\circ} / 45^{\circ}$ proves to provide maximum tensile strength of $34.3 \mathrm{MPa}$ in comparison with a specimen of $0^{\circ}$ raster angle with positive air gap offer lowest tensile strength of $28.1 \mathrm{MPa}$ (27).

Alvarez and Kenny (28) has completed an investigation on the influence of infill percentage on the mechanical properties of FDM ABS parts. In this study, the tensile strength and impact resistance were analyzed for 3D printed specimens manufactured based on ASTM D638 standard, for tensile properties, and ASTM D6110 for impact resistance. The test specimens were manufactured with a linear 5\% increase in infill percentage, starting at $0 \%$ and going up to 100 $\%$. Specimens had a layer thickness of $0.2 \mathrm{~mm}$, raster angles of [0 90], and XYZ build orientation. By using $100 \%$ infill, the maximum tensile strength of $34.57 \mathrm{MPa}$ and the maximum impact resistance of $1.55 \mathrm{~J}$ were obtained.

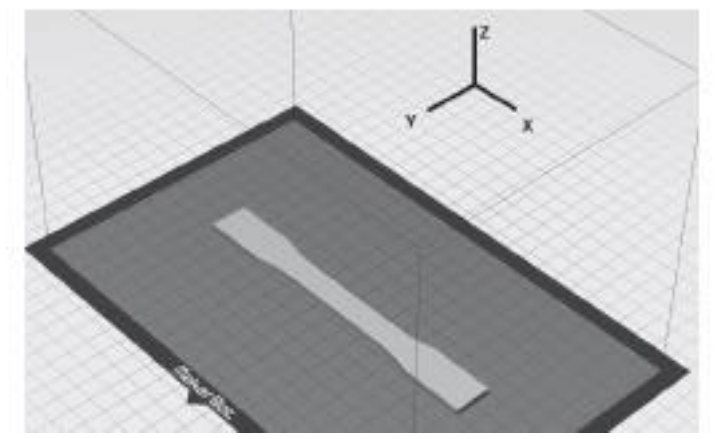

Figure 19: Specimen model for the tensile strength test (28)

In addition to build parameters discussed in previous selections, another key factor which greatly impacts the tensile strength of FDM parts is the choice of filament material. Previous research works used pure thermoplastic filaments (e.g. PLA and ABS). Several authors investigated improvement in mechanical properties obtained by fiber reinforced filaments. Section 1.2.4 provides a summary of these research works. 


\subsubsection{IMPACT OF FIBER REINFORCED FILAMENTS ON TENSILE STRENGTH}

Vairis et al. (29) performed a study on the effect of strain rate and materials on the tensile strength of fused deposition modeling parts. For this study, all specimens were built per ASTM D638, solids dog-bone, with a layer thickness of 0.25 and $0.33 \mathrm{~mm}$ for ABS, and 0.17 and $0.25 \mathrm{~mm}$ for $\mathrm{ABS}+$. It was found that as the test speed increases specimens developed higher tensile strength and elastic modulus. Specimens tested in the highest speed of the experiment had on average about $10 \%$ higher elastic modulus about $11 \%$ higher tensile strength. In addition, the results showed that the ABS+ specimens had an average 59\% higher elastic modulus than the ABS specimens, while their tensile strength was almost double that of ABS specimens.

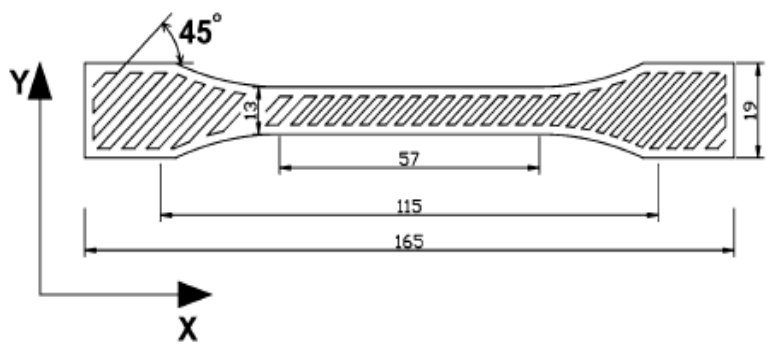

Figure 20: ASTM D638-02a Type I tensile strength test specimen (29)

Love et al. (30) studied the mechanical properties of specimens manufactured using reinforced ABS filaments with $13 \%$ Carbon Fiber $(\mathrm{CF})$ weight content. The addition of $\mathrm{CF}$ increased the strength by approximately $200 \%$ and modulus by $400 \%$ for in-plane samples. Weng et al. (31) investigated the effect of Organic Modified MonTmorillonite (OMMT) added to Acrylonitrile Butadiene Styrene (ABS) nanocomposites using injection molding and FDM. Tensile strength and elastic modulus of specimens prepared by injection molding were increased substantially with the addition of 5wt\% OMMT. The tensile strength increased from $49.6 \mathrm{MPa}$ (control) to $64.4 \mathrm{MPa}$ and the elastic modulus increased from 1.9 GPa (control) to 3.2 GPa. Similarly, for specimens prepared by 3D printing, tensile strength increased from 27.6 to $39.45 \mathrm{MPa}$ and the elastic modulus increased from 1.2 to 3.6 GPa. Türk and Brenni (32) completed a study on FDM of ABSplus-p430 Stratasys, Polyamide 12 (PA12), and DuraFormHST Composite (HST) to investigate the effect of temperature on mechanical properties, such as strength and modulus of elasticity. Mechanical behavior of each material investigated in the build orientations of: $\mathrm{X}$-on edge (XZY), z-upright $(\mathrm{ZXY})$ and y-flat (XYZ) under various temperatures. It was observed that specimens fabricated 
using DuraFormHST (HST) presented highest tensile strength of 39.6 MPa and Modulus of 3.63 $\mathrm{GPa}$ at $\mathrm{y}$-flat (XYZ) in room temperature.

Miller and Safranski (33) tested three different materials of Carbothanes, AC-4075A (75A), AC4085A (85A), and AC-4095A (95A). Specimens were printed with $0.15 \mathrm{~mm}$ layer thickness and $100 \%$ infill. Results showed that increased hard segment content leads to increased stiffness, shear failure stress, and tensile fatigue despite relatively uniform tensile strength for the tested grades. The average tensile strength obtained for $75 \mathrm{~A}, 85 \mathrm{~A}$ and $95 \mathrm{~A}$ were $51.7,57.4$ and $54.3 \mathrm{MPa}$, respectively (33).

Significant experimental testings have been performed on FDM parts to study the impact of build parameters: build orientation, raster angle, layer thickness, air gap, infill percentage, and filament material. Table 2 presents a summary of the obtained results. 
Table 2: Summary of Literature Review

\begin{tabular}{|c|c|c|c|c|c|c|c|}
\hline Paper & Material & Orientation & $\begin{array}{c}\text { Raster Angle } \\
\text { (degree) }\end{array}$ & $\begin{array}{l}\text { Layer Thickness } \\
(\mathrm{mm})\end{array}$ & $\begin{array}{l}\text { infill } \\
\%\end{array}$ & $\begin{array}{l}\text { Tensile strength } \\
\text { (Mpa) }\end{array}$ & $\begin{array}{c}\text { Modulus } \\
\text { (Gpa) }\end{array}$ \\
\hline (2) & ABS & $\mathrm{ND}^{1}$ & $\begin{array}{l}0 \\
45 \\
90 \\
+45 /-45\end{array}$ & 0.1778 & 100 & $\begin{array}{l}25.15 \\
10.11 \\
9.16 \\
16.90\end{array}$ & $\begin{array}{l}1.49 \\
1.04 \\
1.04 \\
1.28\end{array}$ \\
\hline (26) & $\mathrm{ABS}$ & $\mathrm{XYZ}$ & 60 & 0.127 & 100 & 18.091 & ND \\
\hline (24) & ABS & $\begin{array}{l}\text { XZY } \\
\text { XYZ }\end{array}$ & 0 & 0.25 & 100 & $\begin{array}{l}20.82 \\
24.89\end{array}$ & ND \\
\hline (18) & ABS & $\mathrm{XYZ}$ & $\begin{array}{l}0 \\
90\end{array}$ & 0.3 & 100 & $\begin{array}{l}22.0 \\
7.00\end{array}$ & ND \\
\hline (28) & ABS & XYZ & $0 / 90$ & 0.2 & $\begin{array}{l}0 \\
25 \\
50 \\
75 \\
100\end{array}$ & $\begin{array}{l}34.57 \\
\text { (Max at 100\%) }\end{array}$ & ND \\
\hline (34) & ABS-M30 & $\mathrm{XYZ}$ & $45 /-45$ & 0.25 & 100 & 29.7 & ND \\
\hline (6) & ND & $\begin{array}{l}Z Y X \\
Y Z X \\
Y X Z\end{array}$ & 0 & 0.06 & 100 & $\begin{array}{l}28.8 \mid 22.4 \\
73.2 \mid 83.4 \\
75.2 \mid 88.2\end{array}$ & $\begin{array}{l}4.011 \mid 3.266 \\
4.042 \mid 4.040 \\
3.867 \mid 4.409\end{array}$ \\
\hline (9) & ND & $\begin{array}{l}\text { XYZ } \\
\text { YXZ } \\
X Z Y \\
Z X Y\end{array}$ & $0 \mid 45$ & 3.2 & 100 & $\begin{array}{l}46.83 \mid 42.97 \\
55.79 \\
71.03 \mid 47.52 \\
38.48\end{array}$ & $\begin{array}{l}2.01 \mid 2.12 \\
2.28 \\
2.48 \mid 2.12 \\
2.03\end{array}$ \\
\hline
\end{tabular}




\begin{tabular}{|c|c|c|c|c|c|c|c|}
\hline (4) & ND & XYZ & $\begin{array}{l}0 \\
45 \\
90 \\
0 / 90 \\
45 /-45\end{array}$ & 0.2 & 100 & $\begin{array}{l}36 \\
32 \\
33.5 \\
32.5 \\
28\end{array}$ & $\begin{array}{l}1.35 \\
1.10 \\
1.20 \\
1.25 \\
1.10\end{array}$ \\
\hline (6) & ND & $\begin{array}{l}\mathrm{YZ}-\mathrm{H} \\
\mathrm{YZ}-\mathrm{V} \\
\mathrm{ZX}-\mathrm{H} \\
\mathrm{XY}-\mathrm{V}\end{array}$ & $\begin{array}{l}0 \\
90 \\
0 \\
90 \\
\end{array}$ & $0.09 \mid 0.39$ & 100 & $\begin{array}{l}39 \mid 16 \\
41 \mid 22 \\
8 \mid 8 \\
29 \mid 12 \\
\end{array}$ & $\begin{array}{l}1.52 \mid 1.00 \\
1.50 \mid 1.05 \\
1.10 \mid 1.25 \\
0.66 \mid 1.10\end{array}$ \\
\hline (7) & ND & ZXY & 45 & 0.3 & 100 & 40.09 & 3.144 \\
\hline (13) & polycarbonate & ND & $\begin{array}{l}15 \\
45 \\
90\end{array}$ & 0.5 & 100 & $\begin{array}{l}19.03 \\
24.13 \\
59.78\end{array}$ & $\begin{array}{l}1.35 \\
1.36 \\
2.08\end{array}$ \\
\hline (11) & polycarbonate & ND & $45 /-45$ & 0.254 & 100 & $\begin{array}{l}29.60 \\
35.70 \\
20.60\end{array}$ & $\begin{array}{l}1.18 \\
1.58 \\
1.37\end{array}$ \\
\hline (8) & ND & $\begin{array}{l}\text { XYZ } \\
\text { XZY } \\
\text { ZXY }\end{array}$ & $\begin{array}{l}45 /-45 \\
0 / 90 \\
30 /-60\end{array}$ & 0.254 & 100 & $\begin{array}{l}53.22 \\
62.84 \\
35.27\end{array}$ & ND \\
\hline (17) & ND & $\begin{array}{l}\text { XZY } \\
X Y Z \\
Z X Y\end{array}$ & $45 /-45$ & 0.3 & 100 & $\begin{array}{l}15.99 \\
11.70 \\
7.608\end{array}$ & ND \\
\hline (29) & $\begin{array}{l}\text { ABS } \\
\text { ABS+ }\end{array}$ & XYZ & 45 & $\begin{array}{l}0.25 \mid 0.33 \\
0.17 \mid 0.25\end{array}$ & 100 & $\begin{array}{l}13 \mid 11 \\
22.2 \mid 23.7\end{array}$ & $\begin{array}{l}0.3 \mid 0.27 \\
0.50 \mid 0.47\end{array}$ \\
\hline (1) & ND & XYZ & $\begin{array}{l}0 / 90 \\
-45 / 45\end{array}$ & 0.25 & 100 & $\begin{array}{l}25 \text { (Strain5\%) } \\
\text { Not Available }\end{array}$ & ND \\
\hline (19) & ND & $\begin{array}{l}\text { XYZ } \\
\text { ZXY }\end{array}$ & 0 & 0.27 & 100 & $\begin{array}{l}38.5 \\
25.0\end{array}$ & ND \\
\hline
\end{tabular}




\begin{tabular}{|c|c|c|c|c|c|c|c|}
\hline (20) & $\begin{array}{l}\mathrm{ABS} \\
\mathrm{ABS}+\end{array}$ & ND & $\begin{array}{l}0 \\
90 \\
45\end{array}$ & $\begin{array}{l}0.17 \mid 0.25 \\
0.25 \mid 0.33\end{array}$ & 100 & $\begin{array}{l}18.58 \mid 19.01 \\
19.41 \mid 20.68 \\
19.43 \mid 20.43 \\
---------------- \\
-- \\
8.68 \mid 6.61 \\
1.44 \mid 6.79 \\
8.97 \mid 14.87\end{array}$ & ND \\
\hline (30) & ND & $\begin{array}{l}\text { XYZ } \\
\text { ZXY }\end{array}$ & ND & 0.254 & 100 & \begin{tabular}{l|l}
21.04 & 70.69 \\
20.95 & 7.00
\end{tabular} & \begin{tabular}{l|l}
1.22 & 8.91 \\
1.42 & 1.52
\end{tabular} \\
\hline (3) & ND & XYZ & $\begin{array}{l}90 \\
0\end{array}$ & ND & 100 & $\begin{array}{l}46.0 \\
66.3\end{array}$ & $\begin{array}{l}2.84 \\
4.05\end{array}$ \\
\hline (27) & $\mathrm{ABS}$ & XYZ & $\begin{array}{l}45 /-45 \\
0\end{array}$ & ND & 100 & $\begin{array}{l}34.3 \\
28.1\end{array}$ & ND \\
\hline (23) & $\mathrm{ABS}$ & $\begin{array}{l}\text { XYZ } \\
\text { YZX }\end{array}$ & $\begin{array}{l}0 \\
60\end{array}$ & ND & 100 & $\begin{array}{l}36.72 \\
25.37\end{array}$ & ND \\
\hline (19) & $\begin{array}{l}\text { ABS } \\
\text { ABS } \\
\text { JuteFiber }\end{array}$ & $\mathrm{XYZ} \mid \mathrm{ZYX}$ & 0 & ND & 100 & \begin{tabular}{l|l|l}
$33.96 \mid 17.73$ \\
$24.25 \mid 8.63$
\end{tabular} & ND \\
\hline (33) & $\begin{array}{l}\mathrm{AC}-4075 \mathrm{~A}(75 \mathrm{~A}) \\
\mathrm{AC}-4085 \mathrm{~A}(85 \mathrm{~A}) \\
\mathrm{AC}-4095 \mathrm{~A}(95 \mathrm{~A})\end{array}$ & XYZ & ND & 0.15 & 100 & $\begin{array}{l}51.7 \\
57.4 \\
54.3\end{array}$ & ND \\
\hline (12) & PLA & ND & $\begin{array}{l}0 \\
45 \\
90 \\
---- \\
45\end{array}$ & $\begin{array}{l}0.15 \\
--- \\
0.10 \\
0.20\end{array}$ & 100 & $\begin{array}{l}53.59 \\
48.09 \\
43.39 \\
---- \\
49.29 \\
48.49\end{array}$ & ND \\
\hline (16) & Ultem 9085 & $\begin{array}{l}\text { YZX } \\
\text { YXZ } \\
Z X Y\end{array}$ & 0 & ND & 100 & $\begin{array}{l}32.0 \\
27.0 \\
15.0\end{array}$ & ND \\
\hline
\end{tabular}




\begin{tabular}{|c|c|c|c|c|c|c|c|}
\hline (21) & ABS & ND & $0 / 90$ & $\begin{array}{l}0.178 \\
0.254 \\
0.33\end{array}$ & ND & $\begin{array}{l}32 \\
23 \\
27\end{array}$ & ND \\
\hline (15) & ND & $\begin{array}{l}\text { YZX } \\
----- \\
\text { ZXY }\end{array}$ & $\begin{array}{l}0 \\
45 /-45 \\
0 / 90 \\
90 \\
-------- \\
45 /-45 \\
90\end{array}$ & ND & 100 & $\begin{array}{l}34.17 \\
29.62 \\
29.1 \\
24.24 \\
--------- \\
19.80 \\
12.42\end{array}$ & ND \\
\hline (35) & ND & XYZ & & 7.3 & & 24.46 & ND \\
\hline (14) & ND & $\begin{array}{l}\text { YZX } \\
\text { XYZ }\end{array}$ & & & 100 & $\begin{array}{l}55 \\
49\end{array}$ & ND \\
\hline (10) & ND & ND & $\begin{array}{l}45 / 90 \\
0 \\
45 / 9]\end{array}$ & 0.127 & 100 & $\begin{array}{l}29.06 \\
23.08 \\
35.25\end{array}$ & ND \\
\hline (32) & $\begin{array}{l}\text { ABSplus-P430 } \\
\text { PA } \quad 12 \quad 3 D \\
\text { Systems } \\
\text { DuraFoam HST }\end{array}$ & $\begin{array}{l}\mathrm{ZXY} \mid \mathrm{ZXY} \text { or } \\
\mathrm{XYZ}\end{array}$ & & & 100 & \begin{tabular}{l|l|}
14.8 & 32.8 \\
33.7 & 33.3 \\
25.9 & 39.6
\end{tabular} & $\begin{array}{l}2.06 \mid 2.19 \\
1.725 \mid 1.760 \\
1.87 \mid 3.63\end{array}$ \\
\hline (22) & 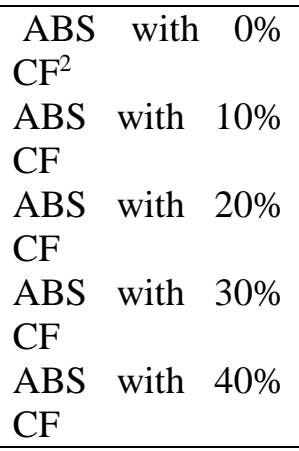 & ND & ND & 0.2 & 100 & $\begin{array}{l}36.6 \\
51.6 \\
61.5 \\
63.6 \\
67.8\end{array}$ & $\begin{array}{l}2.0 \\
7.8 \\
11.7 \\
14.1 \\
14.0\end{array}$ \\
\hline (31) & $\begin{array}{l}\mathrm{ABS} \\
\mathrm{ABS}+\end{array}$ & ND & ND & ND & ND & $\begin{array}{l}27.59 \\
39.48\end{array}$ & $\begin{array}{l}1.2 \\
3.6\end{array}$ \\
\hline
\end{tabular}

1. ND: Not Defined; 2. CF: Carbon Fiber 
As it can be seen in Table 2, a systematic approach towards mechanical characterization of FDM 3D printed parts has not been followed and researchers used random raster angles. In this project, tensile testing of $3 \mathrm{D}$ printed PLA material is used to find mechanical properties along $0^{\circ}$ and $90^{\circ}$ orientations that can be used as input values in Finite Element (FE) simulations. In addition, quasiisotropic stacking sequence, here [45/0/-45/90] 3 , is tested, so reliable experimental data is available for verification of $\mathrm{FE}$ results. Furthermore, 3D printers like other automated manufacturing techniques create defects (gaps, overlaps, offset, etc.) into the final parts considering their tolerances. As it can be seen in Table 2, the impact of defects on mechanical performance of 3D printed parts has not been investigated yet. In this project, certain defects (gaps) are intentionally placed into the parts and their impacts are evaluated using experimental testing. This project report is organized as follows: Section 2 descries the testing methodology and defines 3D printing process parameters. In Section 3, experimental results are presented including stressstrain graphs and Scanning Electron Microscope (SEM) images followed by conclusion and recommendations for future works. 


\section{METHODOLOGY}

This section of the report provides information regarding ASTM D638-14 standard for determining tensile strength and modulus of FDM 3D printed coupons. Coupon design per ASTM D638-14 and intentional defects placement are explained. In addition, 3D printing manufacturing process parameters selected in this study along with the $3 \mathrm{D}$ printer, the testing machine, and the load cell are described.

\subsection{TEST SPECIMENS DESIGN}

The first step in the study is to design the test specimens for determining tensile strength and modulus per ASTM D638-14. There are five different coupon types per ASTM D638-14. Figure 22 demonstrates the standard shapes and dimensions of all five specimen types used for rigid and semi-rigid plastics. Per standard, the preferred specimen is the type I specimen, which is used where the thickness is less than $7 \mathrm{~mm}$. In a case of which the type I specimen does not break in the narrow section, the type II specimen is recommended. The type $\mathrm{V}$ is recommended for use in a case of limited material availability for evaluation. The type IV is usually used when non-rigid and semi-rigid materials are being compared. Lastly, the type III specimen is used where the coupon thickness is between 7 and $14 \mathrm{~mm}$. The type I specimen is selected here, and a 3D model is created in SolidWorks per geometry and dimensions given in Figure 22. Per ASTM D638-14, a coupon thickness of $3.2 \pm 0.4 \mathrm{~mm}$ is given for type I specimens where possible. In this study, coupons are designed for a total thickness of $3.36 \mathrm{~mm}$.
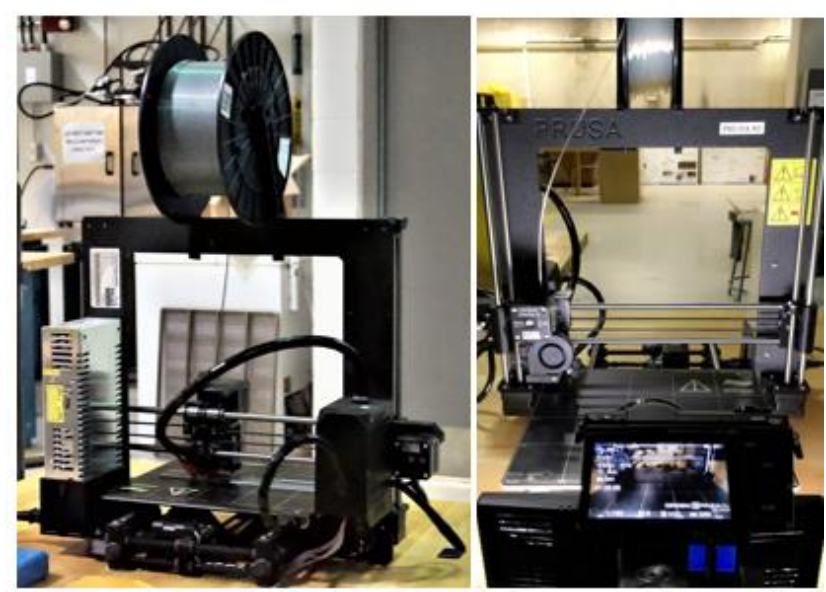

Figure 21: PRUSA 3D printer 

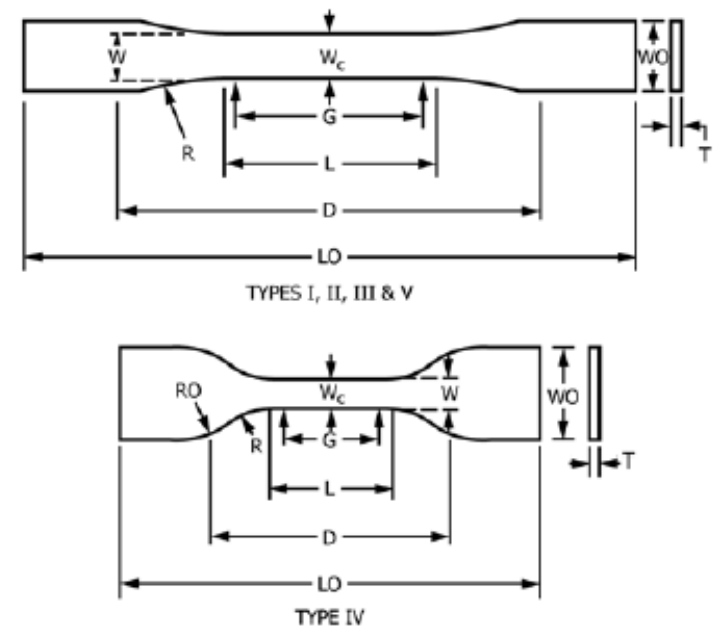

Specimen Dimensions for Thickness, $T$, $\mathrm{mm}$ (in.) ${ }^{A}$

\begin{tabular}{|c|c|c|c|c|c|c|}
\hline \multirow{2}{*}{ Dimensions (see drawings) } & \multicolumn{2}{|c|}{$7(0.28)$ or under } & \multirow{2}{*}{$\begin{array}{c}\text { Over } 7 \text { to } 14(0.28 \text { to } 0.55) \text {, incl } \\
\text { Type III }\end{array}$} & \multicolumn{2}{|c|}{$4(0.16)$ or under } & \multirow{2}{*}{ Tolerances } \\
\hline & Type I & Type II & & Type IV ${ }^{B}$ & Type $\mathrm{V}^{C, D}$ & \\
\hline W-Width of narrow section ${ }^{E, F}$ & $13(0.50)$ & $6(0.25)$ & $19(0.75)$ & $6(0.25)$ & $3.18(0.125)$ & $\pm 0.5( \pm 0.02)^{B, C}$ \\
\hline$L$ - Length of narrow section & $57(2.25)$ & $57(2.25)$ & $57(2.25)$ & $33(1.30)$ & $9.53(0.375)$ & $\pm 0.5( \pm 0.02)^{C}$ \\
\hline wo-Width overall, $\min ^{G}$ & $19(0.75)$ & $19(0.75)$ & $29(1.13)$ & $19(0.75)$ & ... & $+6.4(+0.25)$ \\
\hline WO-Width overall, $\min ^{G}$ & ... & ... & $\ldots$ & ... & $9.53(0.375)$ & $+3.18(+0.125)$ \\
\hline LO-Length overall, $\min ^{H}$ & $165(6.5)$ & $183(7.2)$ & $246(9.7)$ & $115(4.5)$ & $63.5(2.5)$ & no $\max$ (no max) \\
\hline G-Gage length ${ }^{\prime}$ & $50(2.00)$ & $50(2.00)$ & $50(2.00)$ & ... & $7.62(0.300)$ & $\pm 0.25( \pm 0.010)^{C}$ \\
\hline G-Gage length ${ }^{\prime}$ & $\ldots$ & ... & ... & $25(1.00)$ & ... & $\pm 0.13( \pm 0.005)$ \\
\hline$D$-Distance between grips & $115(4.5)$ & $135(5.3)$ & $115(4.5)$ & $65(2.5)^{J}$ & $25.4(1.0)$ & $\pm 5( \pm 0.2)$ \\
\hline$R$-Radius of fillet & $76(3.00)$ & $76(3.00)$ & $76(3.00)$ & $14(0.56)$ & $12.7(0.5)$ & $\pm 1( \pm 0.04)^{C}$ \\
\hline RO-Outer radius (Type IV) & ... & ... & ... & $25(1.00)$ & ... & $\pm 1( \pm 0.04)$ \\
\hline
\end{tabular}

Figure 22: Specimen Dimensions for thickness T (36)

\subsection{TEST SPECIMENS MANUFACTURING}

The 3D model of the specimen is passed to a Slicer software (here, Simplify3D) to prepare Gcodes for manufacturing in a 3D printer. As explained in Section 2, build orientation, raster angle, infill percentage, layer thickness, nozzle temperature, bed temperature, fan speed, and printing speed are important parameters that affect the structural performance of the $3 \mathrm{D}$ printed parts. The objective of this work is to characterize mechanical properties (here tensile strength and modulus) of $3 \mathrm{D}$ printed parts and evaluate the impact of defects. As a result, among the manufacturing parameter, only raster angle and defects inclusion were changed. A mechanical characterization approach, developed for fiber-reinforced composites, is followed here. In this study, [0] $24,[90]_{24}$, and $[45 / 0 /-45 / 90]_{3 s}$ stacking sequences are selected for the experimental testing.

3D printing machines induce defects into the final parts considering their tolerances. For the quasiisotropic stacking sequence, $[45 / 0 / 90 /-45]_{3 \mathrm{~S}}$, a defect (missing bead/s) is placed intentionally in 
3D printed coupons to investigate its impact on tensile strength and modulus of the specimens. Three types of defects are used here: one bead missing in the middle of the coupon in every $0^{\circ}$ layer; four beads missing in the middle of the coupon in every $90^{\circ}$ and; a combination of the two previous defects. Since the gage length section for the coupon is almost four times of its width, four beads are not printed in a $90^{\circ}$ layer to keep its defect area percentage the same as the one for a missing bead in a $0^{\circ}$ layer. Table 3 specifies 6 sets of coupons considered in this study, where the impact of defect inclusion and raster angle are investigated.

\section{Table 3: Specimen Design Parameters}

\begin{tabular}{|l|l|l|}
\hline Coupon ID & Defect & Infill Raster angle (degree) \\
\hline Coupon A & NO & {$[0]_{24}$} \\
\hline Coupon B & NO & {$[90]_{24}$} \\
\hline Coupon C & NO & {$[45 / 0 / 90 /-45]_{3 \mathrm{~S}}$} \\
\hline Coupon D & 1 bead - 0 degree & {$[45 / 0 / 90 /-45]_{3 \mathrm{~S}}$} \\
\hline Coupon E & 4 bead - 90 degree & {$[45 / 0 / 90 /-45]_{3 \mathrm{~S}}$} \\
\hline Coupon F & $\begin{array}{l}1 \text { bead - 0 degree and } \\
4 \text { beads - 90 degree }\end{array}$ & {$[45 / 0 / 90 /-45]_{3 \mathrm{~S}}$} \\
\hline
\end{tabular}

A total of five coupons per each set was manufactured using a Prusa i3 Mk2S printer with a nozzle diameter of $0.4 \mathrm{~mm}$. Optimum 3D printing process parameters are kept constant for all sets of coupons and are as follows:

- Build orientation: XYZ

- Infill percentage: $100 \%$

- Layer thickness: $0.14 \mathrm{~mm}$

- Nozzle/bed temperature: $215 / 60{ }^{\circ} \mathrm{C}$.

- Fan speed: 0 (off)

- Printing speed: $2400 \mathrm{~mm} / \mathrm{min}$ 
- Filament

material:

PLA,

1.75

$\mathrm{mm}$

in

diameter

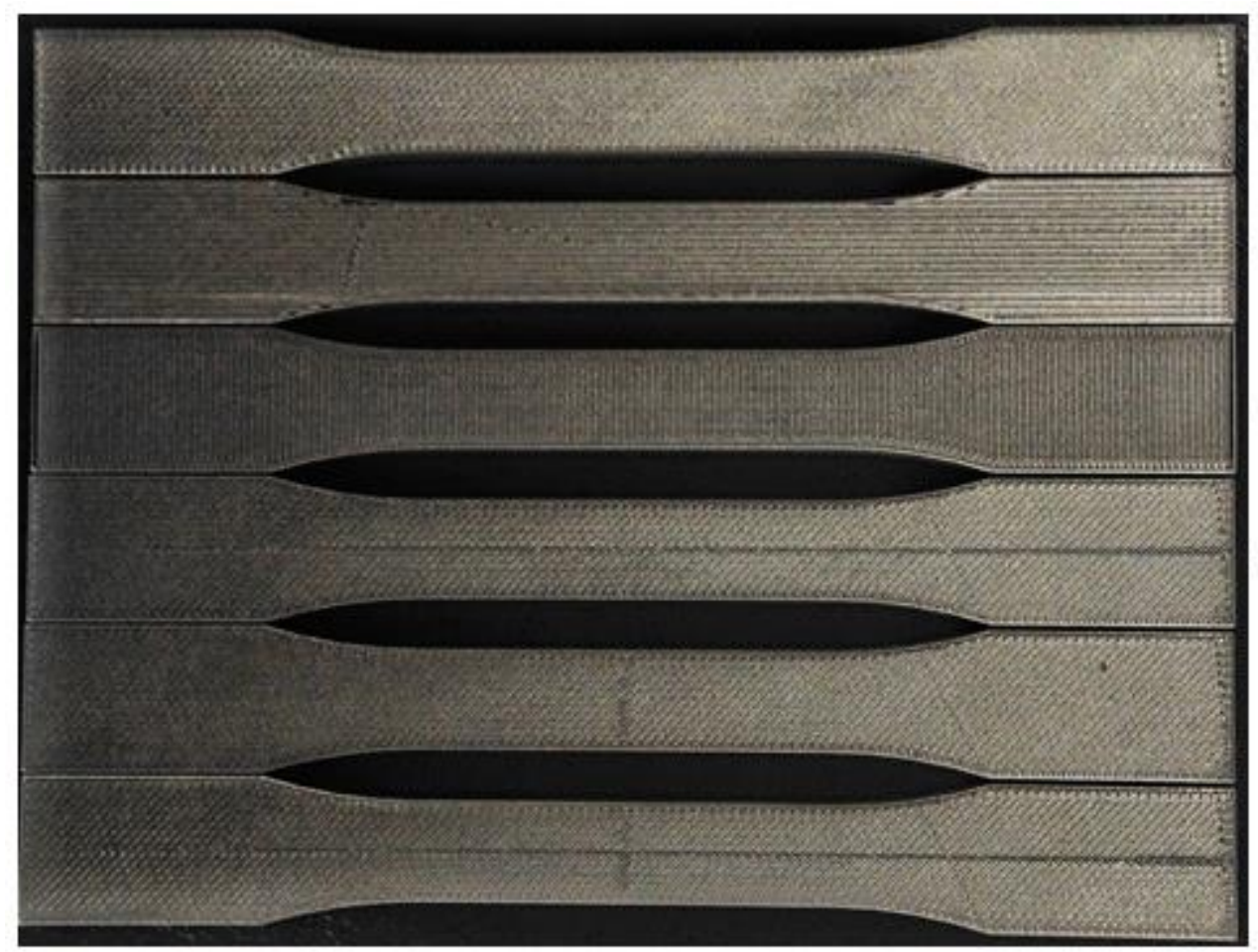

Coupon C

Coupon A

Coupon B

Coupon D

Coupon E

Coupon F

Figure 23 shows one coupon printed per each configuration (Coupons A-F) using Prusa i3 Mk2S.

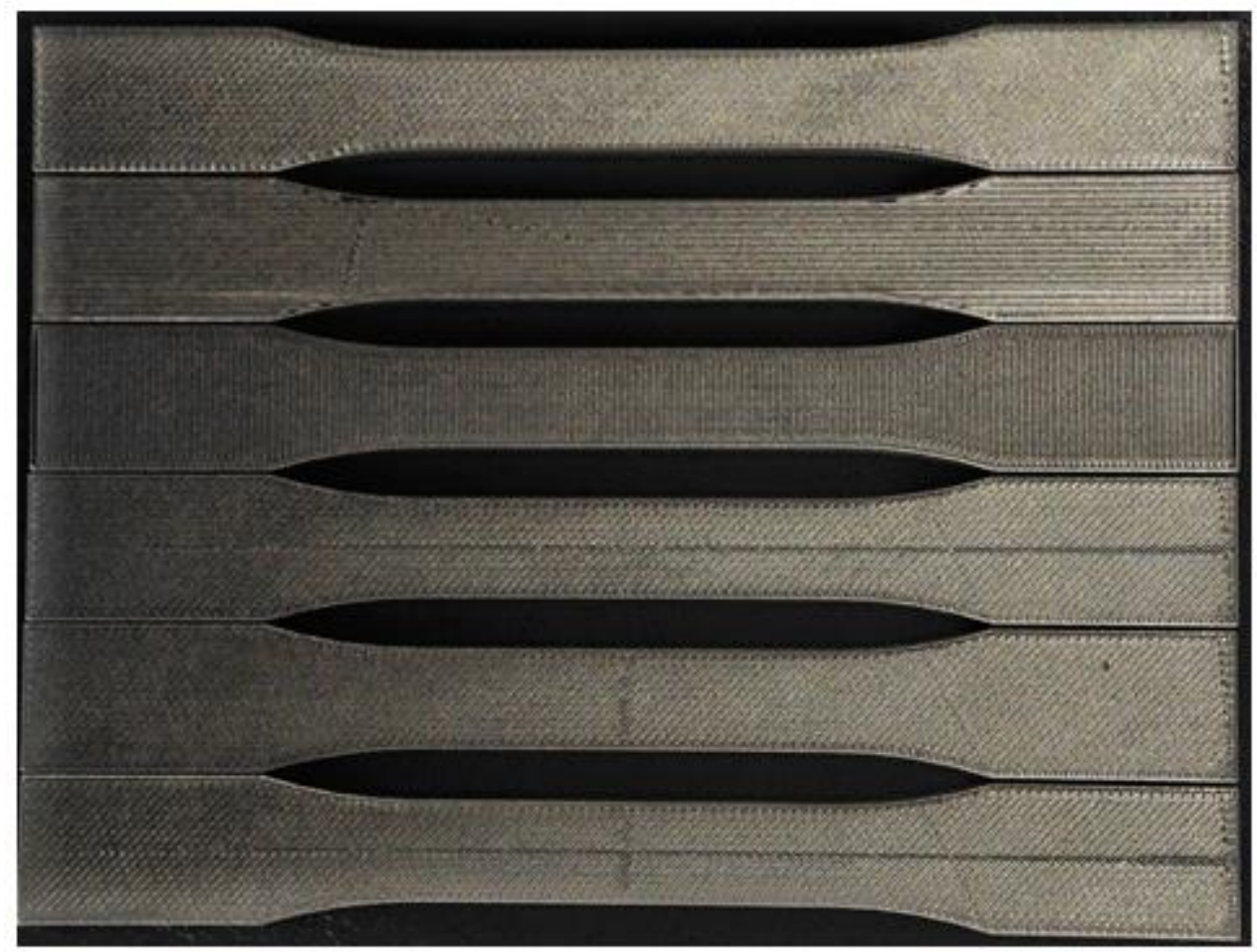

Coupon C

Coupon A

Coupon B

Coupon D

Coupon E

Coupon F 
Figure 23: 3D printed PLA specimens

Below, figures represent the GCOD visualization used for 3D printing of coupons with defect.

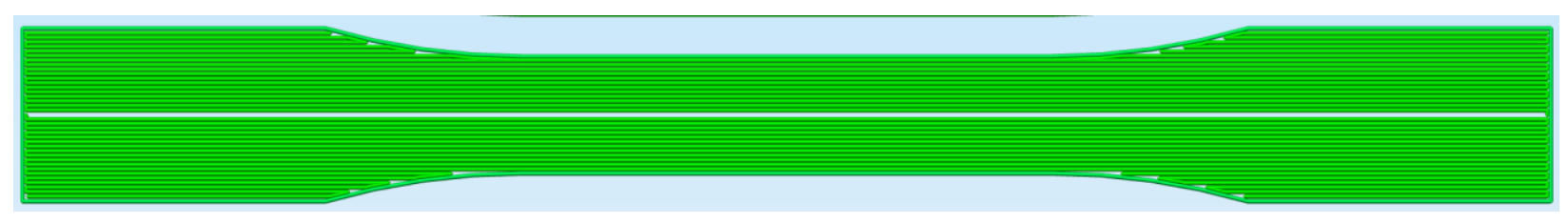

Figure 24: Coupon with defect on 0-degree raster angle

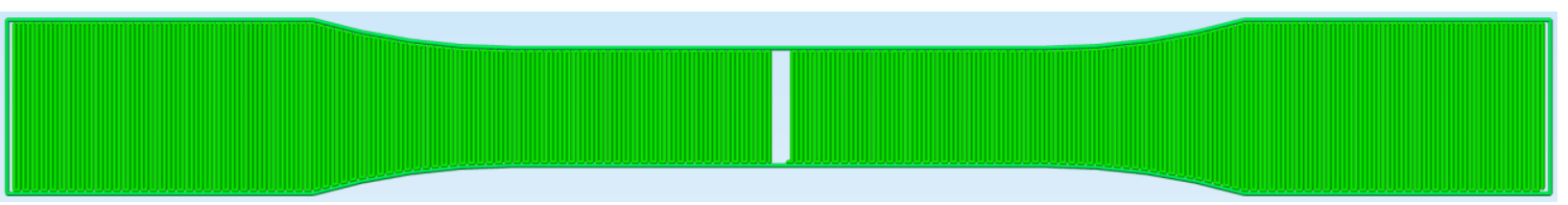

Figure 25Coupon with defect on 90-degree raster angle

Figure 26: Coupon with defect on both 0 and 90-degree raster angle

\subsection{SPECIMENS TESTING \& REPORTING}

Upon completion of coupons manufacturing, the mechanical properties, tensile strength and modulus, of each sample was obtained through tensile experimental testing. To perform this experiment, a universal Testing Machine (UTM) is sued along with an extensometer.

- Universal Testing Machine (UTM): This machine is widely used to perform tensile stress and compressive strength tests on different materials. In this study, United Mechanical Testing Machine is used. This machine uses interchangeable, electronic load cell weighing system. A $10 \mathrm{KN}$ load cell used for all samples with a constant displacement speed of $5 \mathrm{~mm} / \mathrm{min}$.

- Extensometer: A device commonly used during stress testing, which precisely measures the changes in the length of the specimen. This device is being placed on the coupon as shown in Figure 27 to obtain specimen percent elongation. 
Figure 27 depicts experimental test set-up showing United Mechanical Testing machine, extensometer and a PLA FDM 3-D printed coupon. To ensure consistency of results and reliability of data per ASTM D638:2014, a set of five samples from each specimen was built and tested. In this study, a total of 30 specimens is tested to obtain load and strain until failure and further analyses are performed to study the mechanical behavior of the specimens. These results are presented in Section 3 of this report.

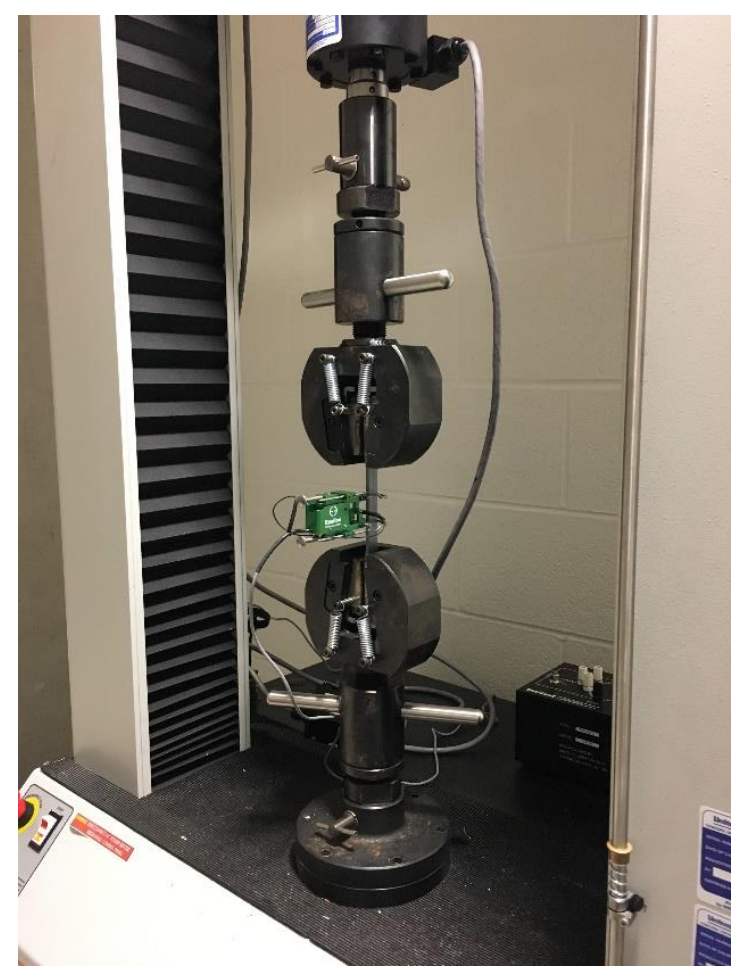

Figure 27: Experimental Test Environment

To obtain the stress-stain curve, the stress value at each point was calculated by dividing the applied tensile load to the specimen by the average original cross-sectional area in the gage length segment of the specimen. 
Statistical analysis needs to be performed on mechanical testing results. The sample mean, the average of all measurements in a sample and an estimate of the population mean, is calculated using Eq. 1ated. Sample mean value for both strength and modulus of all coupons is obtained.

$$
\bar{x}=\frac{x_{1}+x_{2}+\cdots+x_{n}}{n}=\frac{1}{n} \sum_{i=1}^{n} x_{i}
$$

The standard deviation ( $\mathrm{s}$ ) is known as the quantity calculated to indicate the amount of deviation or variation for a population as a whole. The sample standard deviation (s) is calculated using Eq. 2.

$$
s=\sqrt{\frac{1}{n-1} \sum_{i=1}^{n}\left(x_{i}-\bar{x}\right)^{2}} \quad s=\sqrt{\frac{1}{n-1} \sum_{i=1}^{n} x_{i}^{2}-\frac{n}{n-1} \bar{x}^{2}}
$$

The standard deviation shall be used to obtain the Coefficient of Variation (CV), which is a measure of relative variability. The coefficient of variation is the ratio of the standard deviation to the mean calculated as a percentage $(\%)$.

$$
C V=\frac{s}{\bar{x}} 100
$$

Furthermore, Scanning Electron Microscopy (SEM) imaging used to analyze and compare fracture surface between coupons. SEM imaging presented in Section 3 provides crucial information regarding failure mode and gives insight into ultimate tensile strength values. 


\subsection{RESULTS}

Once tensile coupons are designed and manufactured, experimental testing is performed to characterize their mechanical properties (tensile strength and modulus) and evaluate the impact of defects. In this section, all experimental testing results and analyses are provided followed by discussion with directions for future research.

As mentioned in Section 2, results can be divided in two main parts: mechanical characterization of 3D printed parts without defects; and the impact of defects on tensile strength and modulus of 3D printed parts. Raw data along with stress-strain graph for each specimen can be found in the Appendix A of this report.

\subsection{MECHANICAL CHARACTERIZATION OF 3D PRINTED PARTS WITHOUT DEFECTS}

As mentioned in Section 2, three sets of coupons are considered in this section. Per ASTM D63814, Table 4 provides coupons design parameters (defect inclusion and raster angle) along with their average cross section dimensions in the gage ( 5 coupons per set).

Table 4: FDM Tensile coupons without defects print mechanical properties

\begin{tabular}{|l|c|c|c|c|}
\hline Coupon ID & Defect & $\begin{array}{c}\text { Raster angle } \\
(\mathbf{d e g r e e})\end{array}$ & $\begin{array}{c}\text { Coupon width } \\
(\mathbf{m m})\end{array}$ & $\begin{array}{c}\text { Coupon thickness } \\
(\mathbf{m m})\end{array}$ \\
\hline Coupon A-1 & $\mathrm{NO}$ & {$[0]_{24}$} & 12.98 & 3.63 \\
\hline Coupon A-2 & NO & {$[0]_{24}$} & 13.06 & 3.61 \\
\hline Coupon A-3 & NO & {$[0]_{24}$} & 13.08 & 3.58 \\
\hline Coupon A-4 & NO & {$[0]_{24}$} & 13.00 & 3.63 \\
\hline Coupon A-5 & NO & {$[0]_{24}$} & 13.11 & 3.63 \\
\hline Coupon B-1 & NO & {$[90]_{24}$} & 12.98 & 3.48 \\
\hline Coupon B-2 & NO & {$[90]_{24}$} & 13.06 & 3.45 \\
\hline
\end{tabular}




\begin{tabular}{|l|l|c|c|c|}
\hline Coupon B-3 & NO & {$[90]_{24}$} & 12.93 & 3.53 \\
\hline Coupon B-4 & NO & {$[90]_{24}$} & 12.93 & 3.51 \\
\hline Coupon B-5 & NO & {$[90]_{24}$} & 12.93 & 3.53 \\
\hline Coupon C-1 & NO & {$[45 / 0 / 90 /-45]_{3 \mathrm{~S}}$} & 12.90 & 3.51 \\
\hline Coupon C-2 & NO & {$[45 / 0 / 90 /-45]_{3 \mathrm{~S}}$} & 12.95 & 3.51 \\
\hline Coupon C-3 & NO & {$[45 / 0 / 90 /-45]_{3 \mathrm{~S}}$} & 13.00 & 3.51 \\
\hline Coupon C-4 & NO & {$[45 / 0 / 90 /-45]_{3 \mathrm{~S}}$} & 13.11 & 3.45 \\
\hline Coupon C-5 & NO & {$[45 / 0 / 90 /-45]_{3 \mathrm{~S}}$} & 13.11 & 3.48 \\
\hline
\end{tabular}

Figure 28, Figure 30, and Figure 32 represents the stress - strain curve obtained for coupons A-1, B-1 and C-1 respectively. In this study, the modulus was calculated by extending the initial linear section of the stress-stain curve and dividing the difference in stress corresponding to any segment of this straight line by the corresponding difference in strain. This was confirmed by a linear regression fit to the data points with R-squared of 0.999 (Figure 29, Figure 31, and Figure 33).

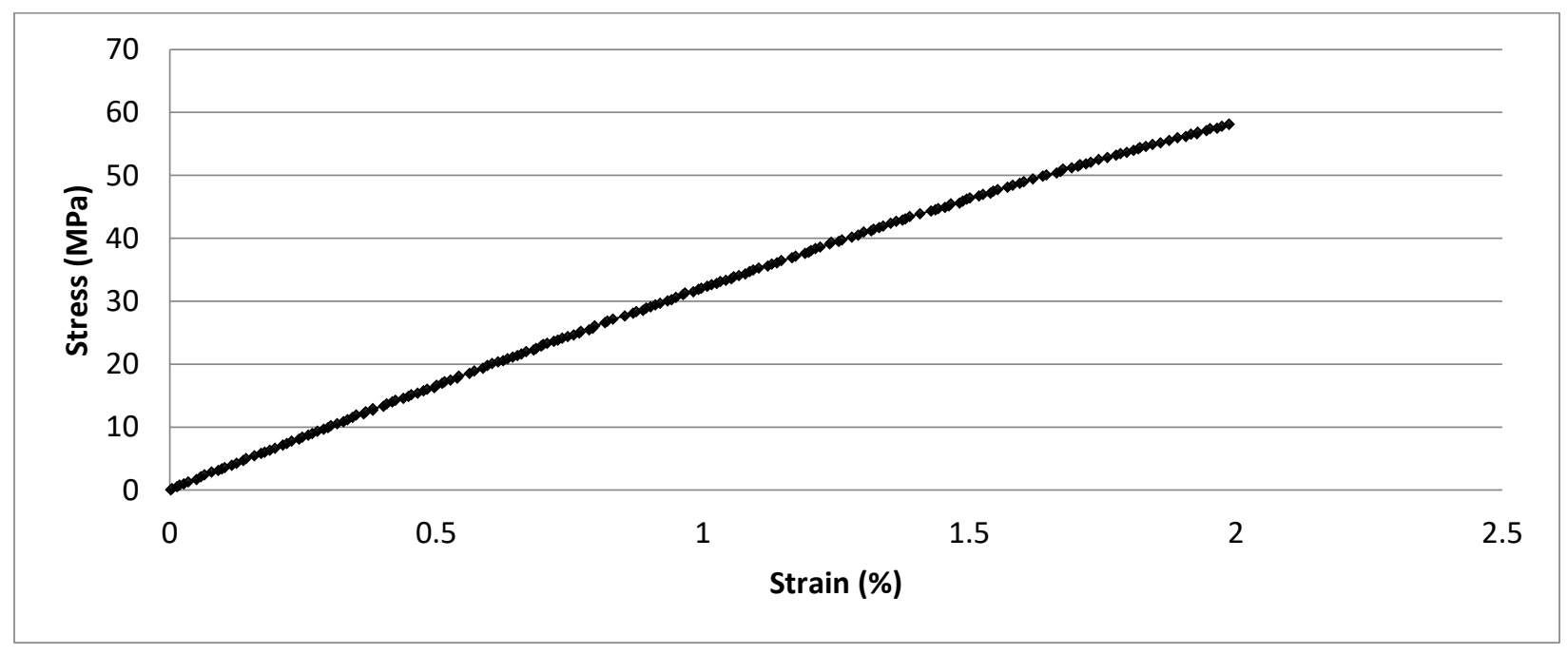

Figure 28: Stress - Strain Curves for Coupon A-1 


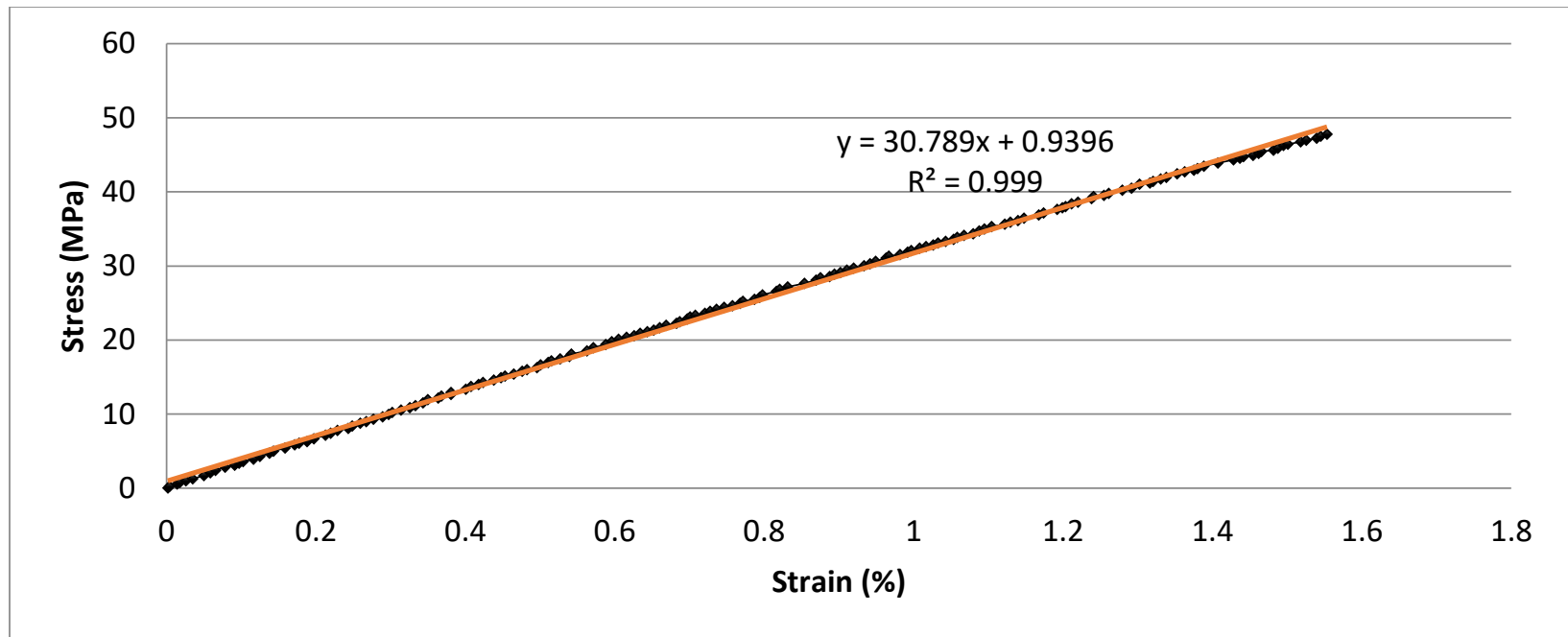

Figure 29: Stress-strain curve coupon A-1 (linear segment)

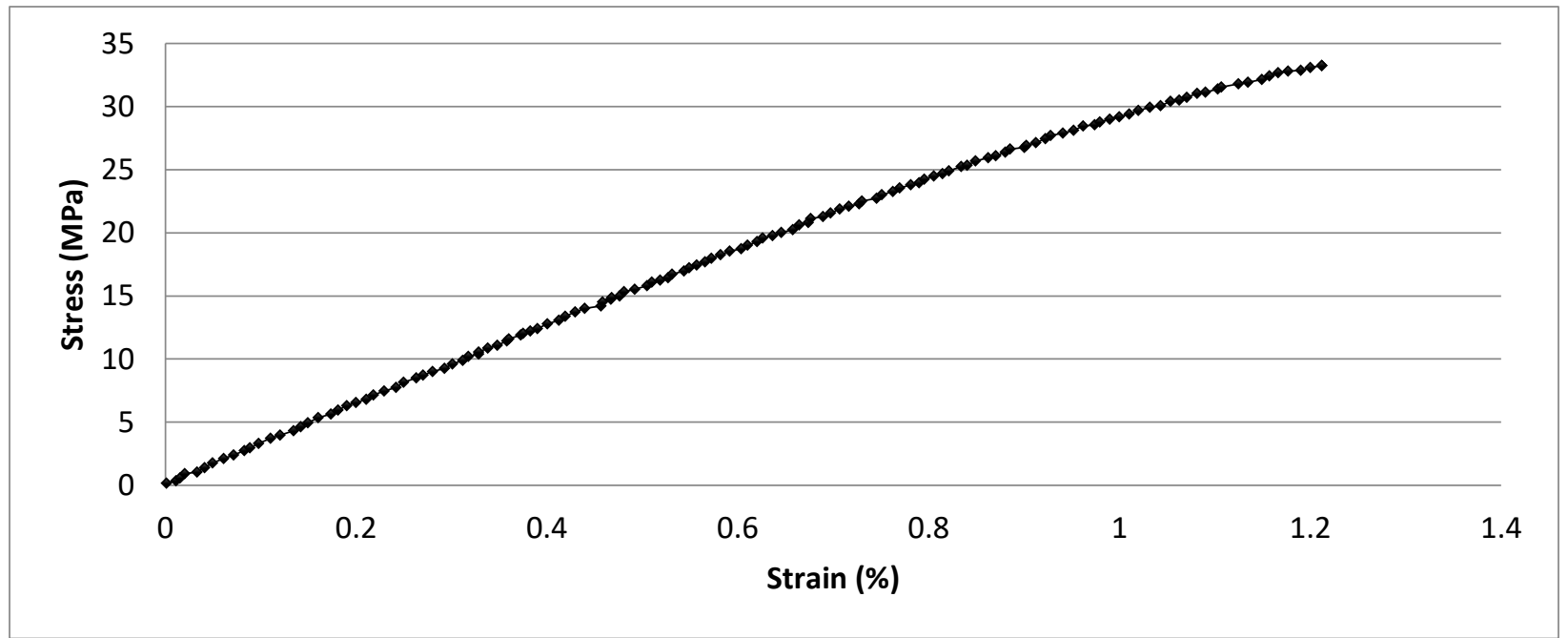

Figure 30: Stress - Strain Curves for Coupon B-1 


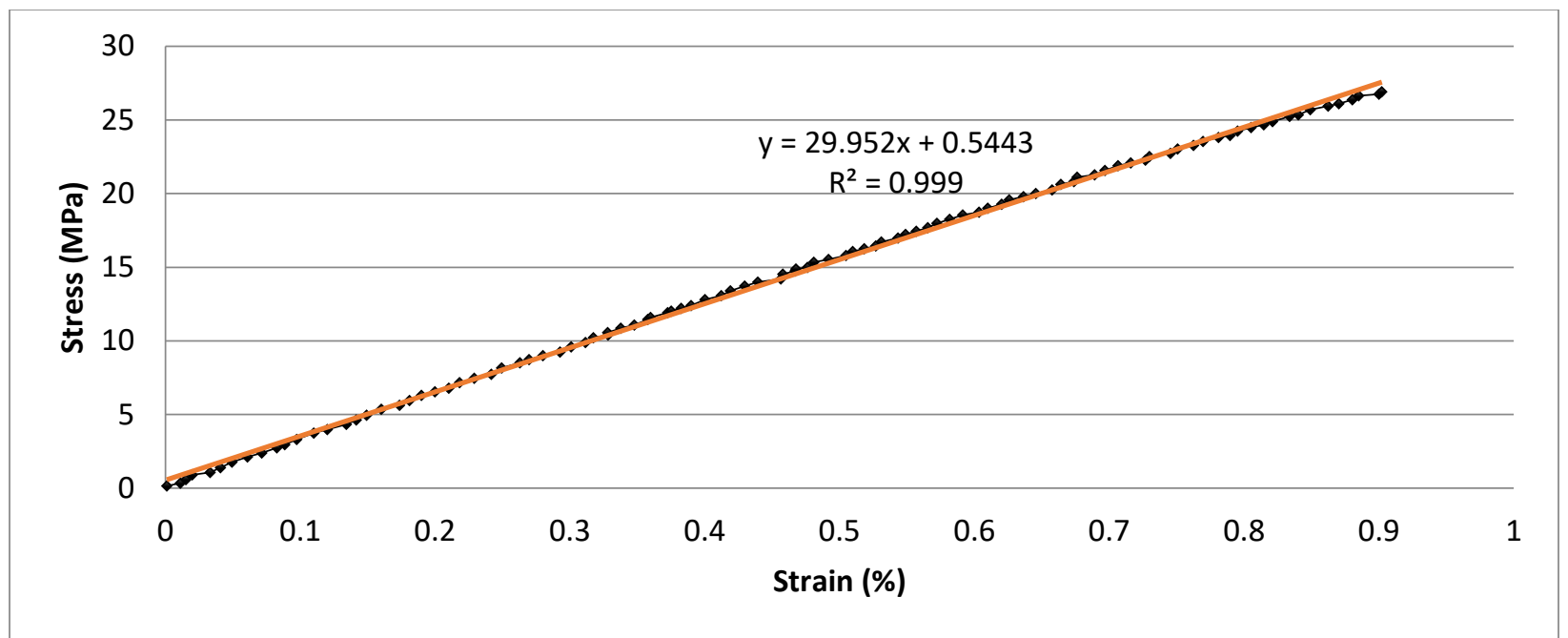

Figure 31: Stress - Strain Curves for Coupon B-1 (linear segment)

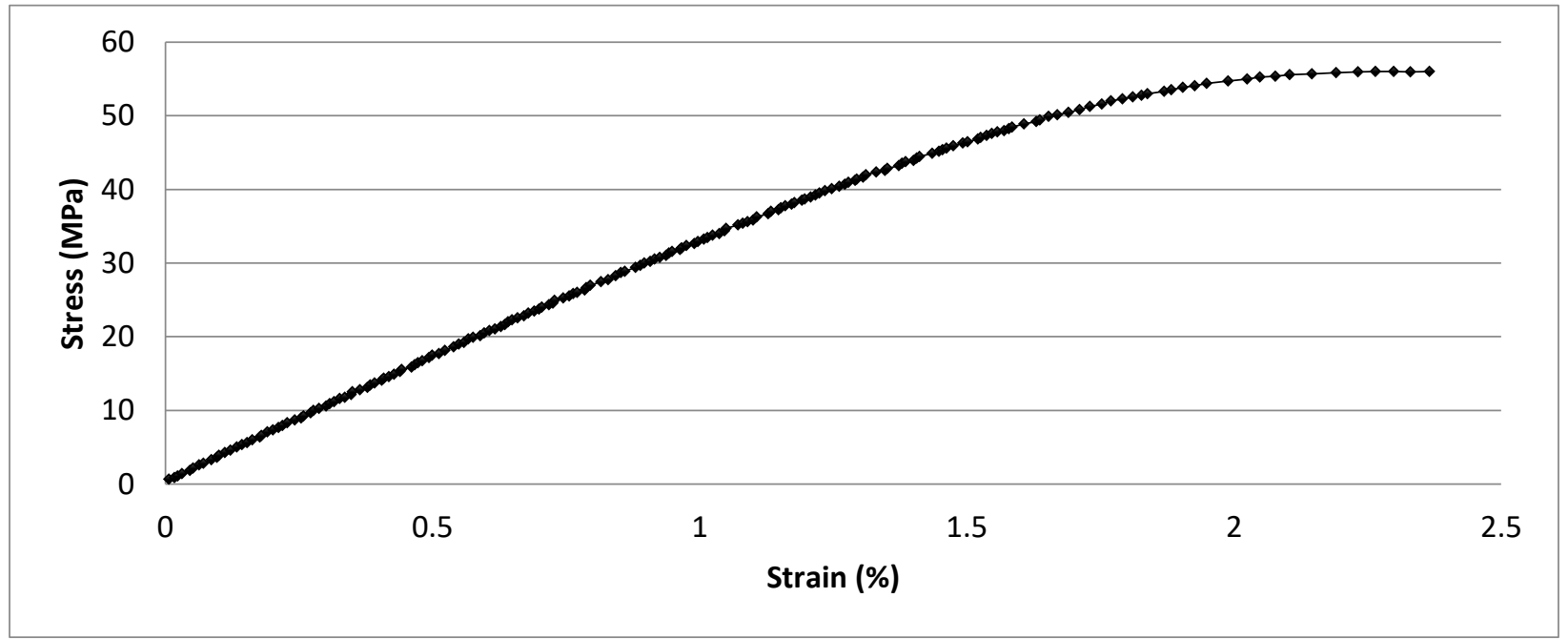

Figure 32: Stress - Strain Curves for Coupon C-1 


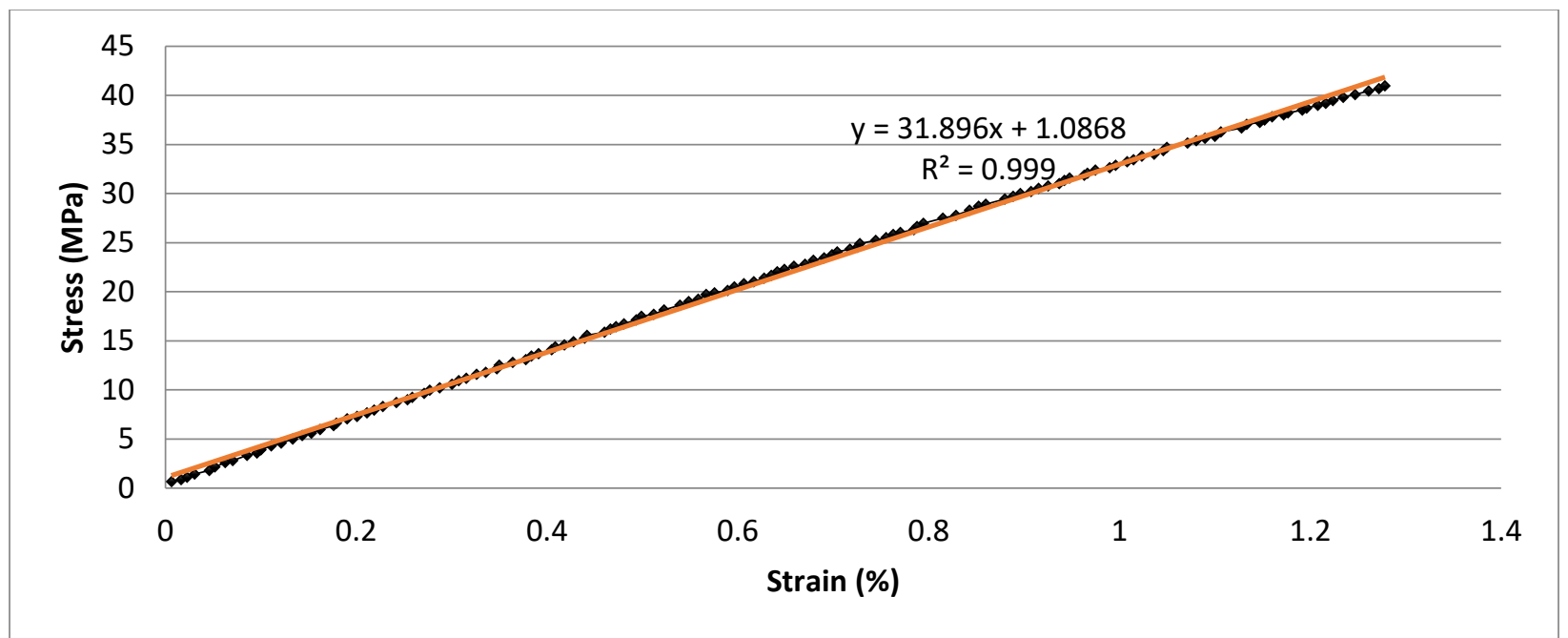

Figure 33: Stress-strain curve coupon C-1 (linear segment)

Tensile strength and modulus results are reported to three significant figures as per ASTM D638. The summery of ultimate tensile strength and modulus of elasticity (stiffness) is tabulated below. Furthermore, the average, standard deviation, and coefficient of variation are calculated for both strength and stiffness of each set of coupons (Coupons A, B, and C). Results of these analyses are presented in Table 5 to Table 7.

Table 5: Coupon A Tensile Test Experimental Results

\begin{tabular}{|c|c|c|c|}
\hline \multicolumn{4}{|c|}{ Coupon A $(1-5)$} \\
\hline Coupon ID & Strength (MPa) & Stiffness $(\mathrm{GPa})$ & Failure strain (\%) \\
\hline A-1 & 58.12 & 3.08 & 1.99 \\
\hline A-2 & 58.26 & 3.14 & 1.94 \\
\hline A-4 & 56.81 & 3.25 & 1.81 \\
\hline A-5 & 58.04 & 3.18 & 2.01 \\
\hline A-6 & 57.38 & 3.01 & 2.03 \\
\hline Average & 57.72 & 3.13 & 1.96 \\
\hline S & 0.61 & 0.09 & 0.09 \\
\hline CV & $1.1 \%$ & $3.0 \%$ & $4.4 \%$ \\
\hline
\end{tabular}

Table 6: Coupon B Tensile Test Experimental Results/

\begin{tabular}{|l|l|l|l|}
\hline \multicolumn{4}{|c|}{ Coupon B (1-5) } \\
\hline Coupon ID & Strength (MPa) & Stiffness (GPa) & Failure strain (\%) \\
\hline
\end{tabular}




\begin{tabular}{|c|c|c|c|}
\hline B-1 & 33.2 & 3.00 & 1.21 \\
\hline B-2 & 35.1 & 3.07 & 1.27 \\
\hline B-3 & 32.1 & 2.91 & 1.24 \\
\hline B-4 & 25.7 & 2.90 & 0.92 \\
\hline B-5 & 28.0 & 2.83 & 1.11 \\
\hline Average & 30.8 & 2.9 & 1.15 \\
\hline s & 3.88 & 0.09 & 0.14 \\
\hline CV & $12.6 \%$ & $3.2 \%$ & $12.3 \%$ \\
\hline
\end{tabular}

Table 7: Coupon C Tensile Test Experimental Results

\begin{tabular}{|c|c|c|c|}
\hline \multicolumn{4}{|c|}{ Coupon C (1-5) } \\
\hline Coupon ID & Strength (MPa) & Stiffness (GPa) & Failure strain \\
\hline C-1 & 56.02 & 3.19 & 2.57 \\
\hline C-2 & 53.14 & 3.03 & 2.34 \\
\hline C-3 & 52.83 & 3.10 & 2.26 \\
\hline C-4 & 55.19 & 3.11 & 2.25 \\
\hline C-5 & 50.23 & 3.12 & 2.32 \\
\hline Average & 53.48 & 3.11 & 2.35 \\
\hline s & 2.26 & 0.06 & 0.13 \\
\hline CV & $4.2 \%$ & $1.8 \%$ & $5.5 \%$ \\
\hline
\end{tabular}

Moreover, SEM imaging for fracture surface of each coupon type is provided using a zoom of 15 times (Figure 34, Figure 35, Figure 36).

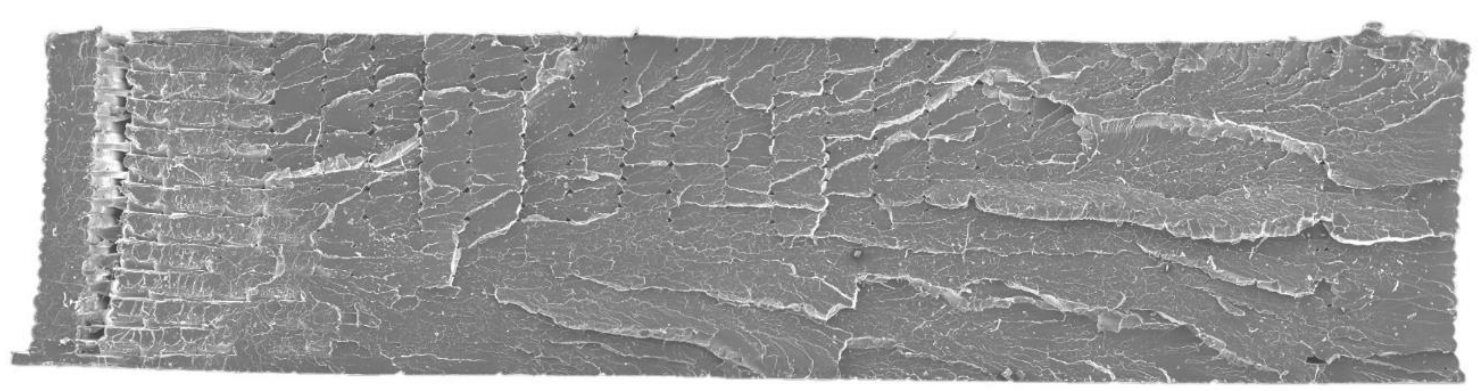

Figure 34. Coupon A SEM image of fracture surface (15x zoom) 


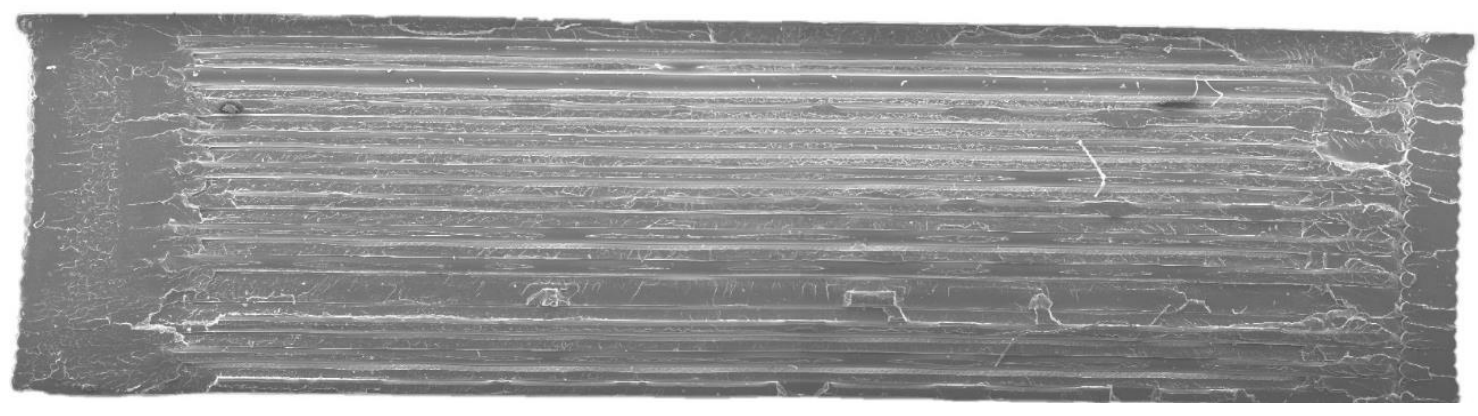

Figure 35. Coupon B SEM image of fracture surface (15x zoom)

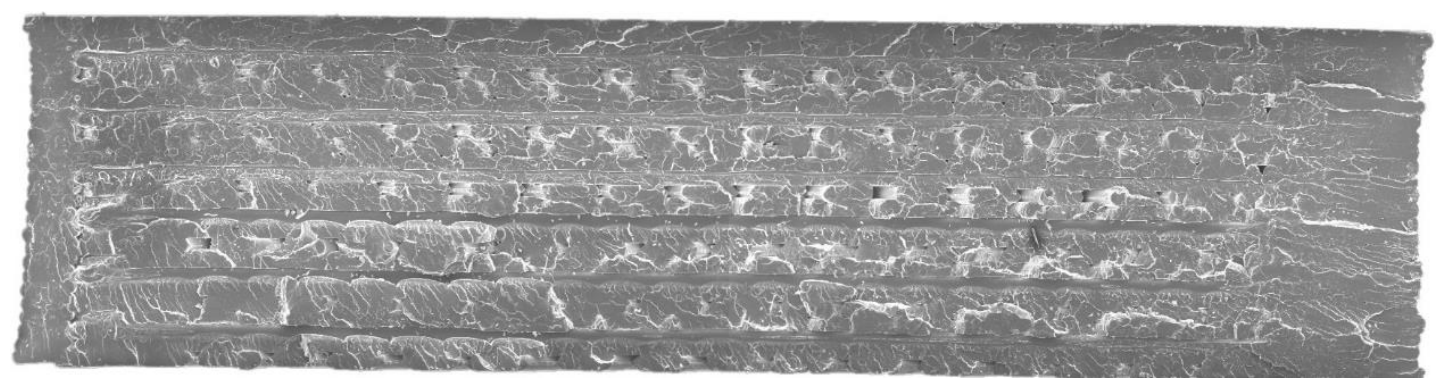

Figure 36. Coupon C SEM image of fracture surface (15x zoom)

\subsection{MECHANICAL CHARACTERIZATION OF 3D PRINTED PARTS WITH DEFECTS}

In this section, the impact of defects on tensile strength and modulus of $3 \mathrm{D}$ printed part is investigated. As discussed in Section 2, a quasi-isotropic layup [45/0/90/-45]3s is selected and defects are introduced into the part. Table 8 provides coupons design parameters (defect inclusion and raster angle) along with their average cross section dimensions in the gage ( 5 coupons per set).

Table 8: FDM Tensile coupons with defects mechanical properties

\begin{tabular}{|l|c|c|c|c|}
\hline Coupon ID & Defect & $\begin{array}{c}\text { Raster angle } \\
(\text { degree })\end{array}$ & $\begin{array}{c}\text { Coupon width } \\
(\mathbf{m m})\end{array}$ & $\begin{array}{c}\text { Coupon thickness } \\
(\mathbf{m m})\end{array}$ \\
\hline Coupon D-1 & 1 bead - 0 degree & {$[45 / 0 / 90 /-45]_{3 \mathrm{~S}}$} & 12.78 & 3.73 \\
\hline
\end{tabular}




\begin{tabular}{|c|c|c|c|c|}
\hline Coupon D-2 & 1 bead - 0 degree & {$[45 / 0 / 90 /-45]_{3 \mathrm{~S}}$} & 12.88 & 3.63 \\
\hline Coupon D-3 & 1 bead - 0 degree & {$[45 / 0 / 90 /-45]_{3 S}$} & 12.90 & 3.48 \\
\hline Coupon D-4 & 1 bead - 0 degree & {$[45 / 0 / 90 /-45]_{3 S}$} & 12.88 & 3.53 \\
\hline Coupon D-5 & 1 bead - 0 degree & {$[45 / 0 / 90 /-45]_{3 \mathrm{~S}}$} & 12.93 & 3.61 \\
\hline Coupon E-1 & 4 bead - 90 degree & {$[45 / 0 / 90 /-45]_{3 \mathrm{~S}}$} & 12.85 & 3.53 \\
\hline Coupon E-2 & 4 bead - 90 degree & {$[45 / 0 / 90 /-45]_{3 \mathrm{~S}}$} & 12.90 & 3.58 \\
\hline Coupon E-3 & 4 bead - 90 degree & {$[45 / 0 / 90 /-45]_{3 \mathrm{~S}}$} & 12.85 & 3.58 \\
\hline Coupon E-4 & 4 bead - 90 degree & {$[45 / 0 / 90 /-45]_{3 \mathrm{~S}}$} & 12.88 & 3.61 \\
\hline Coupon E-5 & 4 bead - 90 degree & {$[45 / 0 / 90 /-45]_{3 \mathrm{~S}}$} & 12.88 & 3.58 \\
\hline Coupon F-1 & $\begin{array}{c}1 \text { bead - } 0 \text { degree } \\
4 \text { beads - } 90 \text { degree }\end{array}$ & {$[45 / 0 / 90 /-45]_{3 \mathrm{~S}}$} & 12.90 & 3.51 \\
\hline Coupon F-2 & $\begin{array}{c}1 \text { bead - } 0 \text { degree } \\
4 \text { beads - } 90 \text { degree }\end{array}$ & {$[45 / 0 / 90 /-45]_{3 \mathrm{~S}}$} & 12.90 & 3.53 \\
\hline Coupon F-3 & $\begin{array}{c}1 \text { bead - } 0 \text { degree } \\
4 \text { beads - } 90 \text { degree }\end{array}$ & {$[45 / 0 / 90 /-45]_{3 \mathrm{~S}}$} & 12.88 & 3.53 \\
\hline Coupon F-4 & $\begin{array}{c}1 \text { bead - } 0 \text { degree } \\
4 \text { beads - } 90 \text { degree }\end{array}$ & {$[45 / 0 / 90 /-45]_{3 \mathrm{~S}}$} & 12.90 & 3.56 \\
\hline Coupon F-5 & $\begin{array}{c}1 \text { bead - } 0 \text { degree } \\
4 \text { beads - } 90 \text { degree }\end{array}$ & {$[45 / 0 / 90 /-45]_{3 \mathrm{~S}}$} & 12.90 & 3.56 \\
\hline
\end{tabular}

Stress-strain curve for samples D-1, E-1, and F-1 with defect are given in Figure 37, Figure 39, and Figure 41 respectively. As in Section 3.1, a linear regression fit for obtaining the modulus of elasticity is used (Figure 38, Figure 40, and Figure 42) 


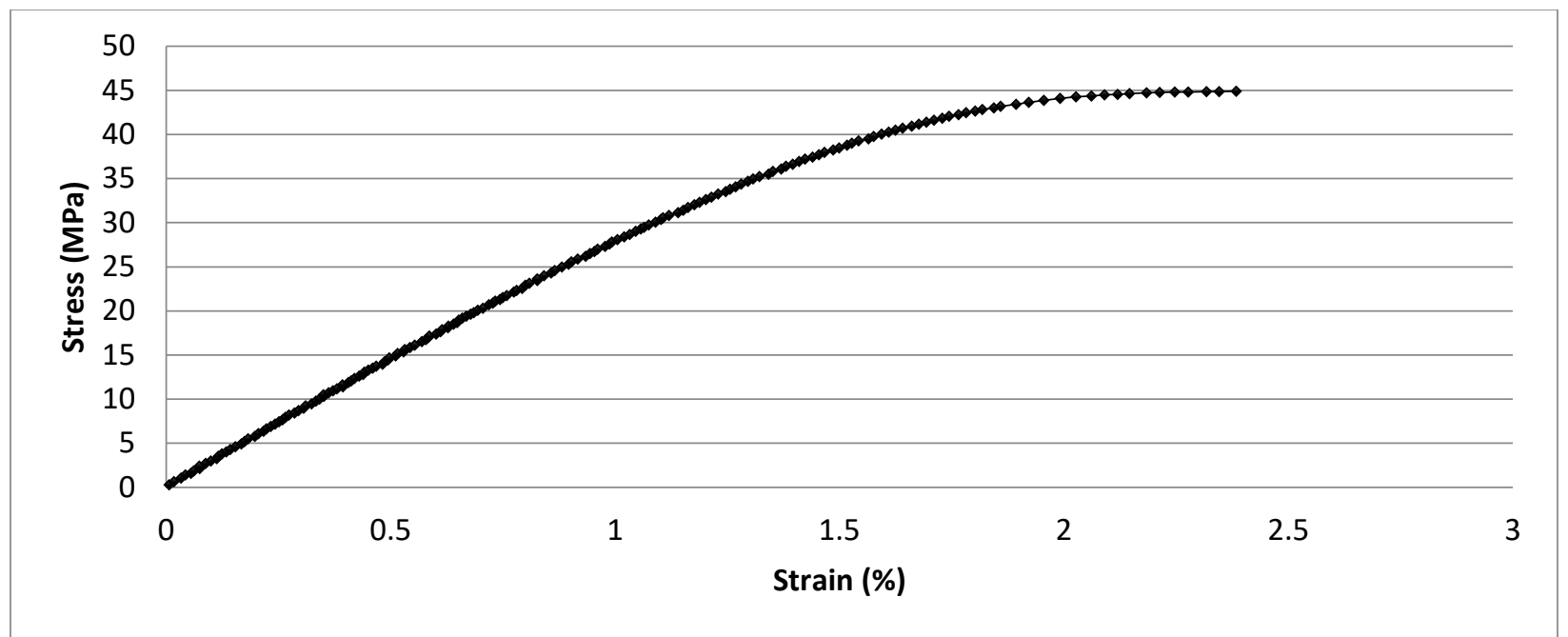

Figure 37: Stress-strain curve coupon D-1

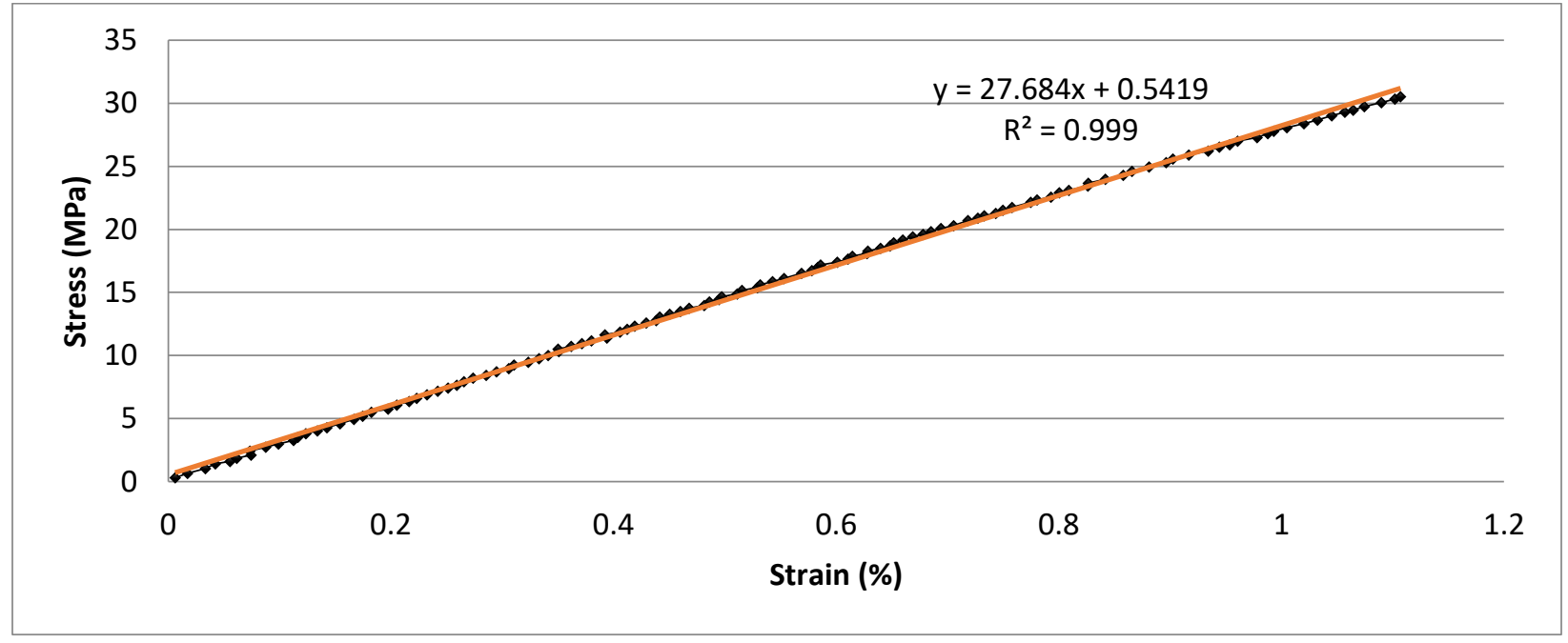

Figure 38: Stress-strain curve coupon D-1 (linear segment) 


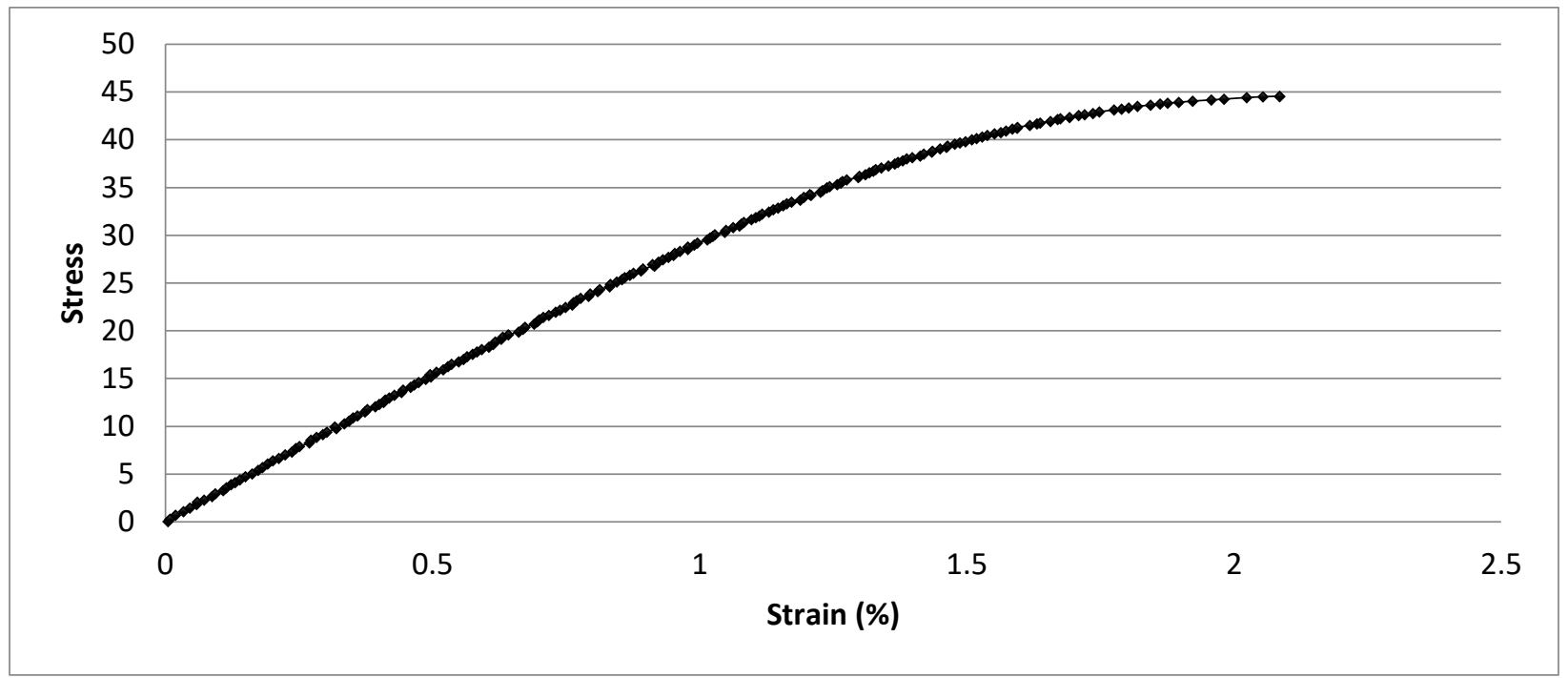

Figure 39: Stress-strain curve coupon E-1

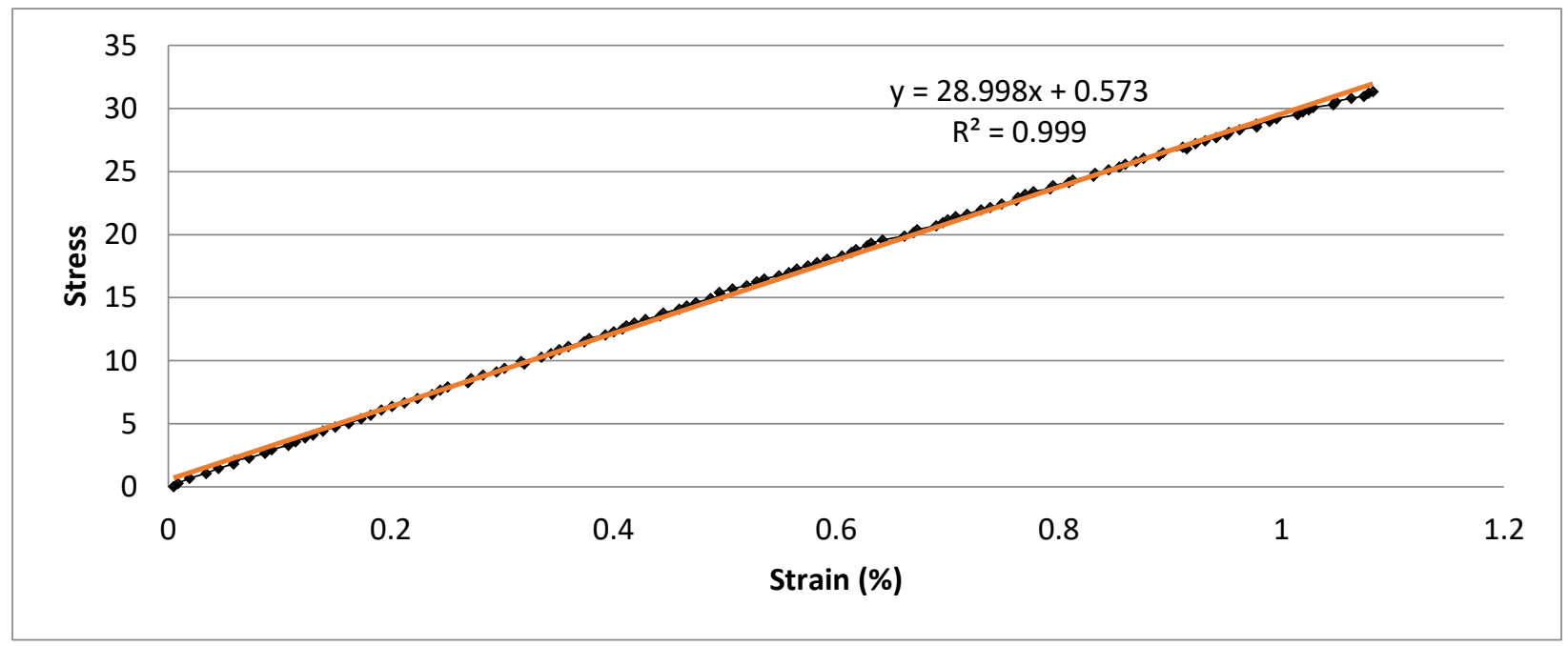

Figure 40: Stress-strain curve coupon E-1 (linear segment) 


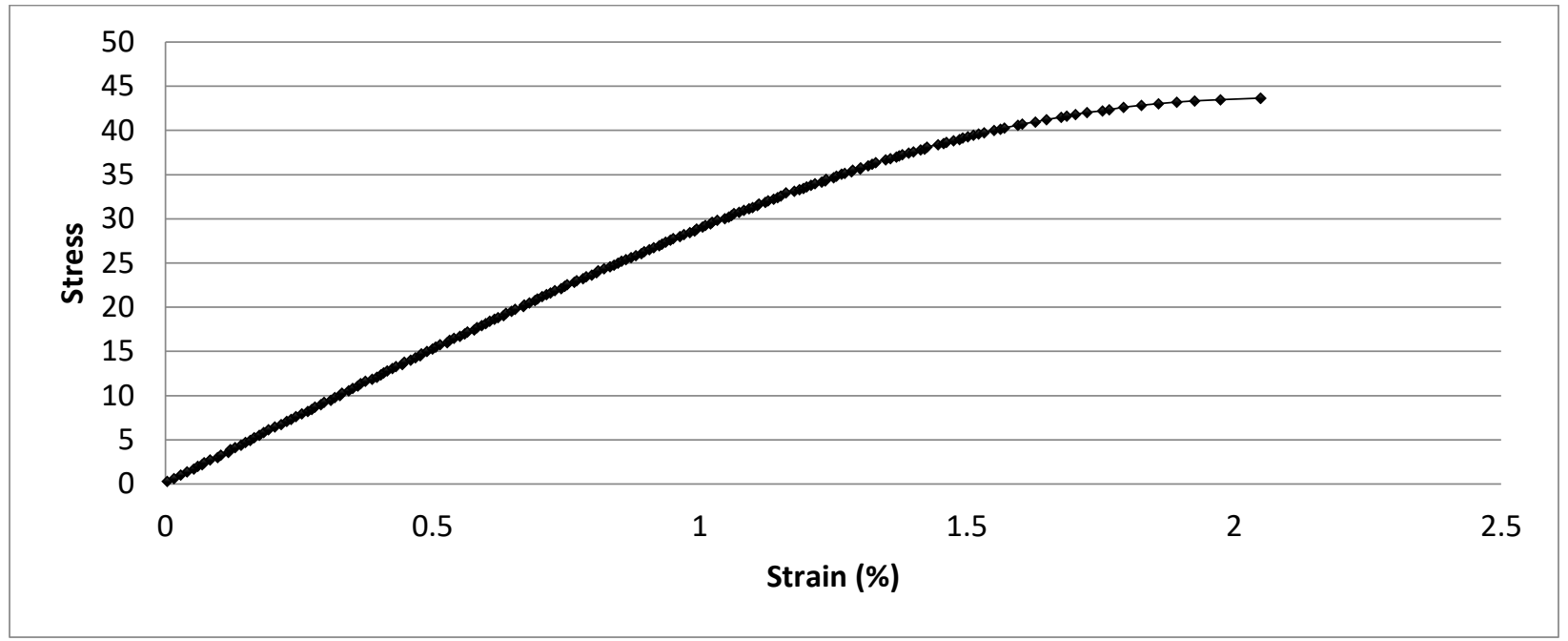

Figure 41: Stress-strain curve coupon F-1

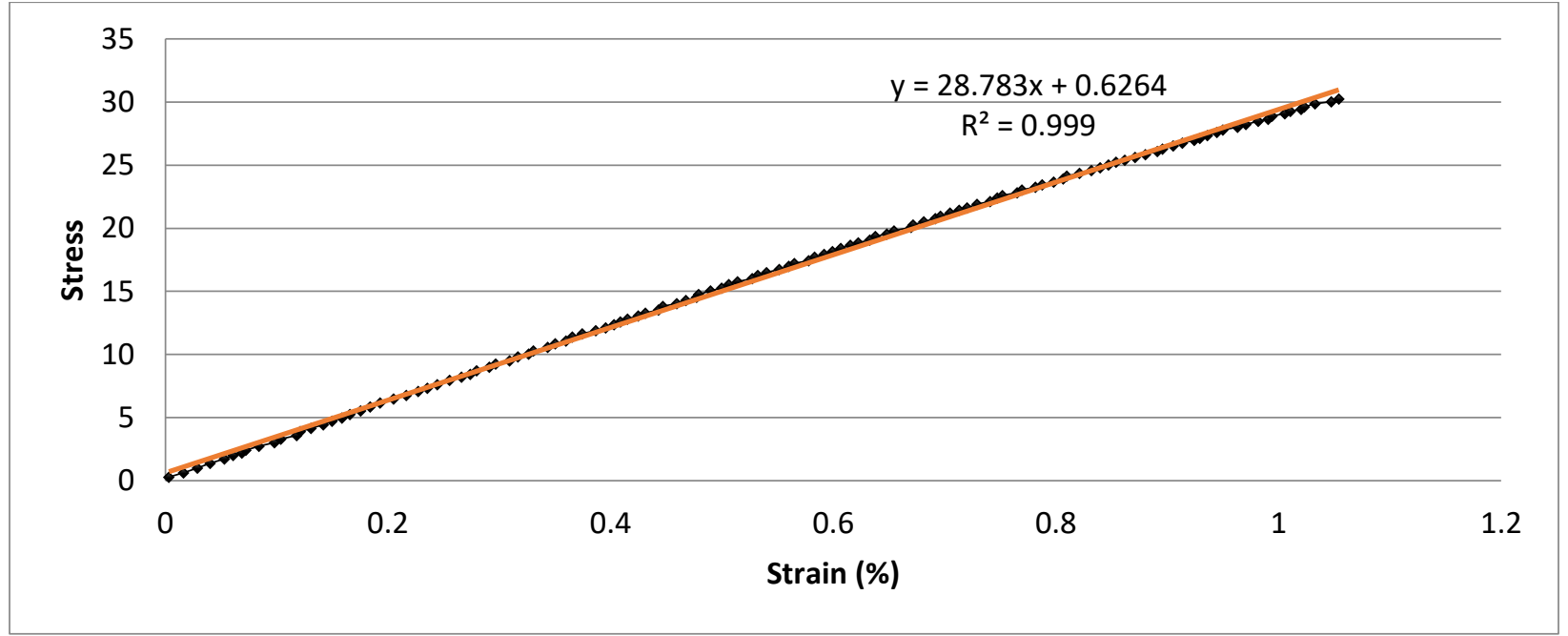

Figure 42: Stress-strain curve coupon F-1 (linear segment)

A summary of ultimate tensile strength and modulus is tabulated along with average, standard deviation, and coefficient of variation calculated for each set of coupons (Coupons D, E, and F). Results of these analyses are presented in

Table 9 to Table 11. 
Table 9: Coupon D Tensile Test Experimental Results

\begin{tabular}{|c|c|c|c|}
\hline \multicolumn{4}{|c|}{ Coupon D (1-5) } \\
\hline Coupon ID & Strength (MPa) & Stiffness (GPa) & Failure strain (\%) \\
\hline D-1 & 44.90 & 2.77 & 2.98 \\
\hline D-2 & 46.64 & 2.84 & 2.59 \\
\hline D-3 & 49.01 & 3.10 & 2.74 \\
\hline D-4 & 48.33 & 2.99 & 3.01 \\
\hline D-5 & 49.00 & 2.91 & 3.07 \\
\hline Average & 47.58 & 2.92 & 2.88 \\
\hline S & 1.78 & 0.13 & 0.20 \\
\hline CV & $3.7 \%$ & $4.5 \%$ & $7.1 \%$ \\
\hline
\end{tabular}

Table 10: Coupon E Tensile Test Experimental Results

\begin{tabular}{|c|c|c|c|}
\hline \multicolumn{4}{|c|}{ Coupon E (1-5) } \\
\hline Coupon ID & Strength (MPa) & Stiffness $(\mathrm{GPa})$ & Failure strain (\%) \\
\hline E-1 & 44.56 & 2.90 & 2.09 \\
\hline E-2 & 43.58 & 2.83 & 2.10 \\
\hline E-3 & 41.74 & 2.77 & 2.09 \\
\hline E-4 & 42.79 & 2.78 & 2.14 \\
\hline E-5 & 39.98 & 2.76 & 1.98 \\
\hline Average & 42.53 & 2.81 & 2.08 \\
\hline S & 1.76 & 0.06 & 0.06 \\
\hline CV & $4.1 \%$ & $2.1 \%$ & $2.9 \%$ \\
\hline
\end{tabular}

Table 11: Coupon F Tensile Test Experimental Results

\begin{tabular}{|c|c|c|c|}
\hline \multicolumn{4}{|c|}{ Coupon F (1-5) } \\
\hline Coupon ID & Strength (MPa) & Stiffness (GPa) & Failure strain (\%) \\
\hline F-1 & 43.66 & 2.88 & 2.05 \\
\hline F-2 & 42.91 & 2.85 & 2.05 \\
\hline F-3 & 42.28 & 2.79 & 2.15 \\
\hline F-4 & 44.73 & 2.92 & 2.03 \\
\hline F-5 & 42.44 & 2.95 & 2.04 \\
\hline Average & 43.20 & 2.88 & 2.06 \\
\hline S & 1.01 & 0.06 & 0.05 \\
\hline CV & $2.3 \%$ & $2.1 \%$ & $2.4 \%$ \\
\hline
\end{tabular}


Moreover, SEM imaging for fracture surface of each coupon type is provided using a zoom of 15 times (Figure 43, Figure 44, and Figure 45).

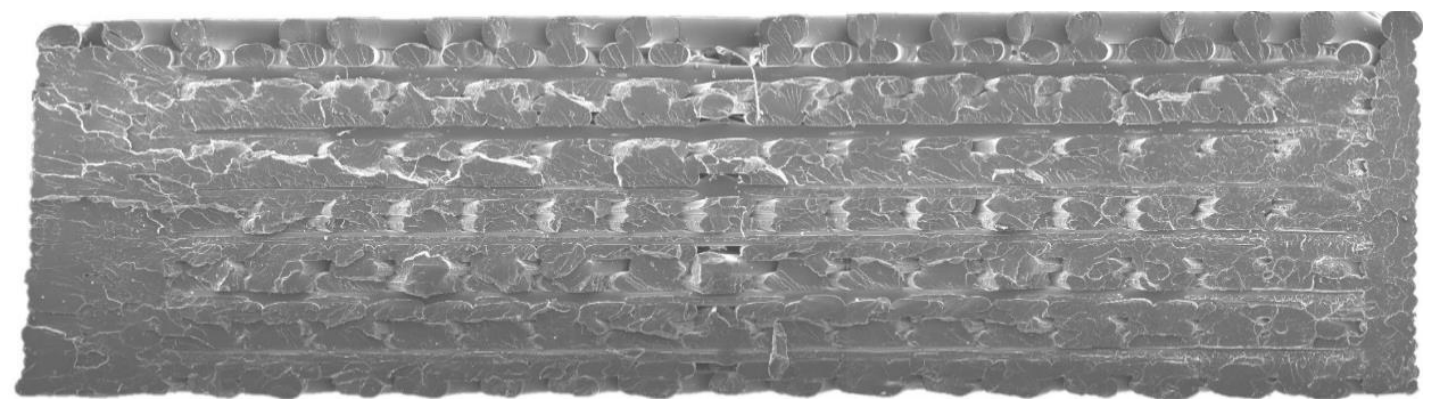

Figure 43. Coupon D SEM image of fracture surface (15x zoom)

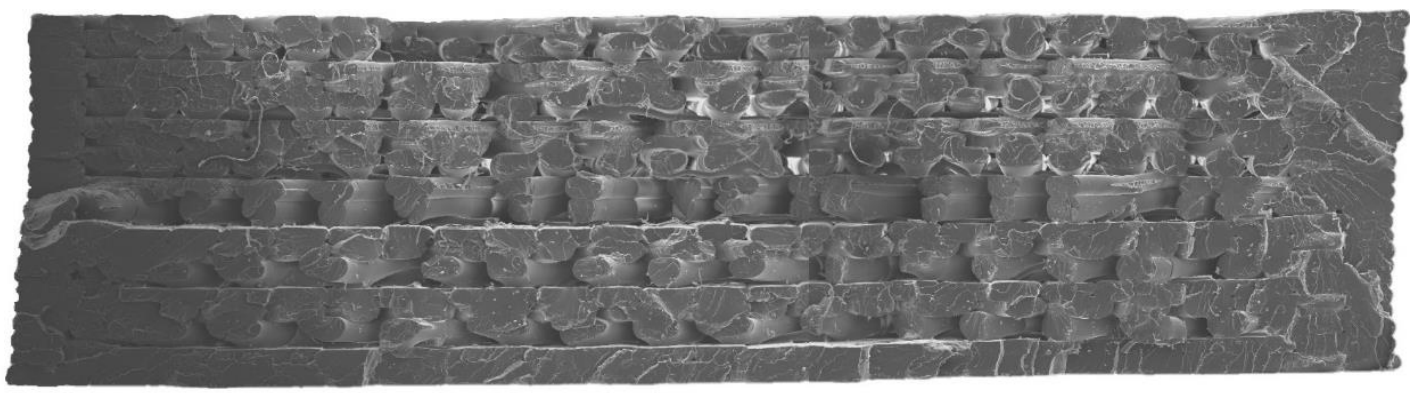

Figure 44. Coupon E SEM image of fracture surface (15x zoom)

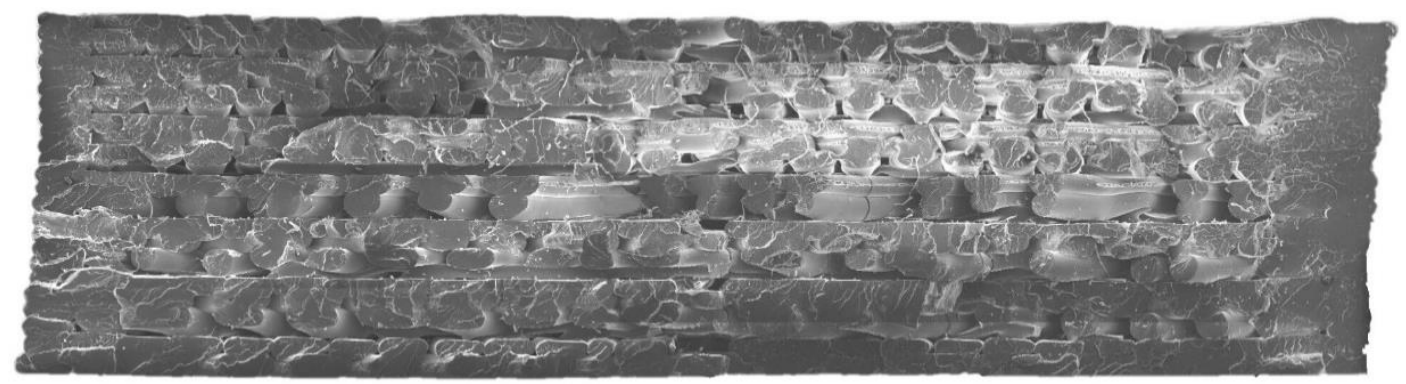

Figure 45. Coupon F SEM image of fracture surface (15x zoom) 


\subsection{DISCUSSION}

In this study, ultimate tensile strength, modulus, failure strain, and stress-strain graphs were obtained for specimens with and without defects. These results were provided individually for each set of coupons in Section 3. Here, a comparison between experimental testing results is made to evaluate the impact of raster angle and impact inclusion on mechanical performance of the FDM $3 \mathrm{D}$ printed parts.

\subsection{SPECIMENS WITHOUT DEFECT}

Table 12 summarizes mean tensile strength, modulus of elasticity, and failure strain for coupons without defects. Figure 46 through Figure 50 are the graphical representation of the testing results and include the error bars. By comparing the mechanical properties provided in Table 12, it can be concluded that the samples with $[0]_{24}$ stacking sequence (Coupon A) have the highest tensile strength and modulus compared with [90] $]_{24}$ and [45/0/90/-45] $]_{3 s}$ samples (Coupons B and C). This is expected since for coupon A all beads are along the loading direction. Coupon B with [90] 24 stacking sequence has the lowest tensile strength, modulus, and failure strain since all beads are perpendicular to the loading direction. Its tensile strength is $53 \%$ of the value for [0] $]_{24}$ specimen (Coupon A), which confirms that FDM 3D printing induces anisotropic properties into the manufactured part. The failure strength and modulus of [45/0/90/-45] 3 s specimens (Coupon C) are close to those of $[0]_{24}$ specimen (Coupon A). Coupon $\mathrm{C}$ with quasi-isotropic stacking sequence has $20 \%$ higher failure strain compared with Coupon A, where all beads are along the loading direction. SEM imaging of coupons $\mathrm{A}$ and $\mathrm{C}$ fracture surface (Figure 34 and Figure 36) shows a brittle failure for the specimens, while this is not the case for coupon B (Figure 35). This similarity in the fracture surface explains the close average tensile strength and modulus for coupons A and C

Table 12: Tensile strength and Modulus of specimens without defect

\begin{tabular}{|l|c|c|c|}
\hline Coupon ID & Strength Mean (MPa) & Modulus Mean (GPA) & Failure strain (\%) \\
\hline Coupon A & 57.72 & 3.13 & 1.96 \\
\hline
\end{tabular}




\begin{tabular}{|l|l|l|l|}
\hline Coupon B & 30.80 & 2.94 & 1.15 \\
\hline Coupon C & 53.48 & 3.11 & 2.35 \\
\hline
\end{tabular}

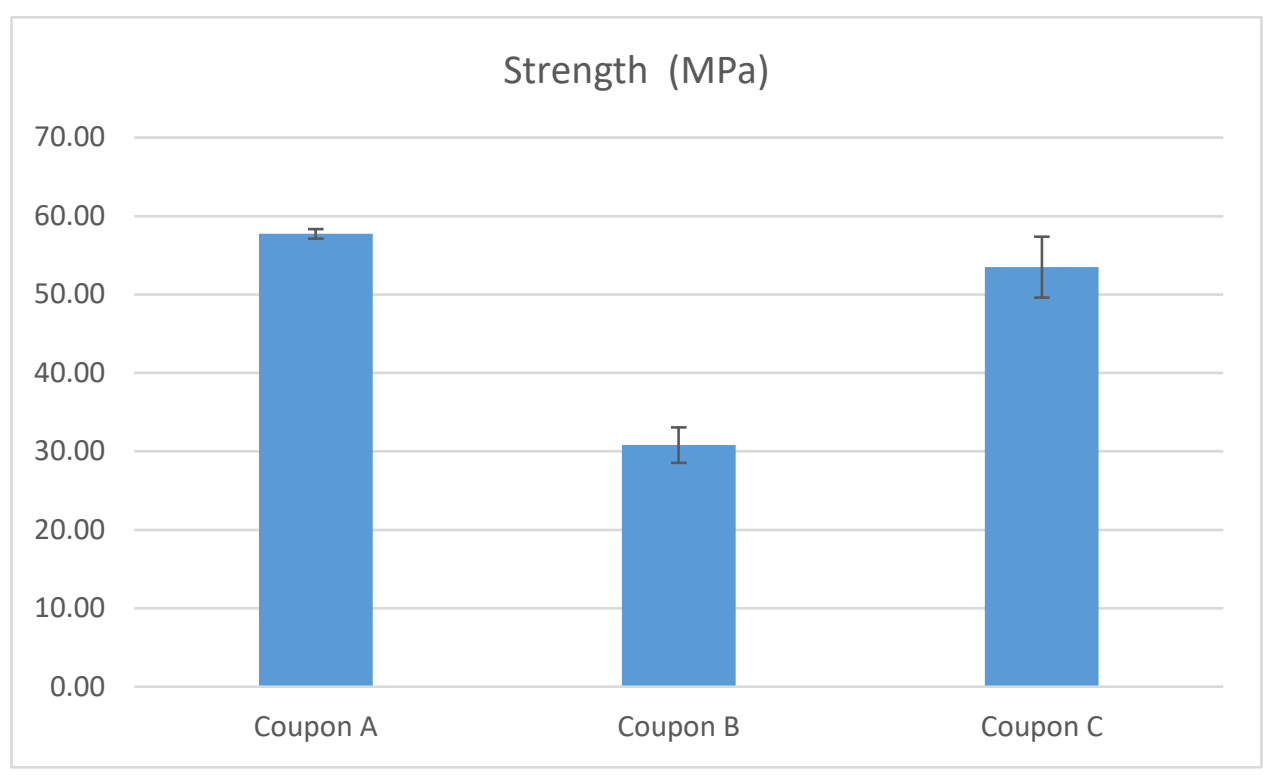

Figure 46: Tensile Strength of specimens without defects

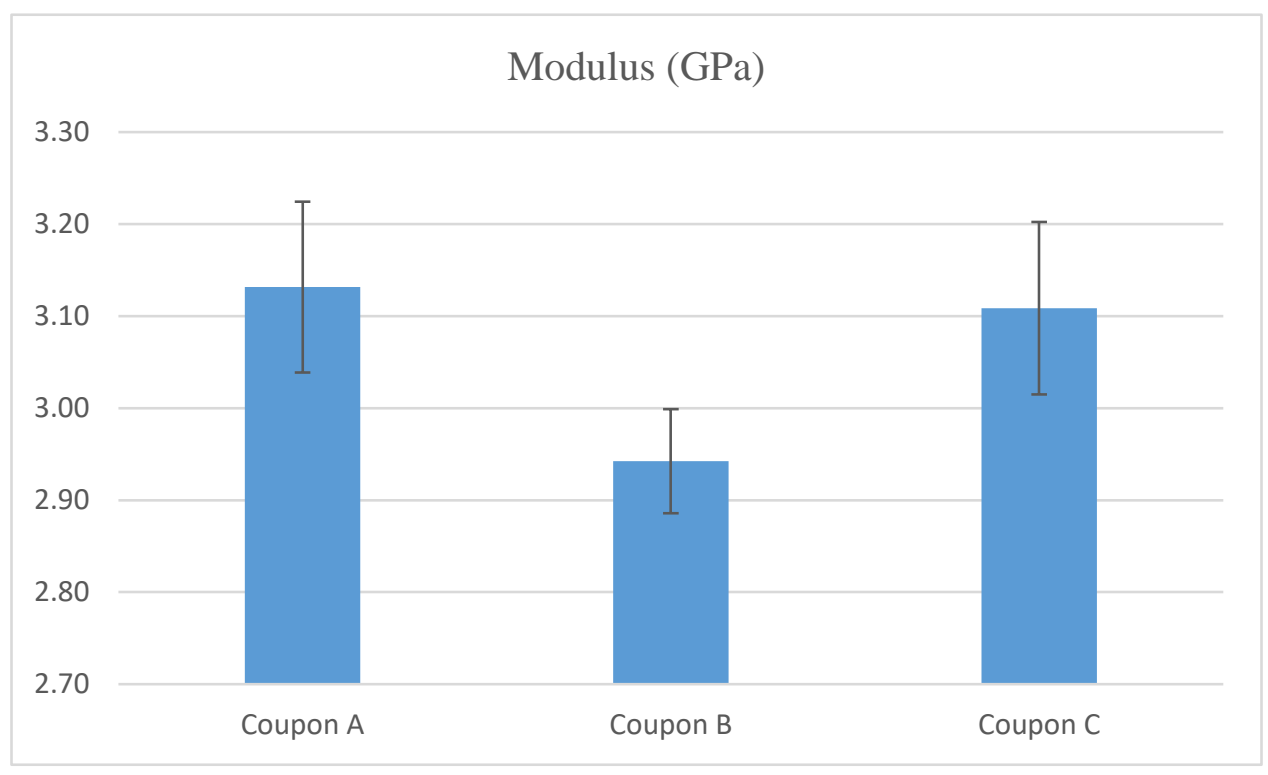

Figure 47: Modulus of specimens without defects 


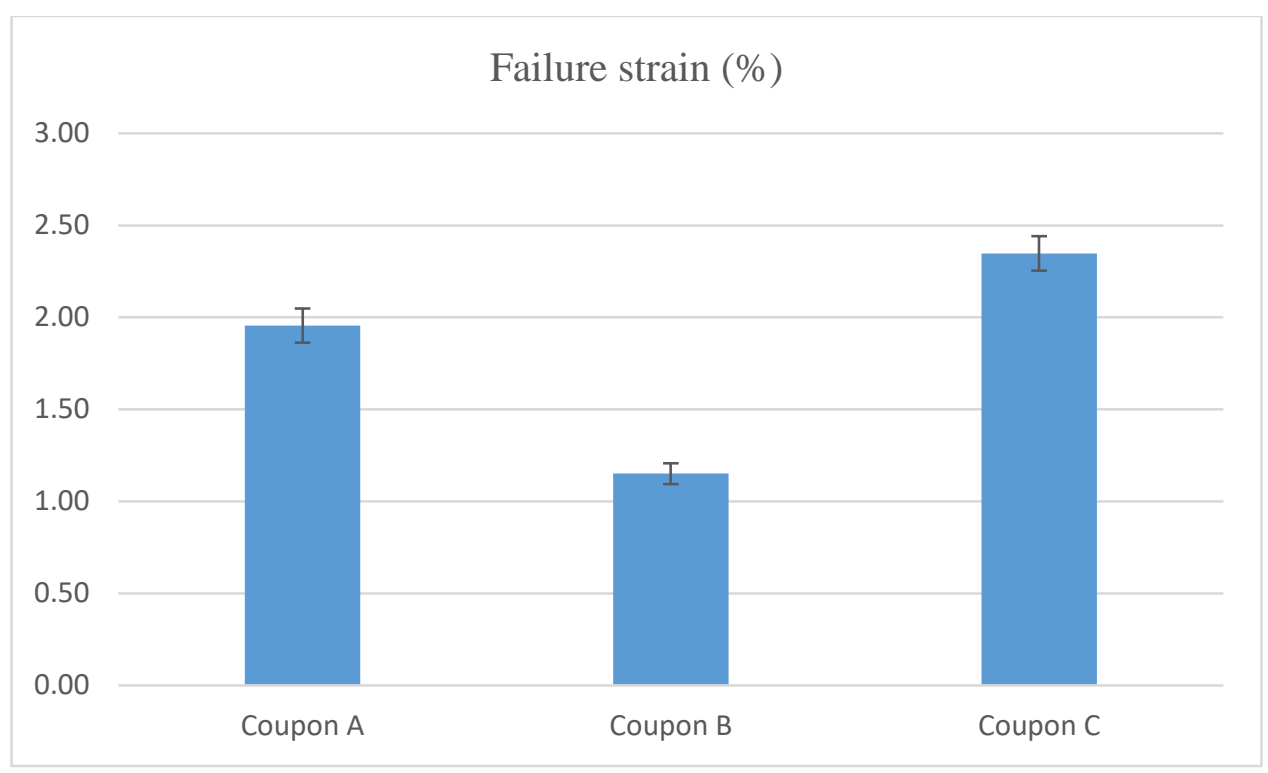

Figure 48. Failure strain of specimens without defects

\subsection{SPECIMENS WITH DEFECT}

Table 13 summarizes mean tensile strength, modulus of elasticity, and failure strain for the quasiisotropic specimen without defect (baseline) and the ones with various types of defects. Figure 49 through Figure 51 are the graphical representation of the testing results and included error bars.

Table 13: Tensile strength and Modulus of specimens with defect

\begin{tabular}{|l|c|c|c|}
\hline Coupon ID & Strength Mean (MPa) & Modulus Mean (GPA) & Failure strain (\%) \\
\hline Coupon C & 53.48 & 3.11 & 2.35 \\
\hline Coupon D & 47.58 & 2.92 & 2.88 \\
\hline Coupon E & 42.53 & 2.81 & 2.08 \\
\hline Coupon F & 43.20 & 2.88 & 2.06 \\
\hline
\end{tabular}

By comparing the mechanical properties provided in Table 13, it can be seen that the defect in the form of one $0^{\circ}$ bead missing (Coupon D) reduces tensile strength and modulus of the specimens by $12.4 \%$ and $6.1 \%$, respectively compared with the baseline (Coupon C). On the other hand, $22.6 \%$ increase in failure strain is observed for Coupon D compared with the baseline. For Coupon 
$\mathrm{D}$, the defect (one $0^{\circ}$ bead missing) is along the loading direction and the material redistribution is the main reason behind the increase in failure strain, resulting in a ductile failure. The ductile nature of the failure for Coupon D is evident from SEM imaging (Figure 43) compared with the brittle failure for the baseline, Coupon C (Figure 36). For the same defect area percentage as coupon D (four $90^{\circ}$ beads missing, Coupon E), further reduction in tensile strength (20.5\%) and modulus (9.6\%) is observed compared with the baseline. This can be related to the fact that the defect for Coupon $\mathrm{E}$ is perpendicular to the loading direction and has a more severe impact on mechanical properties compared with a defect along the loading direction, Coupon D. Contrary to Coupon D, there was a reduction in failure strain as well (11.5\%) compared with the baseline. SEM image of the fracture surface for Coupon E (Figure 44) shows beads cut without undergoing a large strain, hence almost keeping their original cross section shape. For the combined defects case (one $0^{\circ}$ bead and four $90^{\circ}$ beads missing, Coupon $\mathrm{F}$ ), there is no meaningful difference in tensile strength, modulus, and failure strain with the sole four $90^{\circ}$ beads missing case (Coupon E). This is expected since the defect perpendicular to the loading direction (four $90^{\circ}$ beads missing) causes a failure in the coupon before any significant impact from one $0^{\circ}$ bead missing. SEM imaging of the fracture surface from Coupons E (Figure 44) and F (Figure 45) shows a similar pattern that further validates close results in tensile strength, modulus, and failure strain.

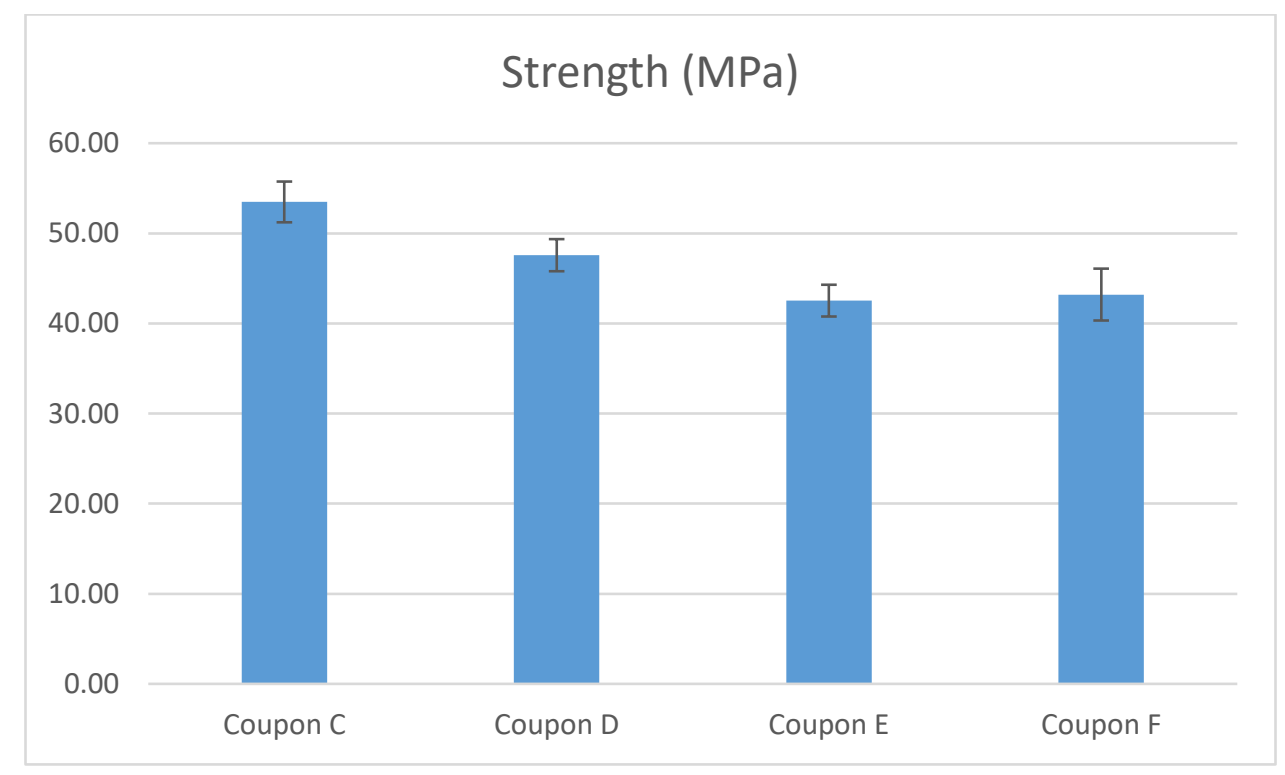

Figure 49: Tensile Strength of specimens with defects compared with the baseline (Coupon C). 


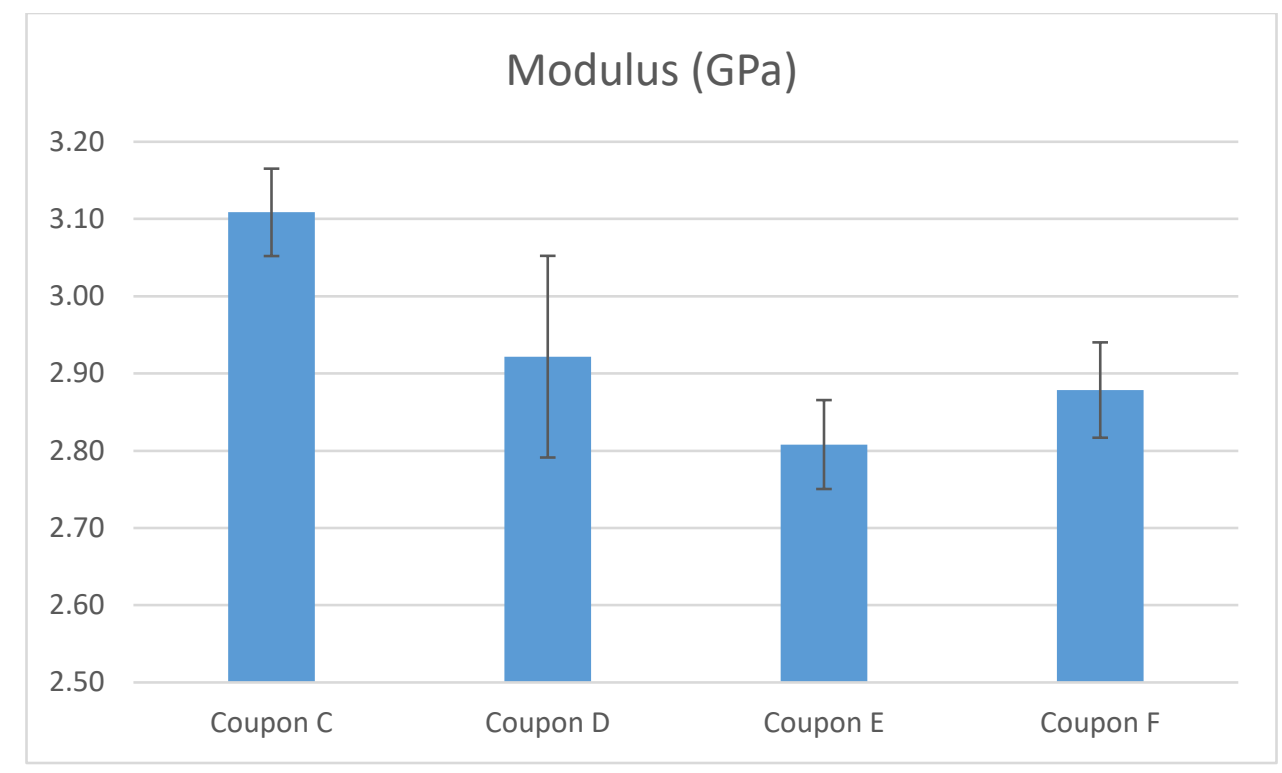

Figure 50: Modulus of specimens with defects compared with the baseline (Coupon C).

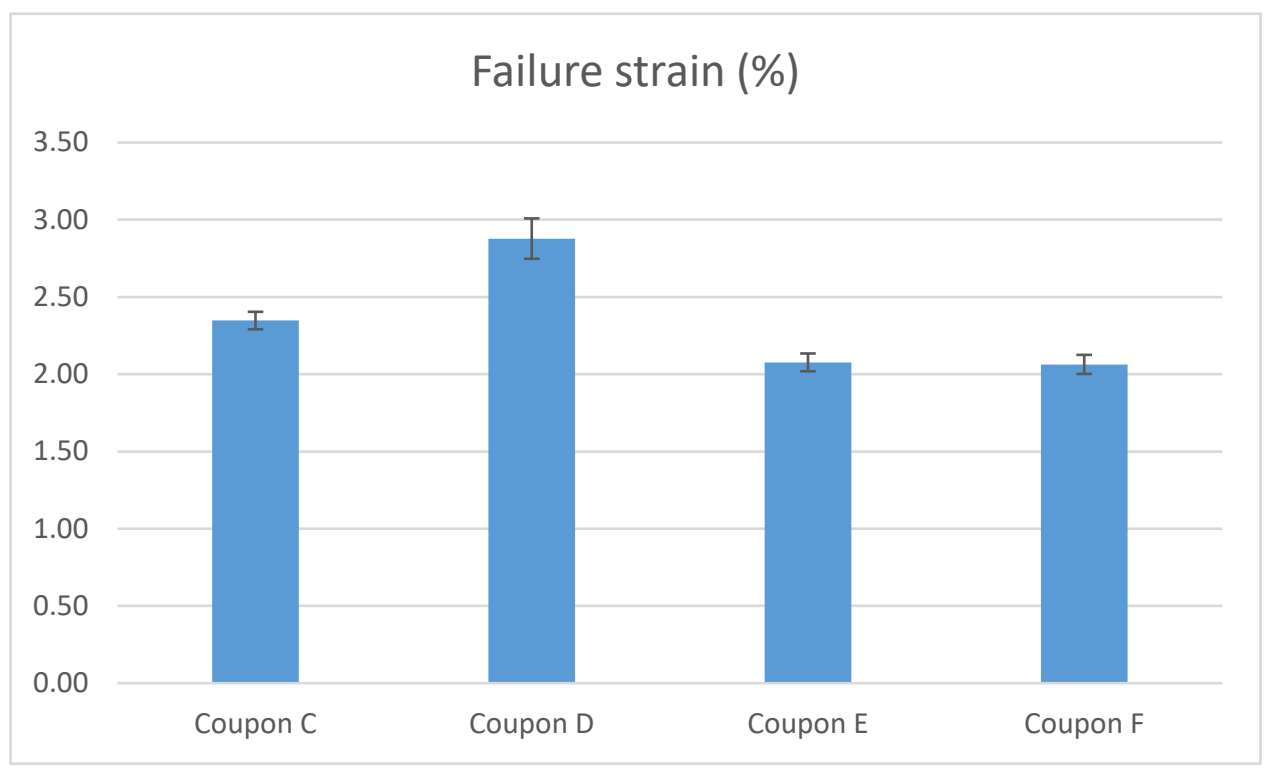

Figure 51. Failure strain of specimens with defects compared with the baseline (Coupon C). 


\subsection{CONCLUSION AND FUTURE WORK}

In this report, experimental investigation of FDM 3D printed parts out of PLA per ASTM D638 has been performed. Tensile strength, modulus, and failure strain for specimens with and without defects have been obtained and SEM imaging of fracture surfaces has been performed. A systematic approach has been followed to characterize 3D printed parts out of PLA, where directional properties have been investigated

For specimens without defects, it is observed that FDM 3D printing of PLA introduces anisotropic behavior to the specimens, where printing along the loading direction ([0] $\left.]_{24}\right)$ showed a tensile strength of 57.7 MPa compared with printing perpendicular to the loading direction with a tensile strength of $30.8 \mathrm{MPa} .[0]_{24}$ stacking sequence results in the highest tensile strength and modulus compared with [90] 24 and [45/0/90/-45] $]_{3 s}$ samples. Quasi-isotropic stacking has $20 \%$ higher failure strain compared with the case where all beads are along the loading direction, $[0]_{24}$. SEM imaging of the fracture surfaces for all coupons confirms the observed trends in tensile strength and failure strain. These results further confirm the findings by other researchers presented in the literature review section.

The quasi-isotropic stacking is selected as the baseline to investigate the impact of defect on mechanical performance of FDM 3D printed parts out of PLA. It is found that for the same defect area percentage, a defect perpendicular to the loading direction has a more severe impact on tensile strength, modulus, and failure strain compared with a defect along the loading direction. Compared with the baseline, $20.5 \%$ reduction in tensile strength, $9.6 \%$ in modulus, and $11.5 \%$ in failure strain are found.

FDM 3D printing is the trending additive manufacturing process across different industries from Automotive to Aerospace and there will be an increase and spread to the use of different materials in $3 \mathrm{D}$ printing. The approach used in this study can be followed to characterize any new material and investigate its mechanical performance. The results presented in this report can be further utilized in 
1. Building Finite Element (FE) model of FDM 3D printed parts: Mechanical characterization using experimental testing is very time consuming and costly; as a result, virtual testing (FE simulation) has drawn the attention of industry. Experimental results obtained in this report for $[0]_{24}$ and $[90]_{24}$ can be used as input data to build FE model of FDM 3D printed parts. In addition, quasi-isotropic results can be used for validating the accuracy of FE simulations. Mechanical performance of complex geometries can be investigated using FE simulations and optimum stacking sequence can be obtained for different loading

2. Building FE model of FDM 3D printed parts including the impact of defects: Structural parts can be designed and optimized for certain structural properties that later can be manufactured using FDM 3D printing. Defects inherent to the process and/or design which emerge during manufacturing impact mechanical performance of the final parts. It is critical to evaluate the structural performance of the parts including the impact of defects. This way, there is no need for conservative safety factors to account for the impact of defects since it can be precisely calculated. Experimental results in this report for specimens with defects can be used to develop novel elements to build computationally efficient FE models. This study evaluates the impact of missing bead(s) or gap(s) defects on tensile strength, modulus, and failure strain of 3D printed parts. Other types of defects, e.g. overlaps which is an excessive materials or bead(s), can be investigated as well. Overlaps result in waviness of deposited beads and create a thickness variation that is interesting to investigate as well 


\section{APPENDIX}

The work presented in this section includes the experimental test data obtained for all coupons, without defects $(\mathrm{A}-\mathrm{C})$ and with defects $(\mathrm{D}-\mathrm{F})$.

Table 14: Coupon A properties

\begin{tabular}{|c|c|c|c|c|c|c|c|}
\hline Coupon & $\begin{array}{c}\text { Maximum } \\
\text { force } \\
\text { (lbf) }\end{array}$ & $\begin{array}{c}\text { Cross section } \\
\left.\mathbf{( i n}^{2}\right)\end{array}$ & $\begin{array}{c}\text { Width } \\
\text { (in) }\end{array}$ & $\begin{array}{c}\text { Thickness } \\
\text { (in) }\end{array}$ & $\begin{array}{c}\text { Failure } \\
\text { stress (Psi) }\end{array}$ & $\begin{array}{c}\text { Strength } \\
(\mathbf{M P a})\end{array}$ & $\begin{array}{c}\text { Modulus } \\
(\mathbf{G P a})\end{array}$ \\
\hline $\mathbf{A}-1$ & 620.241 & 0.074 & 0.511 & 0.144 & 8429.026 & 58.1 & 3.08 \\
\hline $\mathbf{A - 2}$ & 608.006 & 0.072 & 0.514 & 0.140 & 8449.223 & 58.255 & 3.137 \\
\hline $\mathbf{A - 3}$ & 603.173 & 0.072 & 0.506 & 0.143 & 8322.056 & 57.4 & 3.01 \\
\hline $\mathbf{A - 4}$ & 590.650 & 0.072 & 0.512 & 0.140 & 8240.094 & 56.8 & 3.25 \\
\hline $\mathbf{A - 5}$ & 608.1318 & 0.07224 & 0.516 & 0.14 & 8418.214 & 58.0 & 3.18 \\
\hline
\end{tabular}

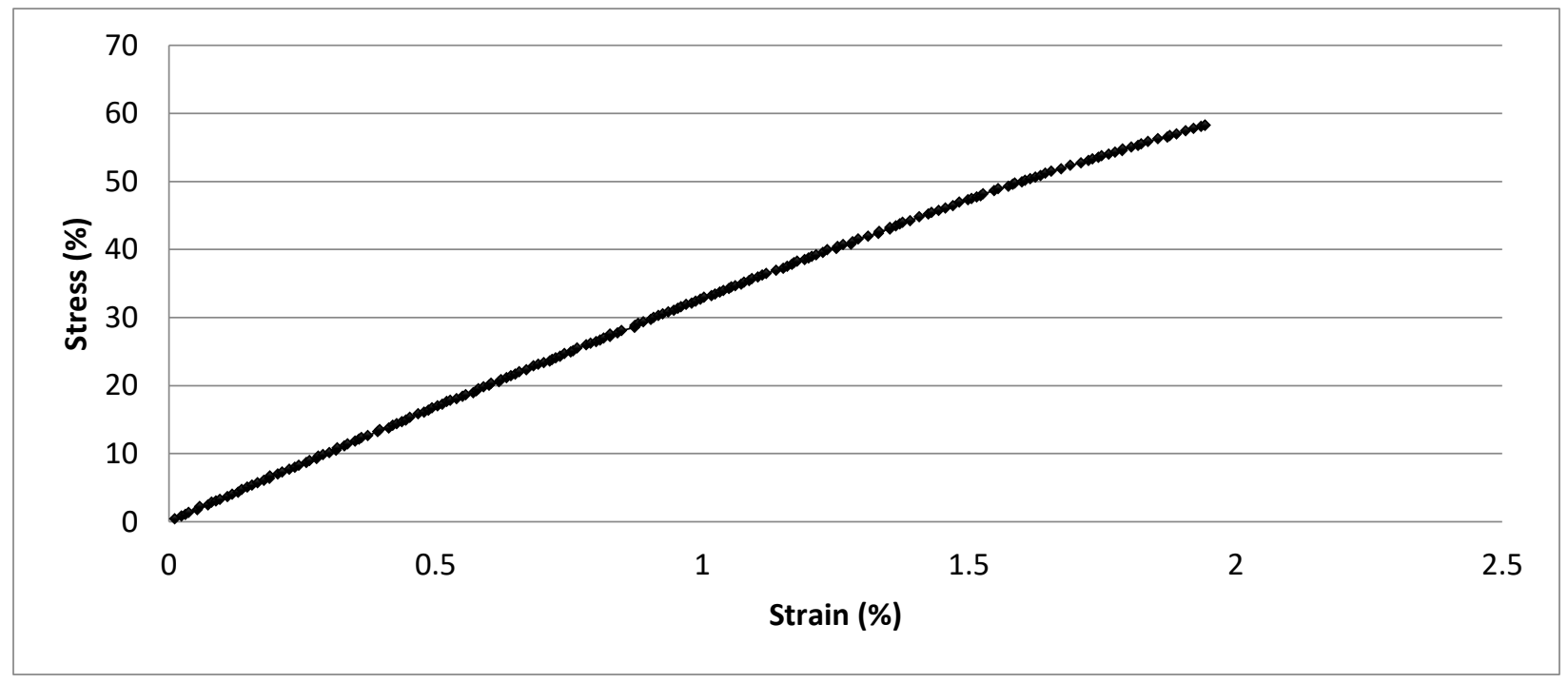

Figure 52: Stress - Strain Curves for Coupon A-2 


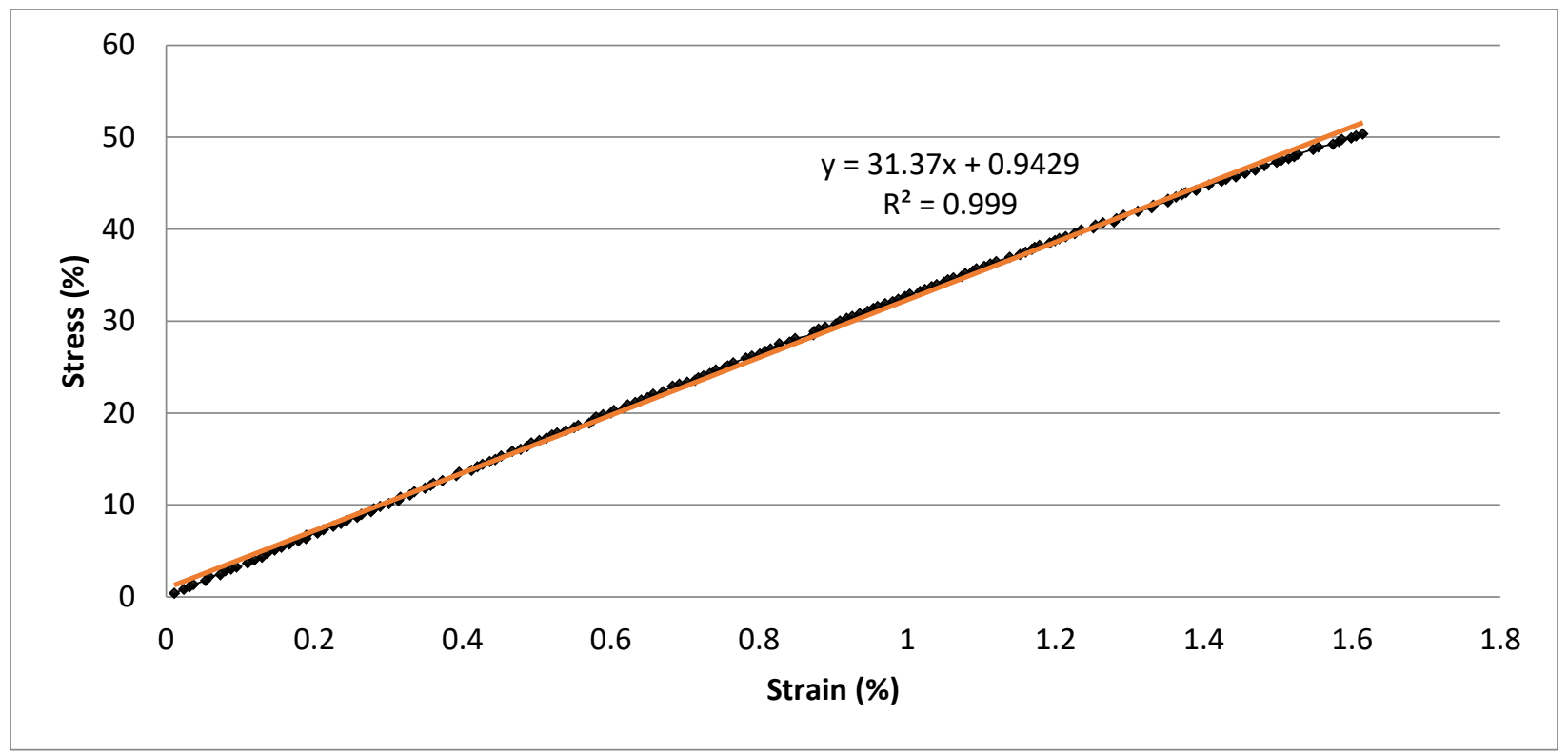

Figure 53: Stress-strain curve coupon A-2 (linear segment)

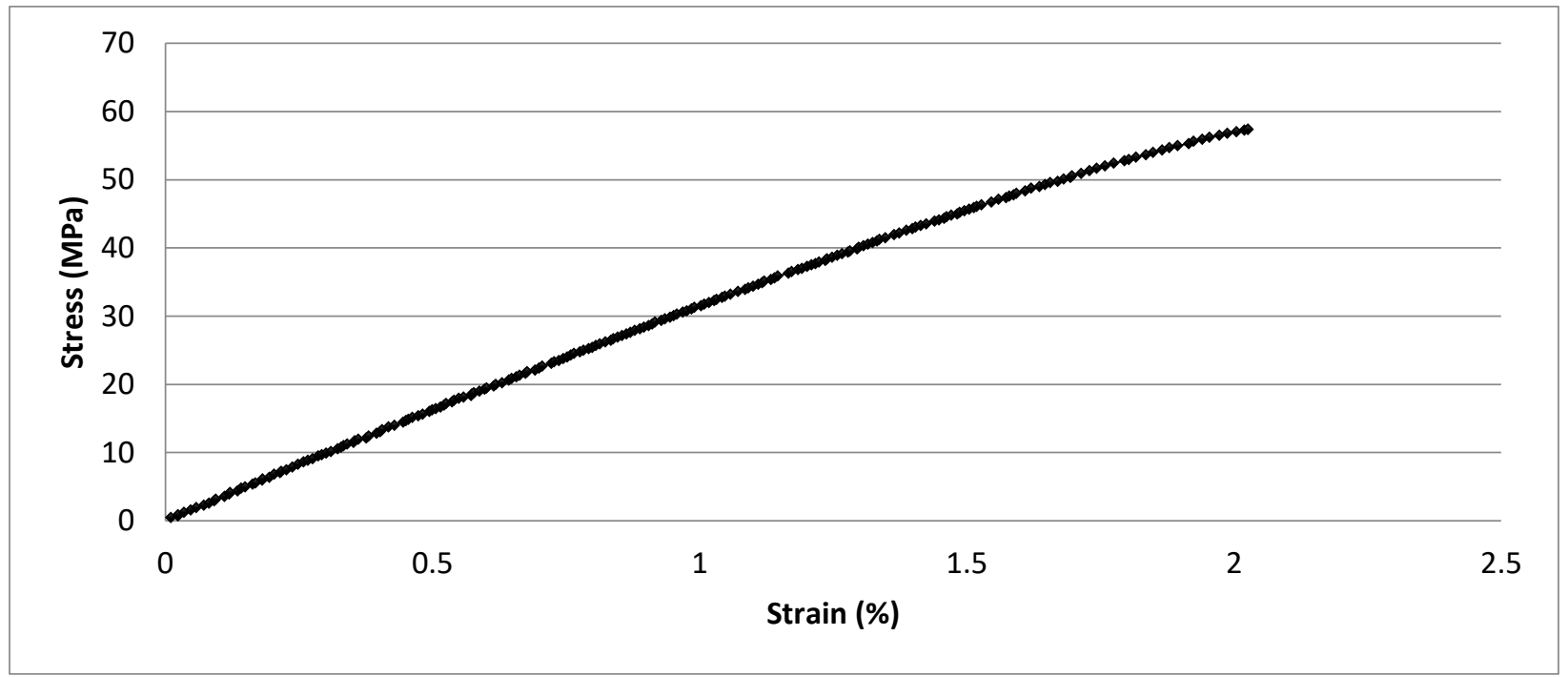

Figure 54: Stress - Strain Curves for Coupon A-3 


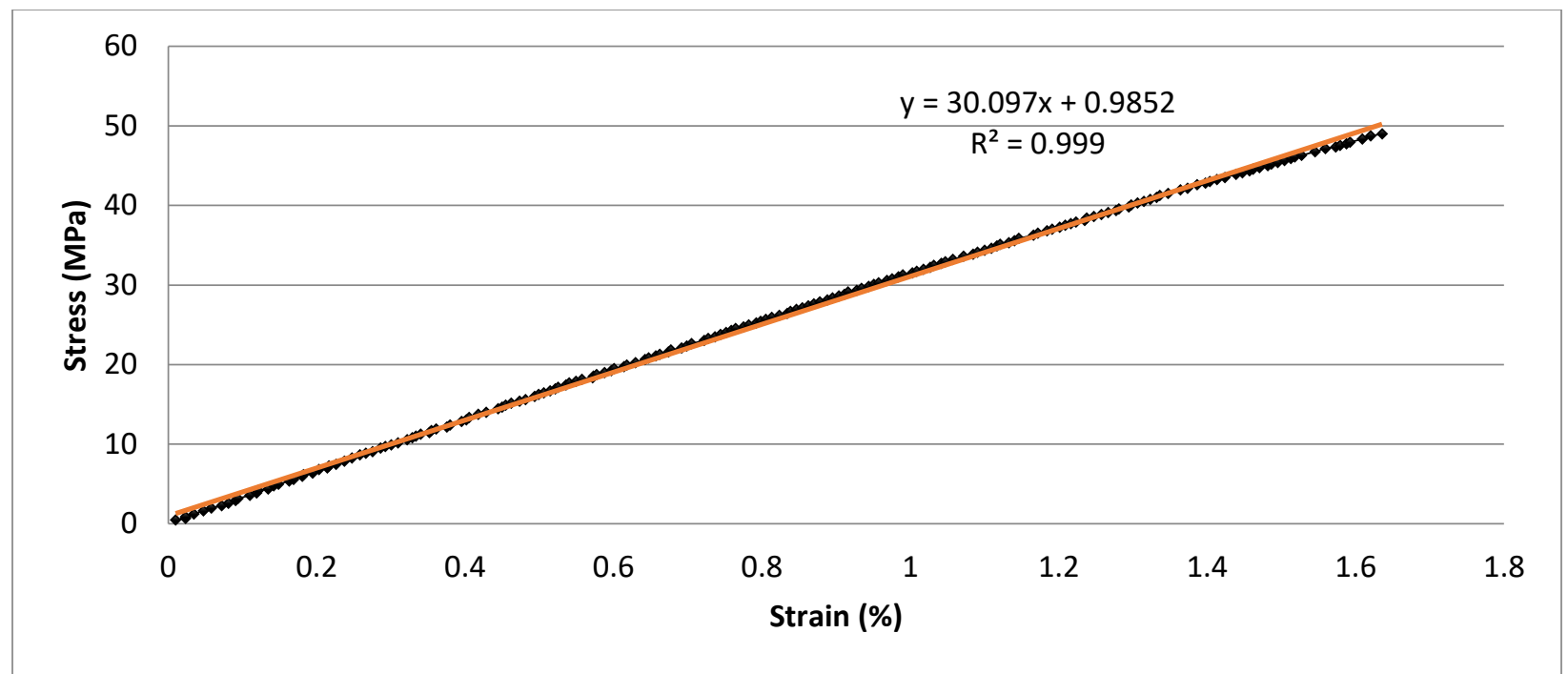

Figure 55: Stress-strain curve coupon A-3 (linear segment)

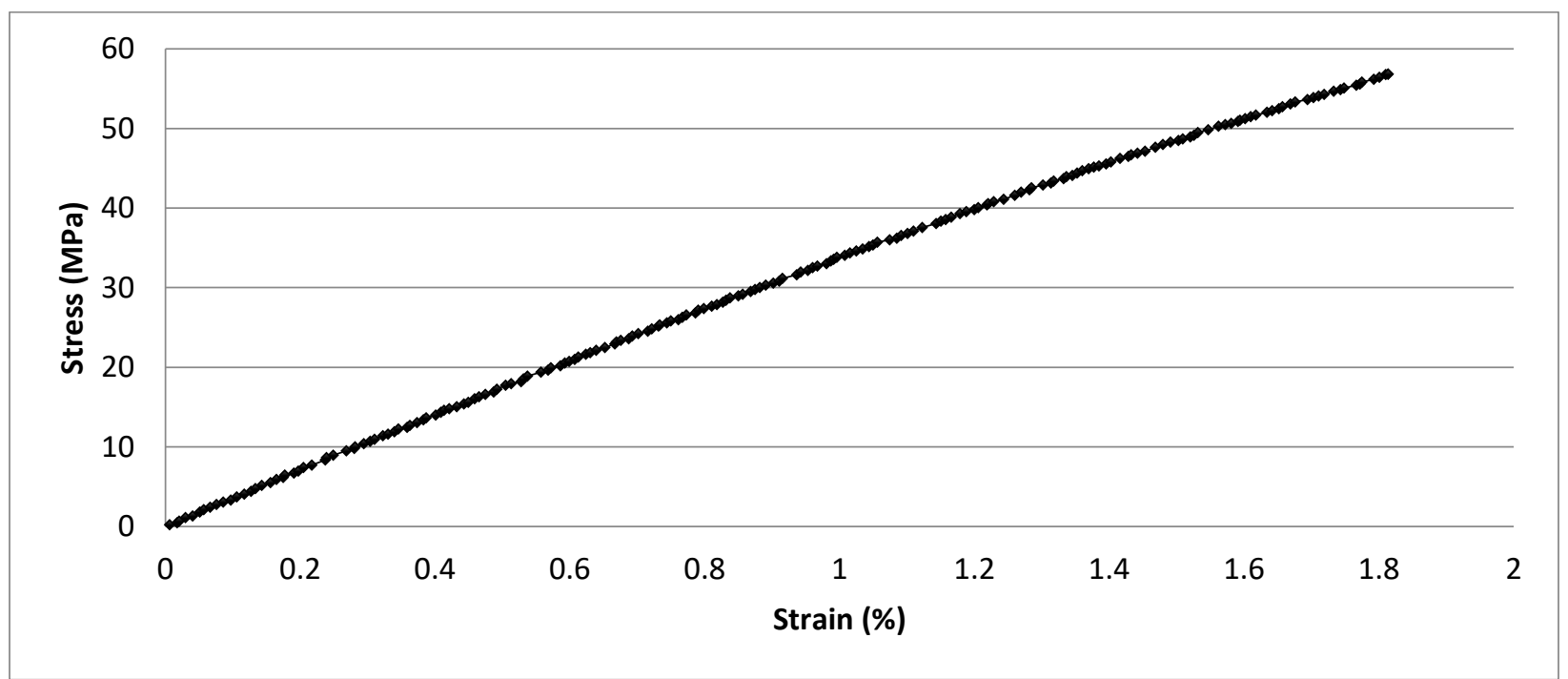

Figure 56: Stress - Strain Curves for Coupon A-4 


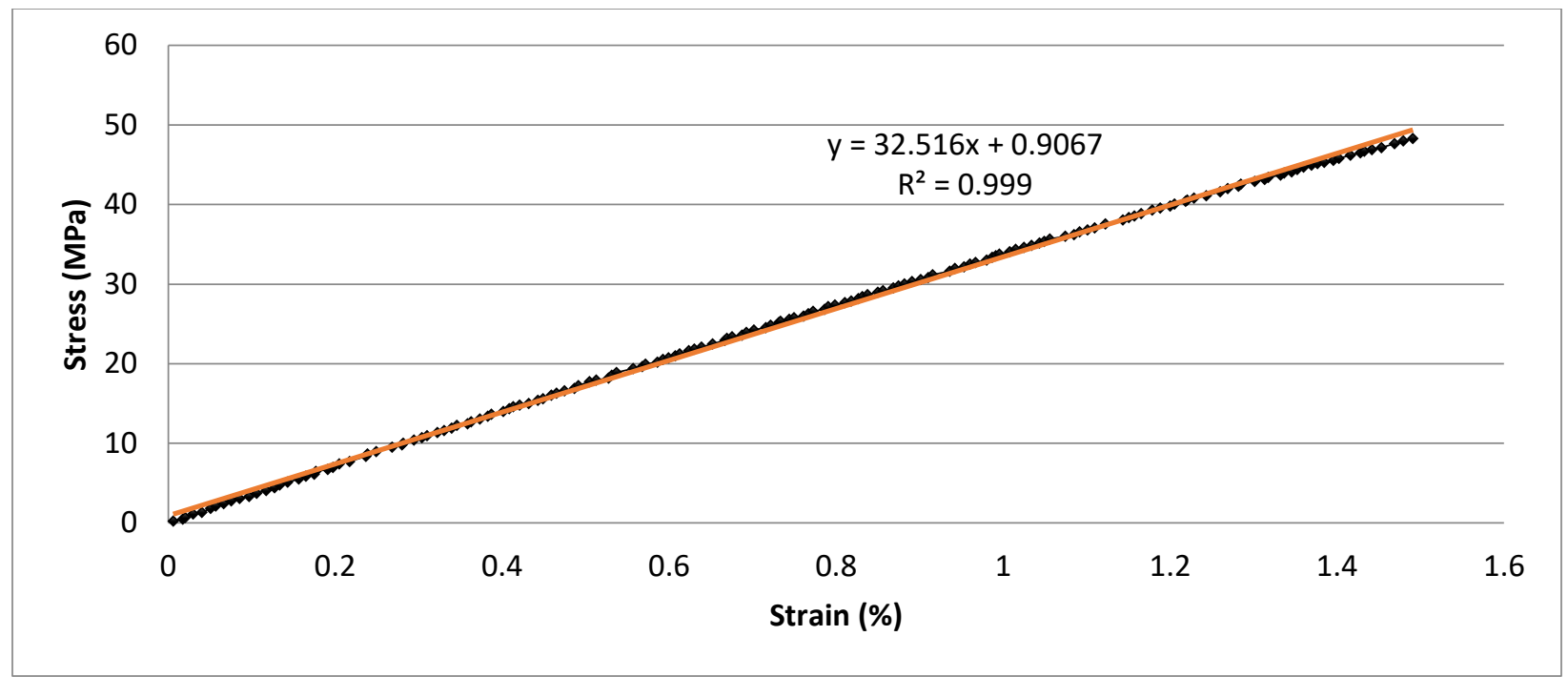

Figure 57: Stress-strain curve coupon A-4 (linear segment)

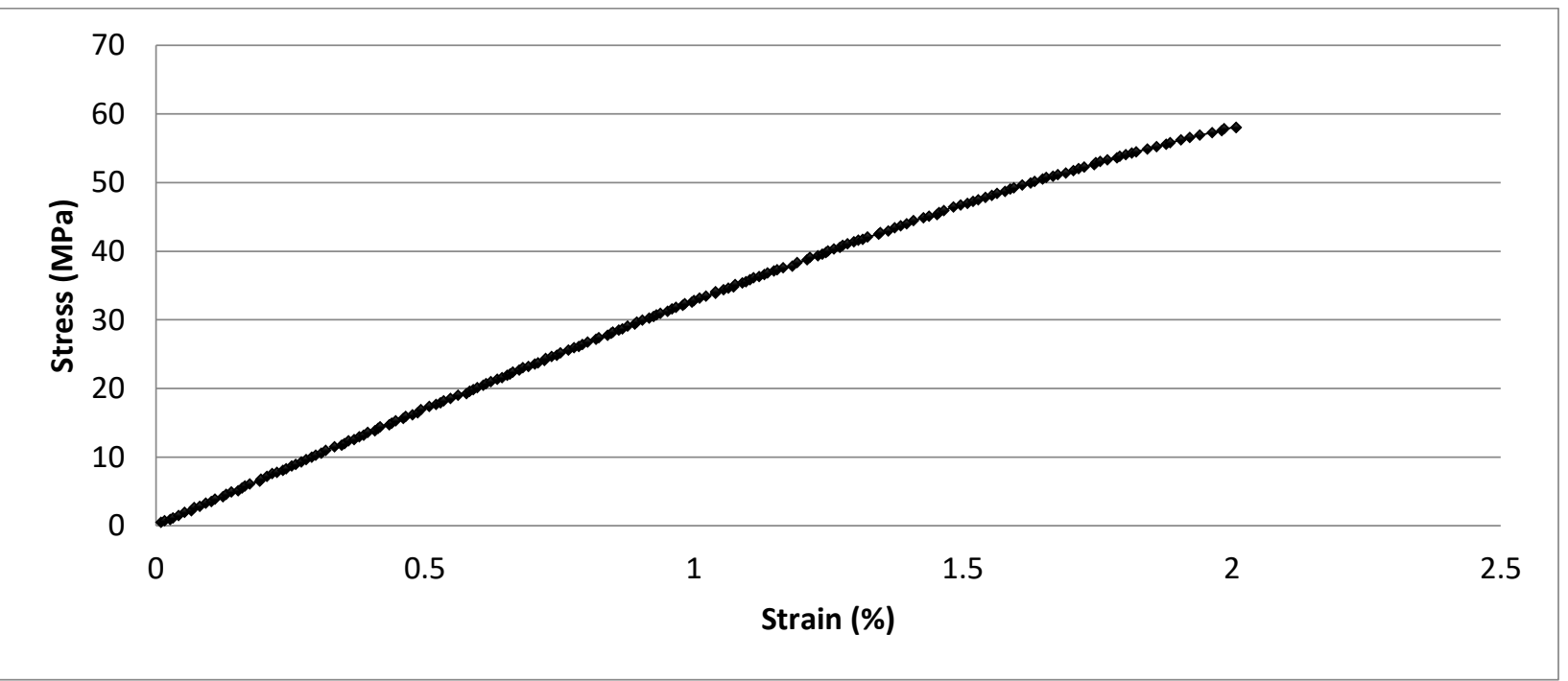

Figure 58: Stress - Strain Curves for Coupon A-5 


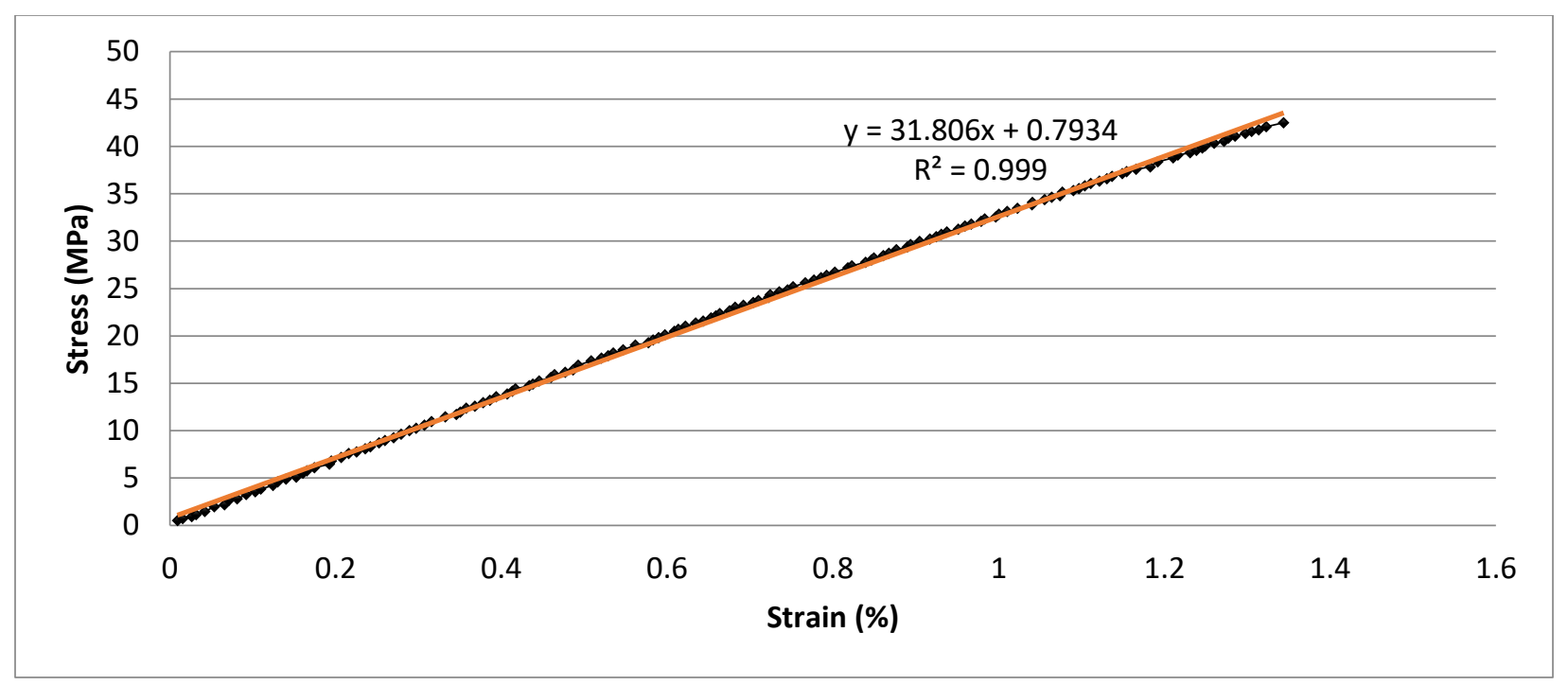

Figure 59: Stress-strain curve coupon A-5 (linear segment)

Table 15: Coupon B properties

\begin{tabular}{|c|c|c|c|c|c|c|c|}
\hline Coupon & $\begin{array}{c}\text { Maximum } \\
\text { force } \\
\text { (lbf) }\end{array}$ & $\begin{array}{c}\text { Cross section } \\
\mathbf{( i n}^{\mathbf{2}} \text { ) }\end{array}$ & $\begin{array}{c}\text { Width } \\
\text { (in) }\end{array}$ & $\begin{array}{c}\text { Thickness } \\
\text { (in) }\end{array}$ & $\begin{array}{c}\text { Failure } \\
\text { stress (Psi) }\end{array}$ & $\begin{array}{c}\text { Strength } \\
(\mathbf{M P a})\end{array}$ & $\begin{array}{c}\text { Modulus } \\
(\mathbf{G P a})\end{array}$ \\
\hline $\mathbf{B}-\mathbf{1}$ & 337.542 & 0.070 & 0.511 & 0.137 & 4821.547 & 33.2 & 3.00 \\
\hline $\mathbf{B}-\mathbf{2}$ & 355.605 & 0.070 & 0.514 & 0.136 & 5087.041 & 35.1 & 3.07 \\
\hline $\mathbf{B}-3$ & 328.898 & 0.071 & 0.509 & 0.139 & 4648.669 & 32.1 & 2.91 \\
\hline $\mathbf{B}-\mathbf{4}$ & 261.498 & 0.070 & 0.509 & 0.138 & 3722.812 & 25.7 & 2.90 \\
\hline $\mathbf{B}-5$ & 286.849 & 0.071 & 0.509 & 0.139 & 4054.346 & 28.0 & 2.83 \\
\hline
\end{tabular}




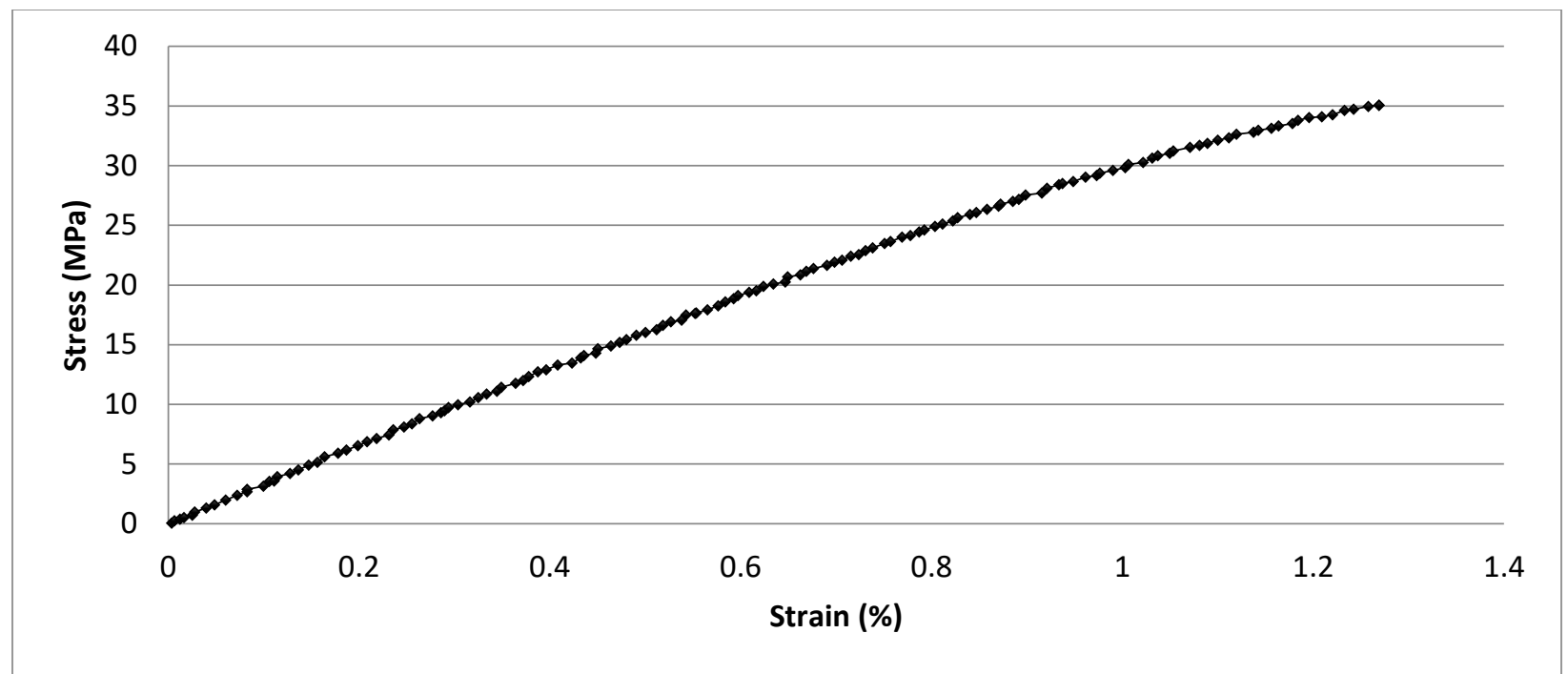

Figure 60: Stress - Strain Curves for Coupon B-2

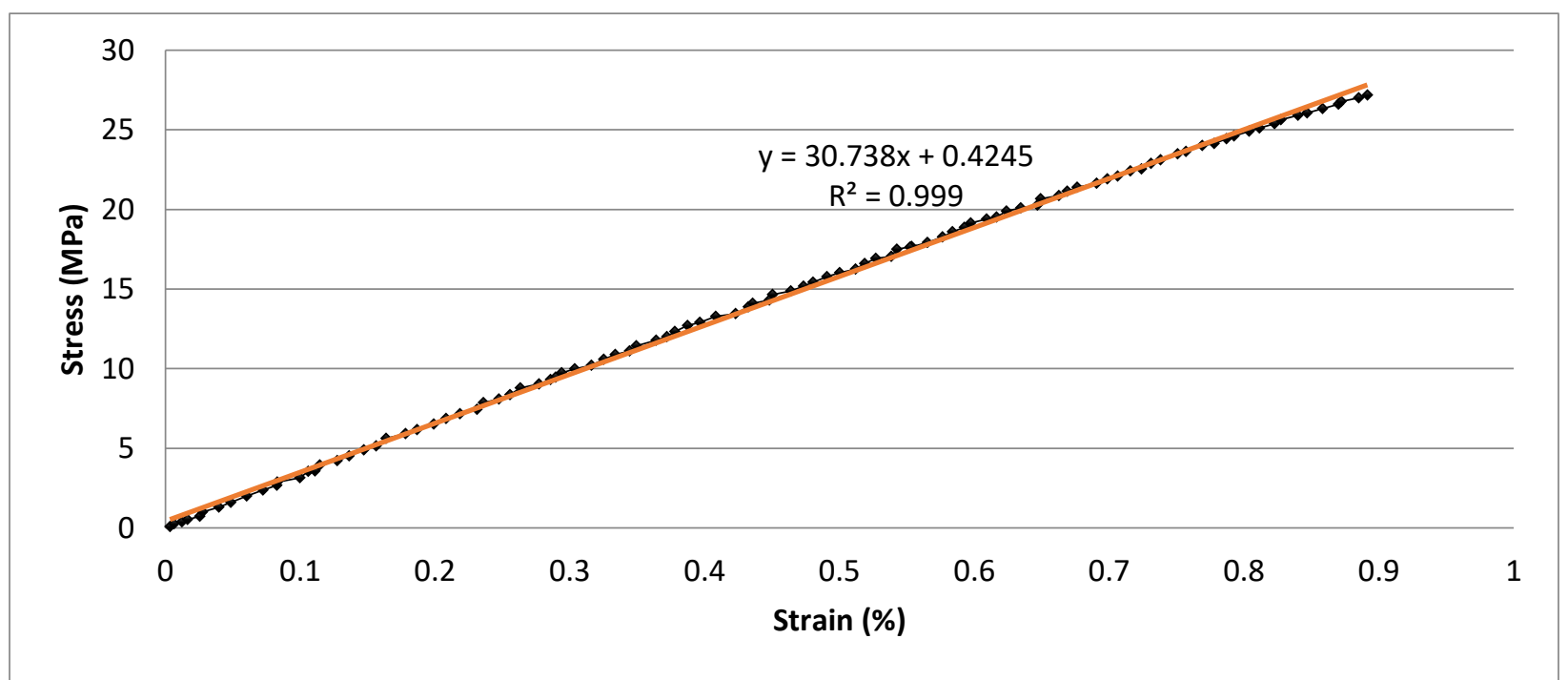

Figure 61: Stress - Strain Curves for Coupon B-2 (linear segment) 


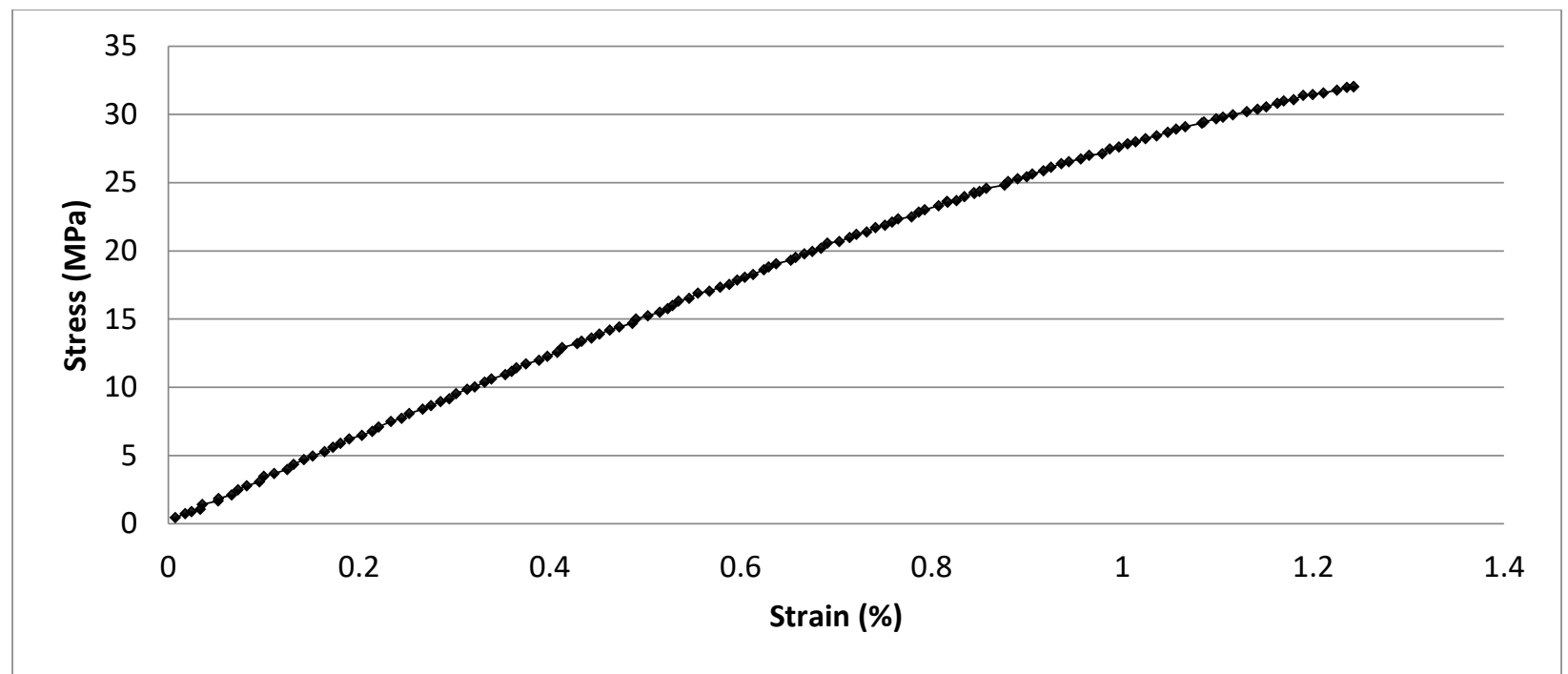

Figure 62: Stress - Strain Curves for Coupon B-3

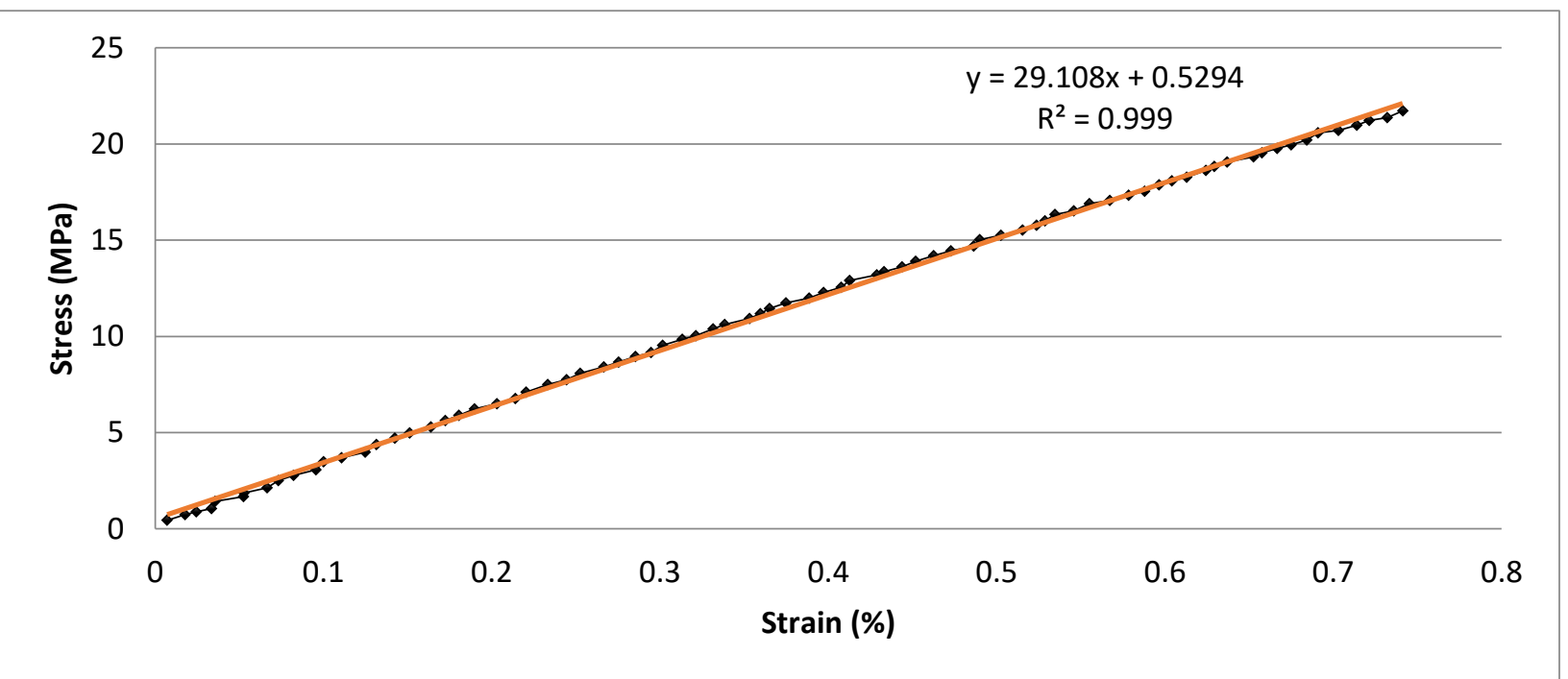

Figure 63: Stress - Strain Curves for Coupon B-3 (linear segment) 


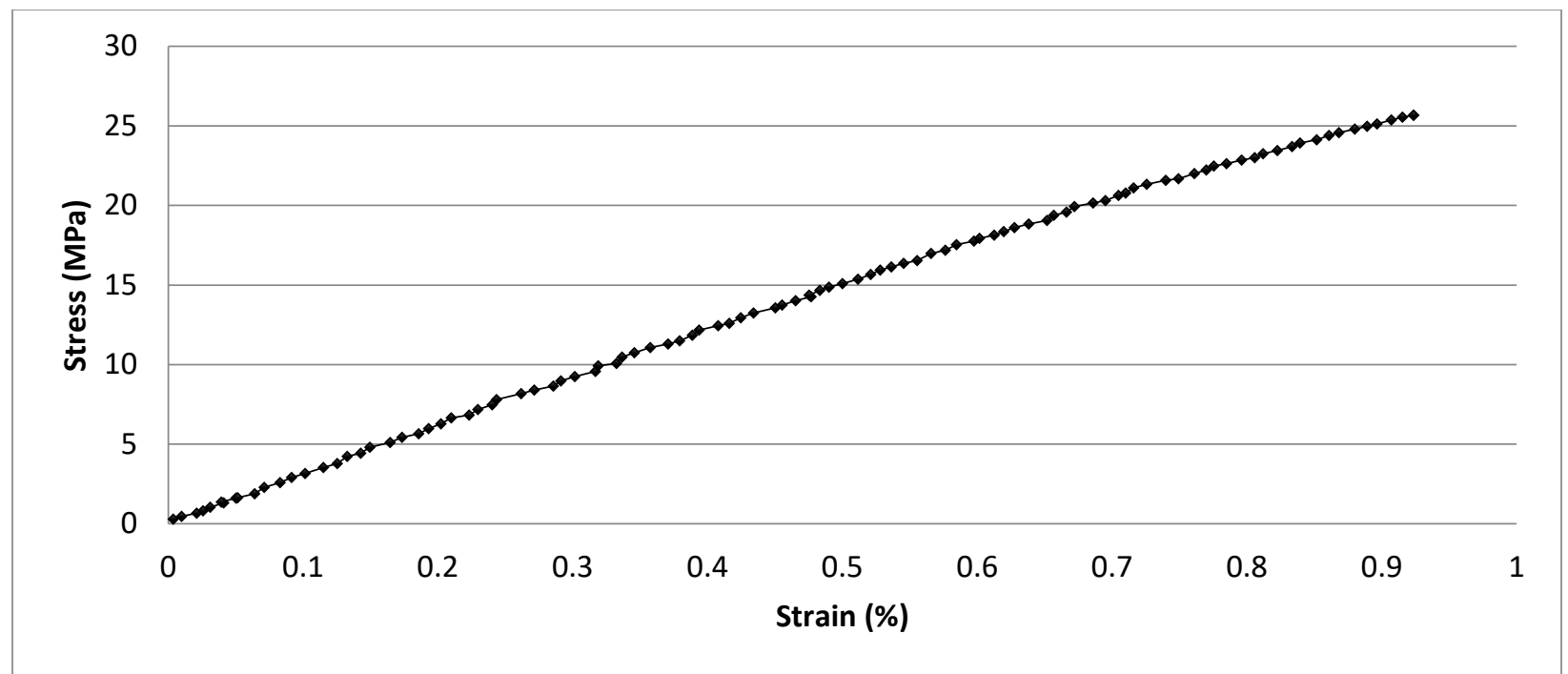

Figure 64: Stress - Strain Curves for Coupon B-4

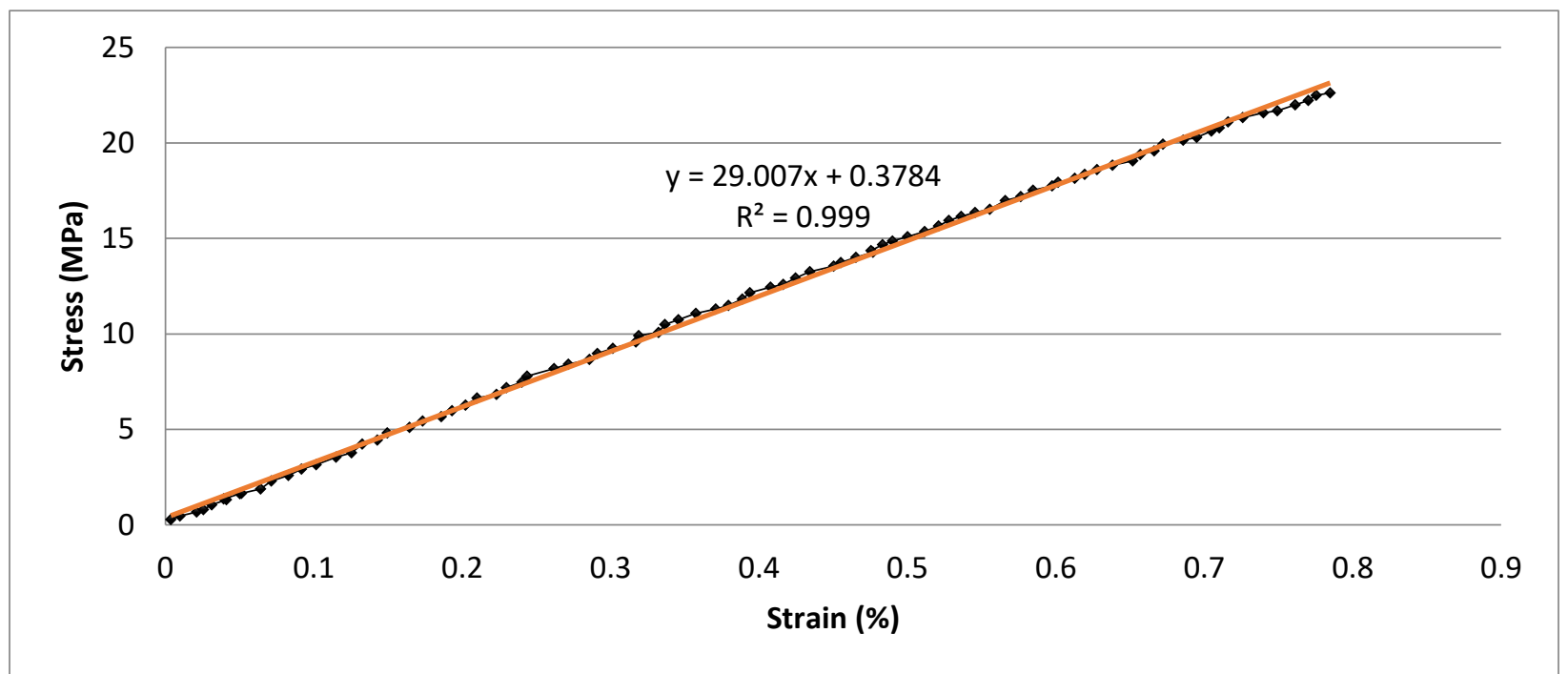

Figure 65: Stress - Strain Curves for Coupon B-4 (linear segment) 


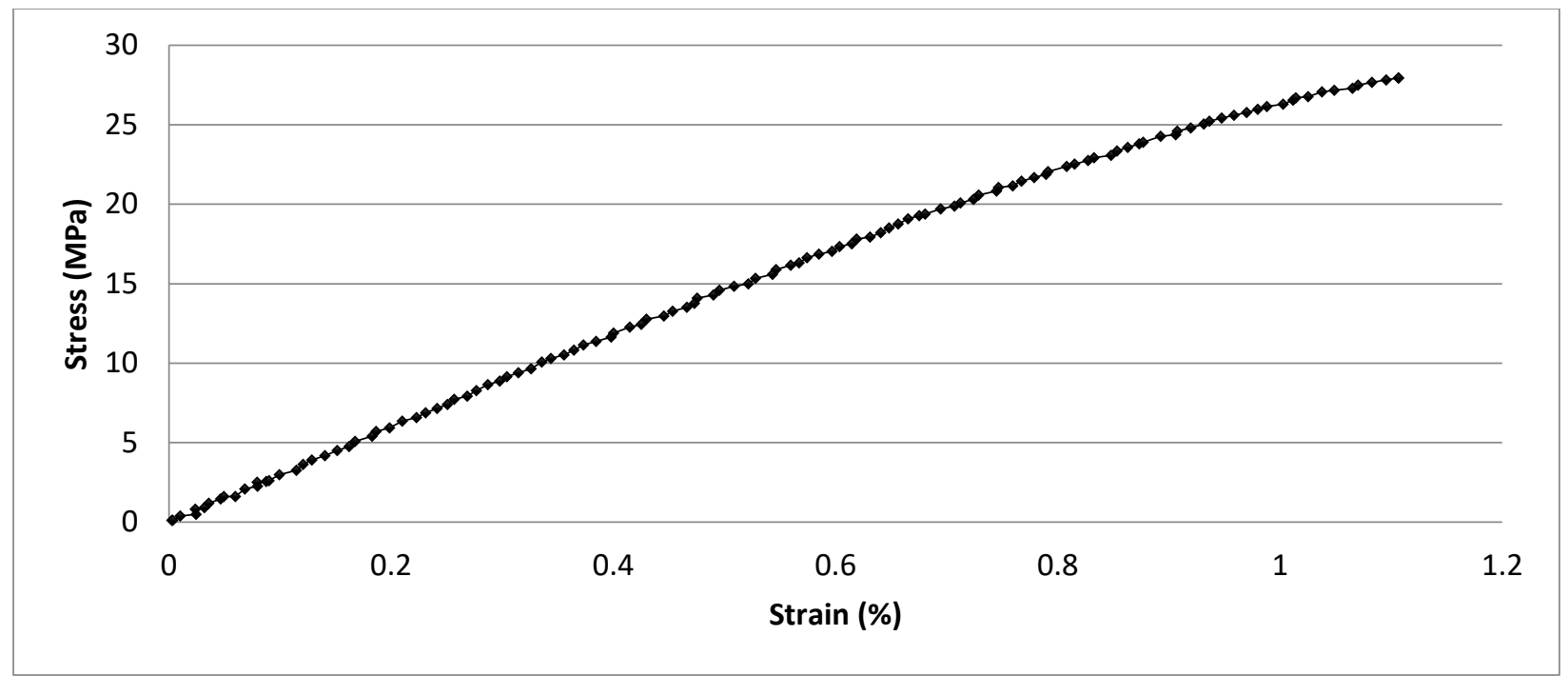

Figure 66: Stress - Strain Curves for Coupon B-5

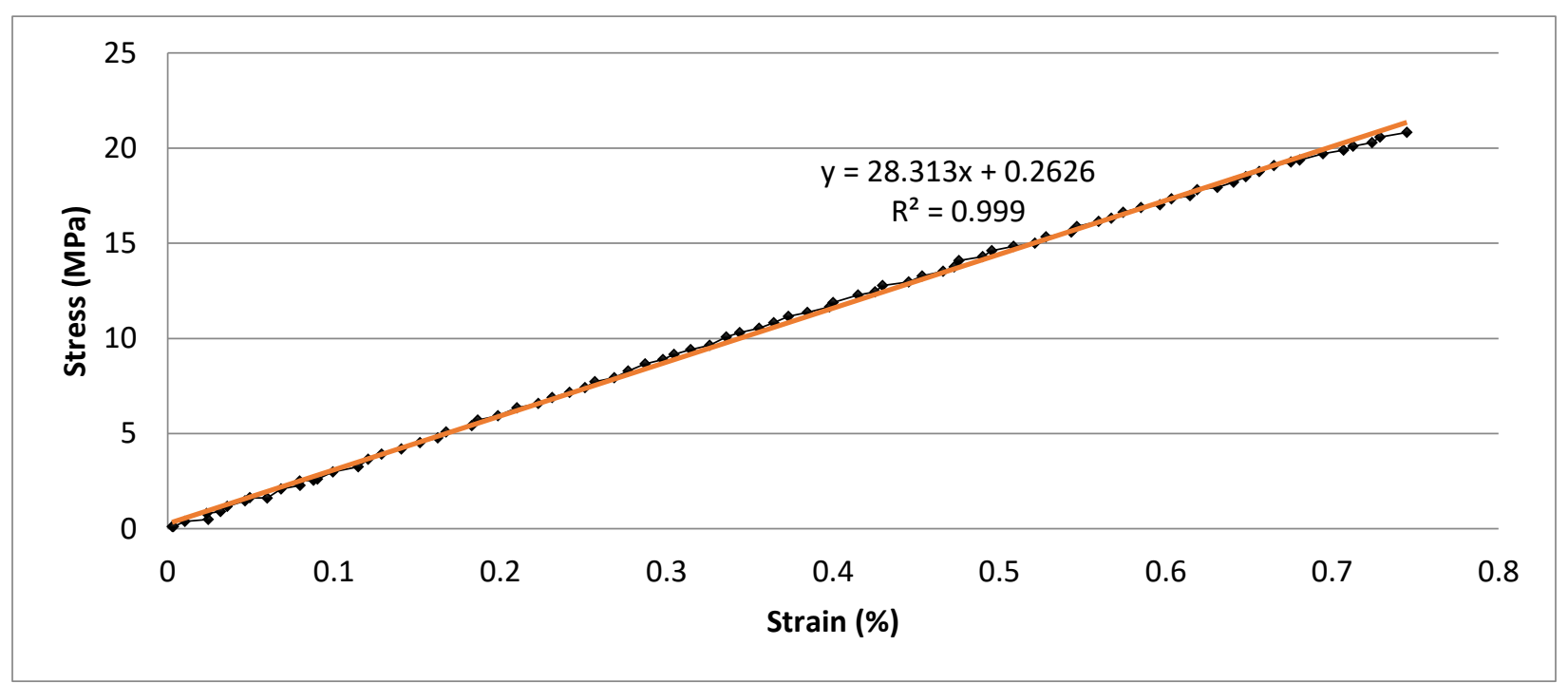

Figure 67: Stress - Strain Curves for Coupon B-5 (linear segment)

Table 16: Coupon $\mathrm{C}$ properties

\begin{tabular}{|c|c|c|c|c|c|c|c|}
\hline Coupon & $\begin{array}{c}\text { Maximum } \\
\text { force } \\
\text { (lbf) }\end{array}$ & $\begin{array}{c}\text { Cross section } \\
\left.\mathbf{( i n}^{\mathbf{2}}\right)\end{array}$ & $\begin{array}{c}\text { Width } \\
\text { (in) }\end{array}$ & $\begin{array}{c}\text { Thickness } \\
\text { (in) }\end{array}$ & $\begin{array}{c}\text { Failure } \\
\text { stress (Psi) }\end{array}$ & $\begin{array}{c}\text { Strength } \\
(\mathbf{M P a})\end{array}$ & $\begin{array}{c}\text { Modulus } \\
(\mathbf{G P a})\end{array}$ \\
\hline $\mathbf{C}-1$ & 569.616 & 0.070 & 0.508 & 0.138 & 8125.296 & 56.0 & 3.19 \\
\hline $\mathbf{C}-2$ & 542.464 & 0.070 & 0.510 & 0.138 & 7707.639 & 53.1 & 3.03 \\
\hline
\end{tabular}




\begin{tabular}{|c|c|c|c|c|c|c|c|}
\hline $\mathbf{C - 3}$ & 541.389 & 0.071 & 0.512 & 0.138 & 7662.323 & 52.8 & 3.10 \\
\hline $\mathbf{C - 4}$ & 561.775 & 0.070 & 0.516 & 0.136 & 8005.229 & 55.2 & 3.11 \\
\hline $\mathbf{C - 5}$ & 510.066 & 0.070 & 0.511 & 0.137 & 7285.927 & 50.2 & 3.12 \\
\hline
\end{tabular}

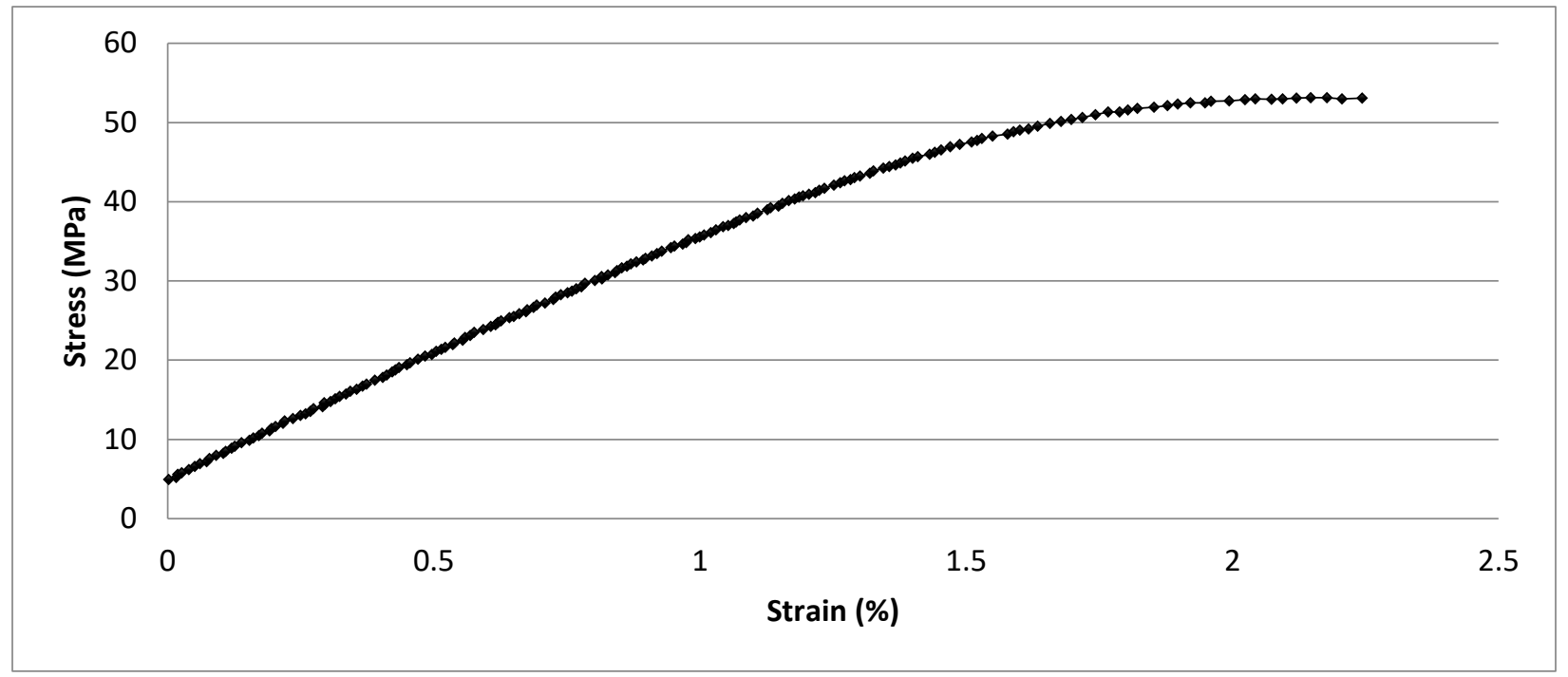

Figure 68: Stress - Strain Curves for Coupon C-2

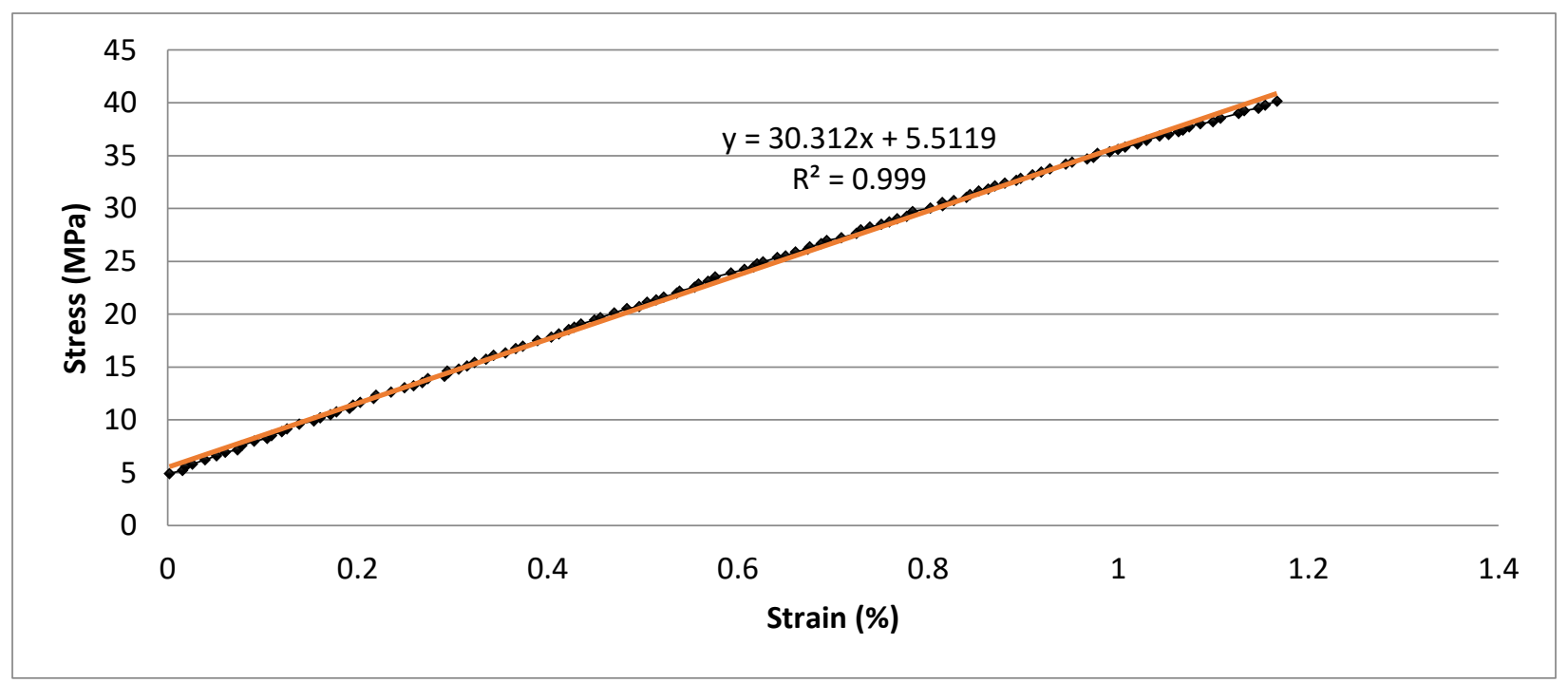

Figure 69: Stress-strain curve coupon C-2 (linear segment) 


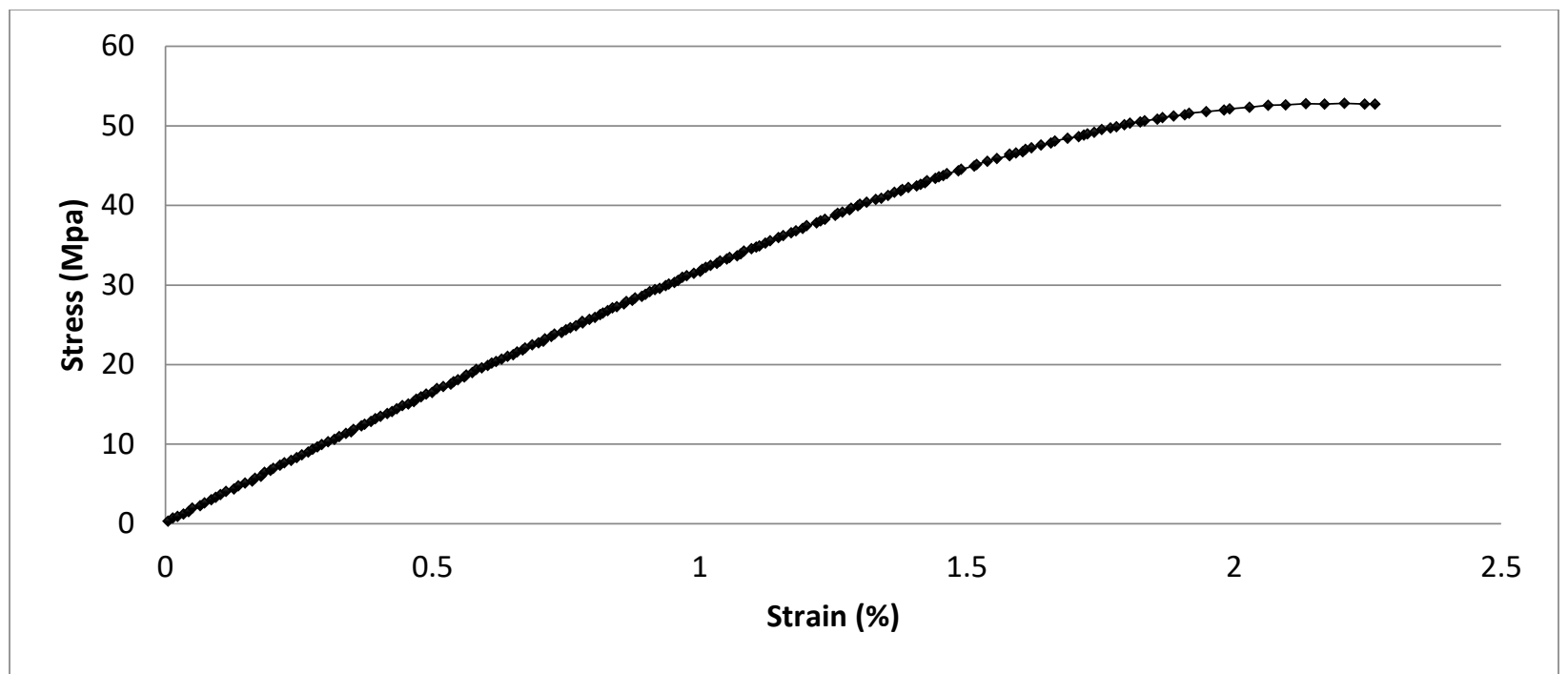

Figure 70: Figure 1: Stress - Strain Curves for Coupon C-3

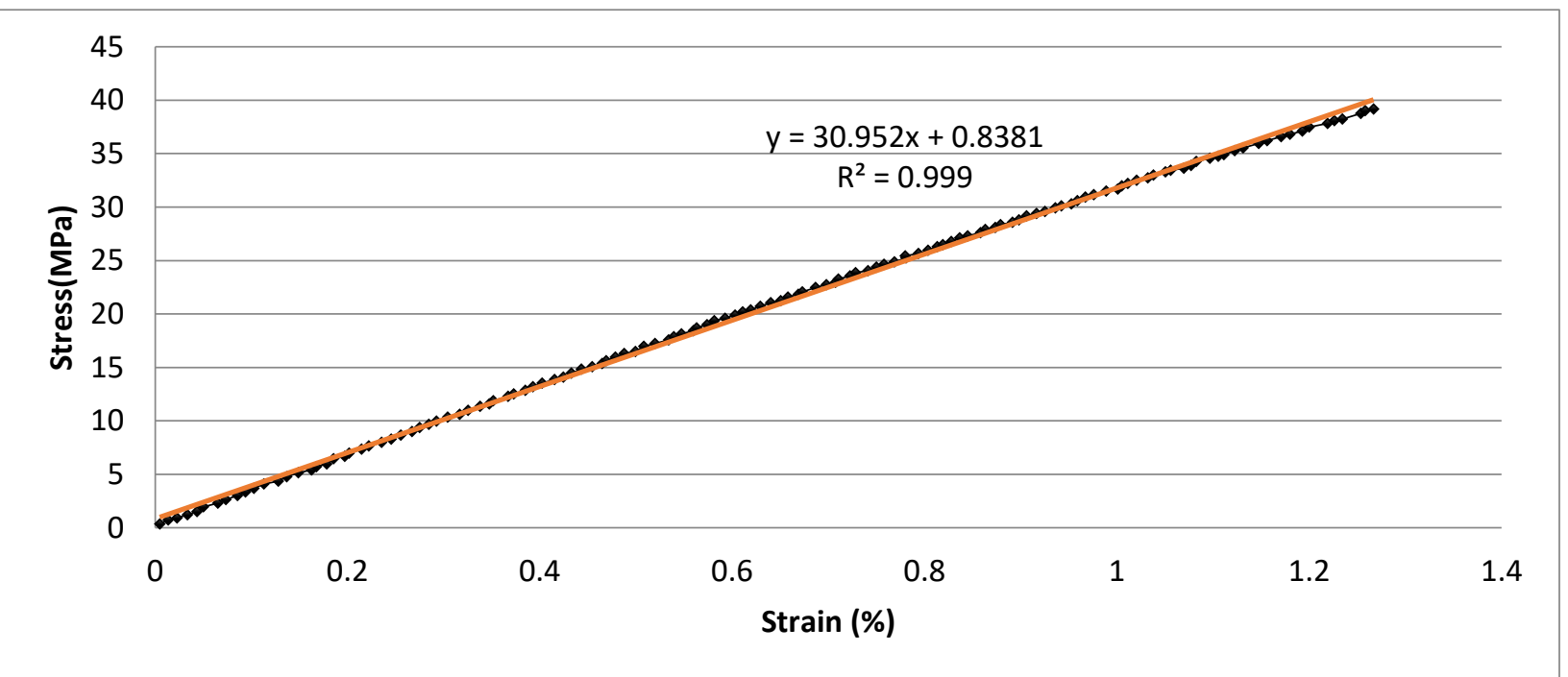

Figure 71: Stress-strain curve coupon C-3 (linear segment) 


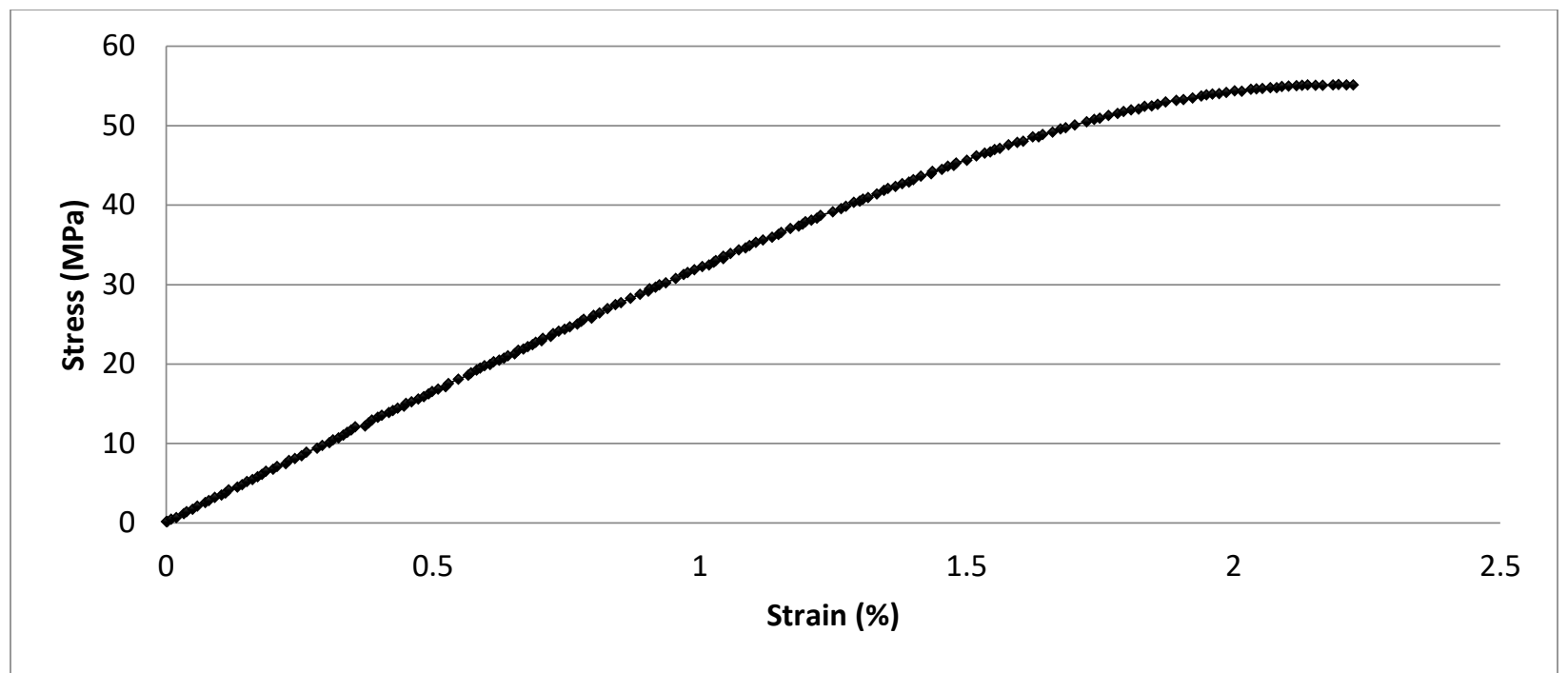

Figure 72: Stress - Strain Curves for Coupon C-4

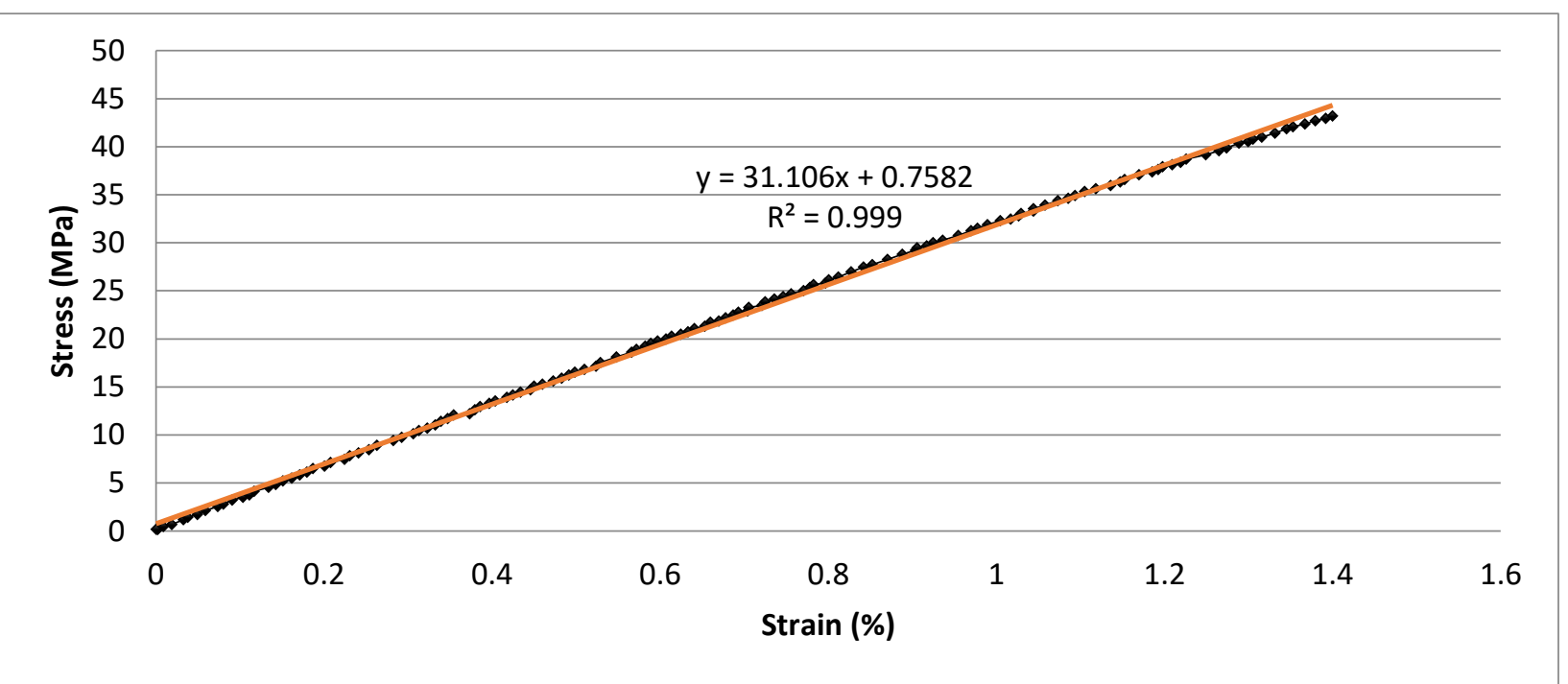

Figure 73: Stress-strain curve coupon C-4 (linear segment) 


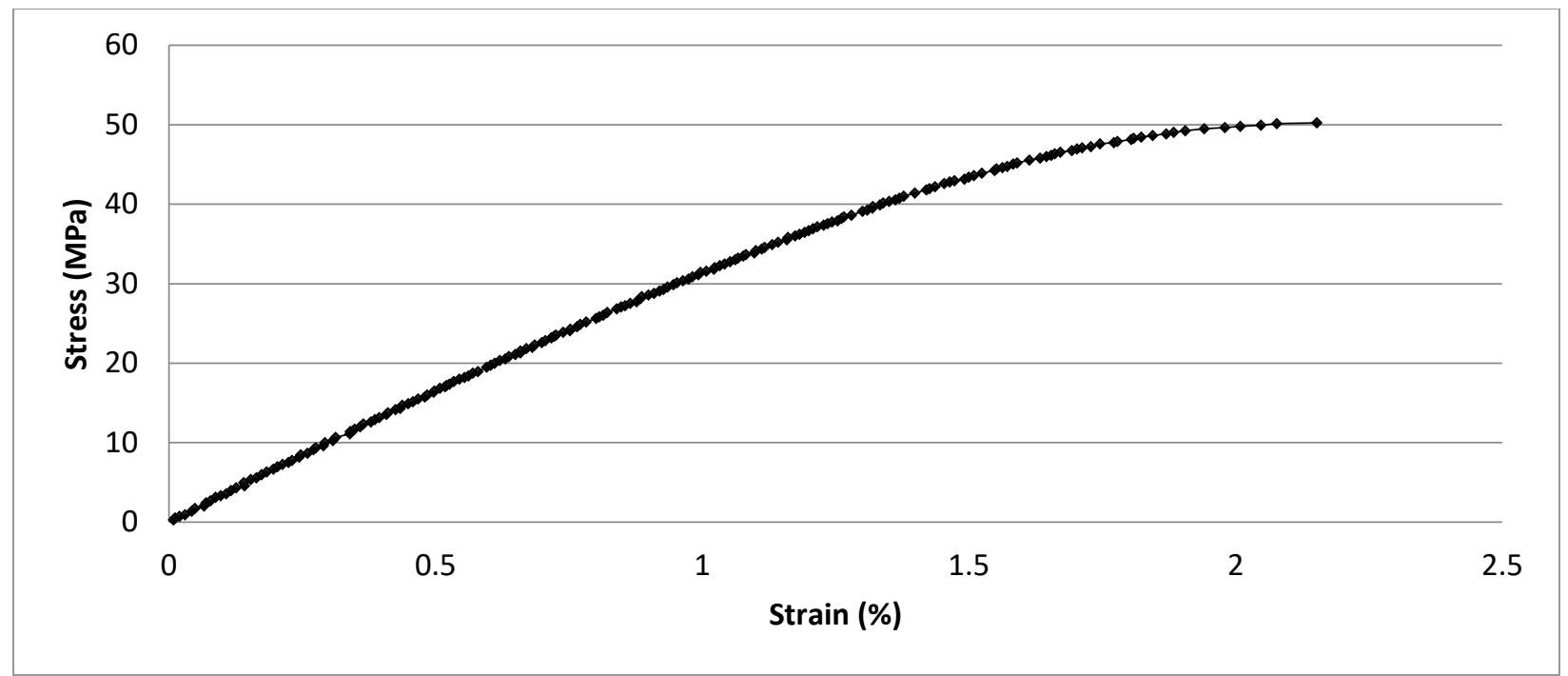

Figure 74: Stress - Strain Curves for Coupon C-5

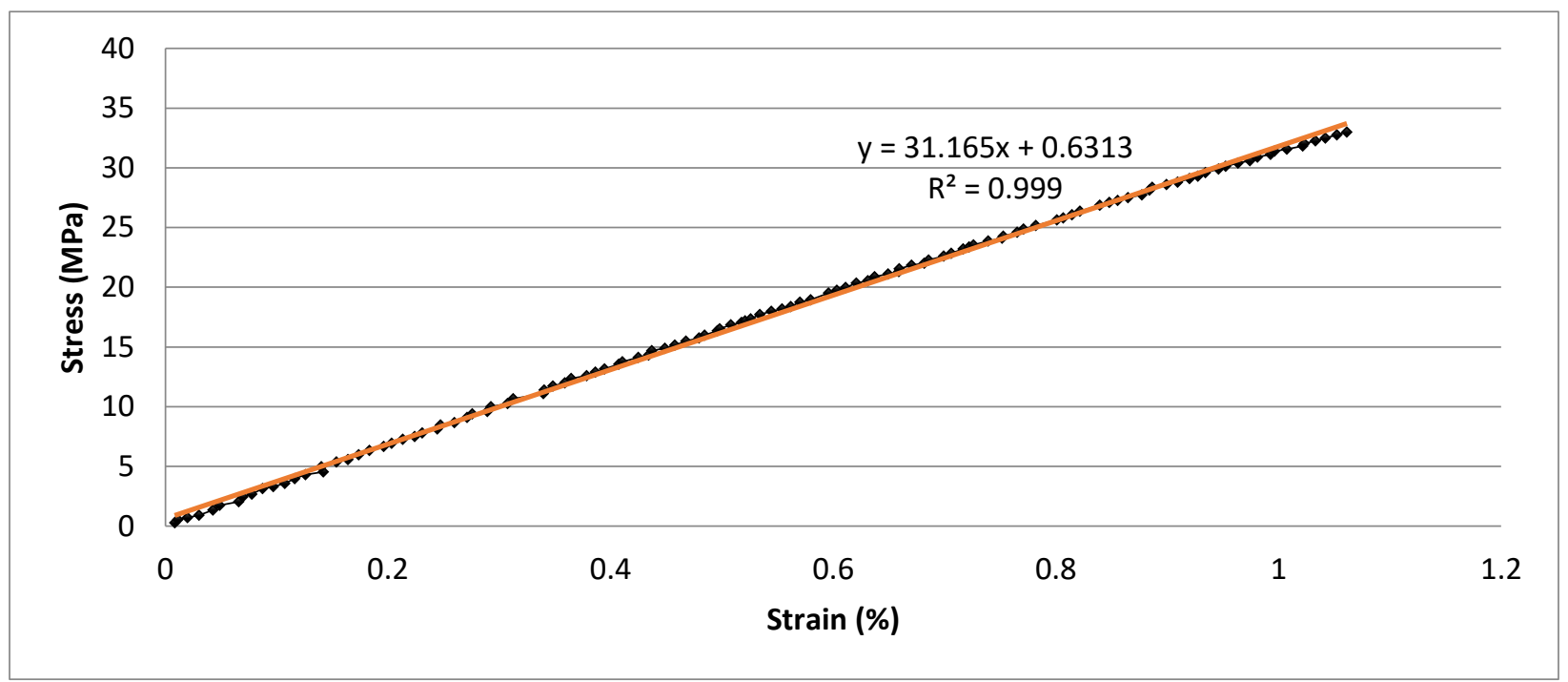

Figure 75: Stress-strain curve coupon C-5 (linear segment)

Table 17: Coupon D properties

\begin{tabular}{|c|c|c|c|c|c|c|c|}
\hline Coupon & $\begin{array}{c}\text { Maximum } \\
\text { force } \\
\text { (lbf) }\end{array}$ & $\begin{array}{c}\text { Cross section } \\
\left.\mathbf{( i n}^{\mathbf{2}}\right)\end{array}$ & $\begin{array}{c}\text { Width } \\
\text { (in) }\end{array}$ & $\begin{array}{c}\text { Thickness } \\
\text { (in) }\end{array}$ & $\begin{array}{c}\text { Failure } \\
\text { stress (Psi) }\end{array}$ & $\begin{array}{c}\text { Strength } \\
(\mathbf{M P a})\end{array}$ & $\begin{array}{c}\text { Modulus } \\
(\mathbf{G P a})\end{array}$ \\
\hline D-1 & 480.383 & 0.074 & 503 & 147 & 6511.610 & 44.9 & 2.77 \\
\hline D-2 & 488.983 & 0.072 & 507 & 143 & 6764.710 & 46.6 & 2.84 \\
\hline
\end{tabular}




\begin{tabular}{|c|c|c|c|c|c|c|c|}
\hline D-3 & 493.491 & 0.069 & 508 & 137 & 7108.086 & 49.0 & 3.10 \\
\hline D-4 & 493.661 & 0.070 & 507 & 139 & 7009.573 & 48.3 & 2.99 \\
\hline D-5 & 512.483 & 0.072 & 509 & 142 & 7107.127 & 49.0 & 2.91 \\
\hline
\end{tabular}

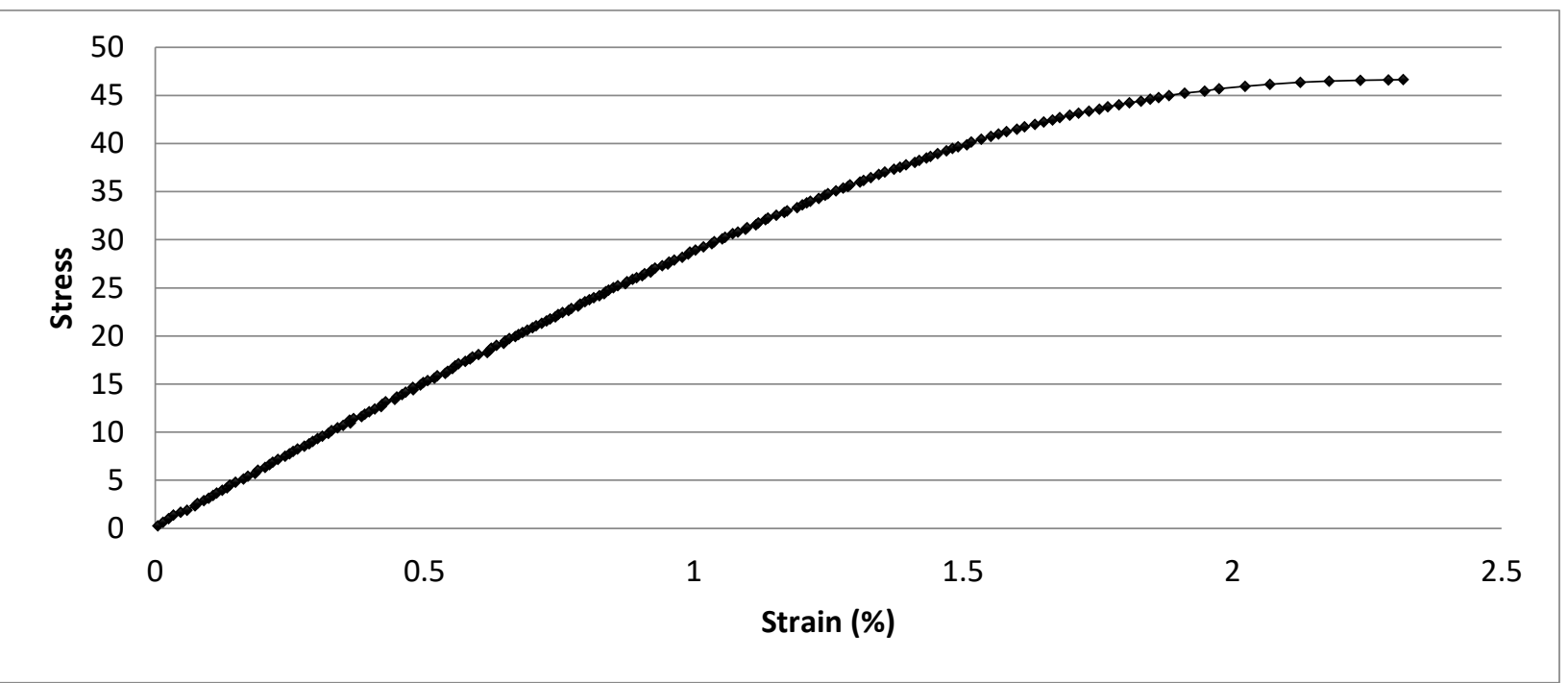

Figure 76: Stress-strain curve coupon D-2

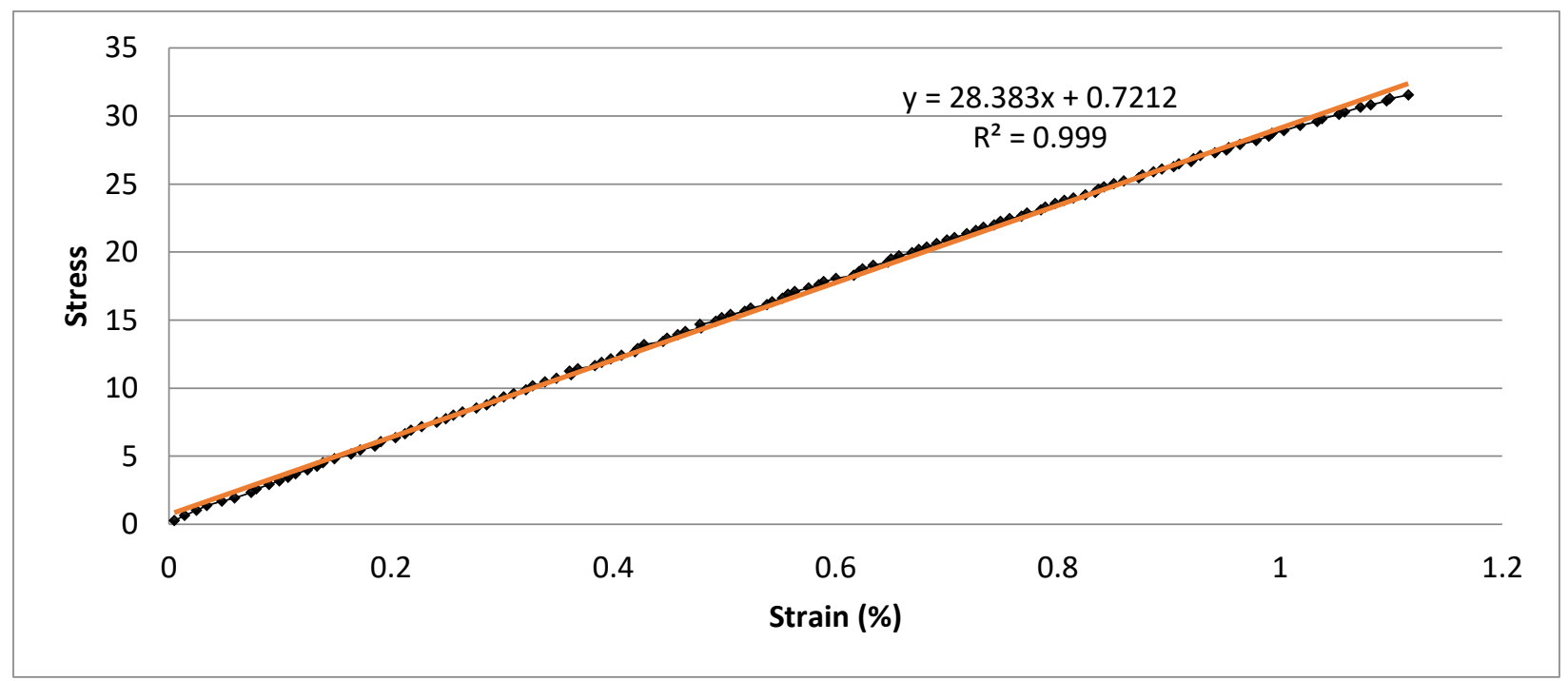

Figure 77: Stress-strain curve coupon D-2 (linear segment) 


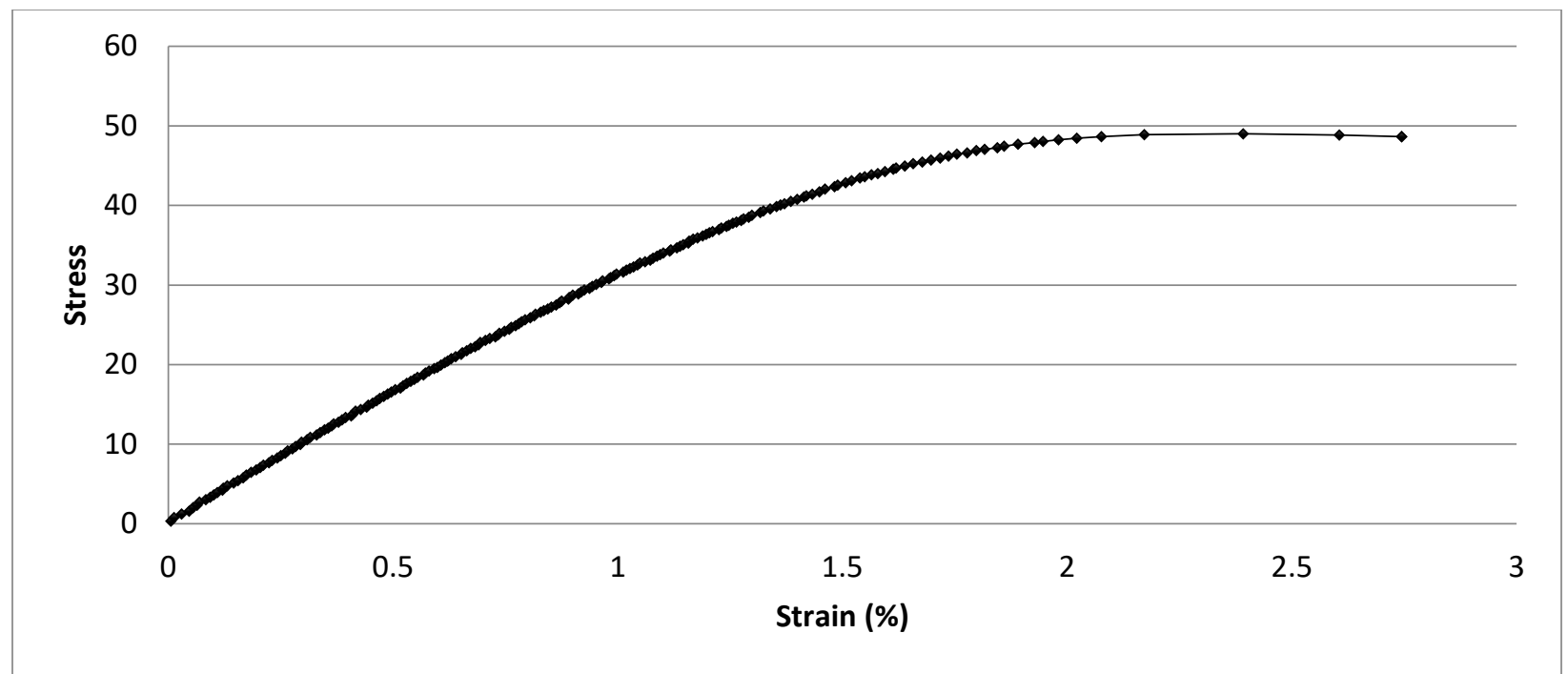

Figure 78: Stress-strain curve coupon D-3

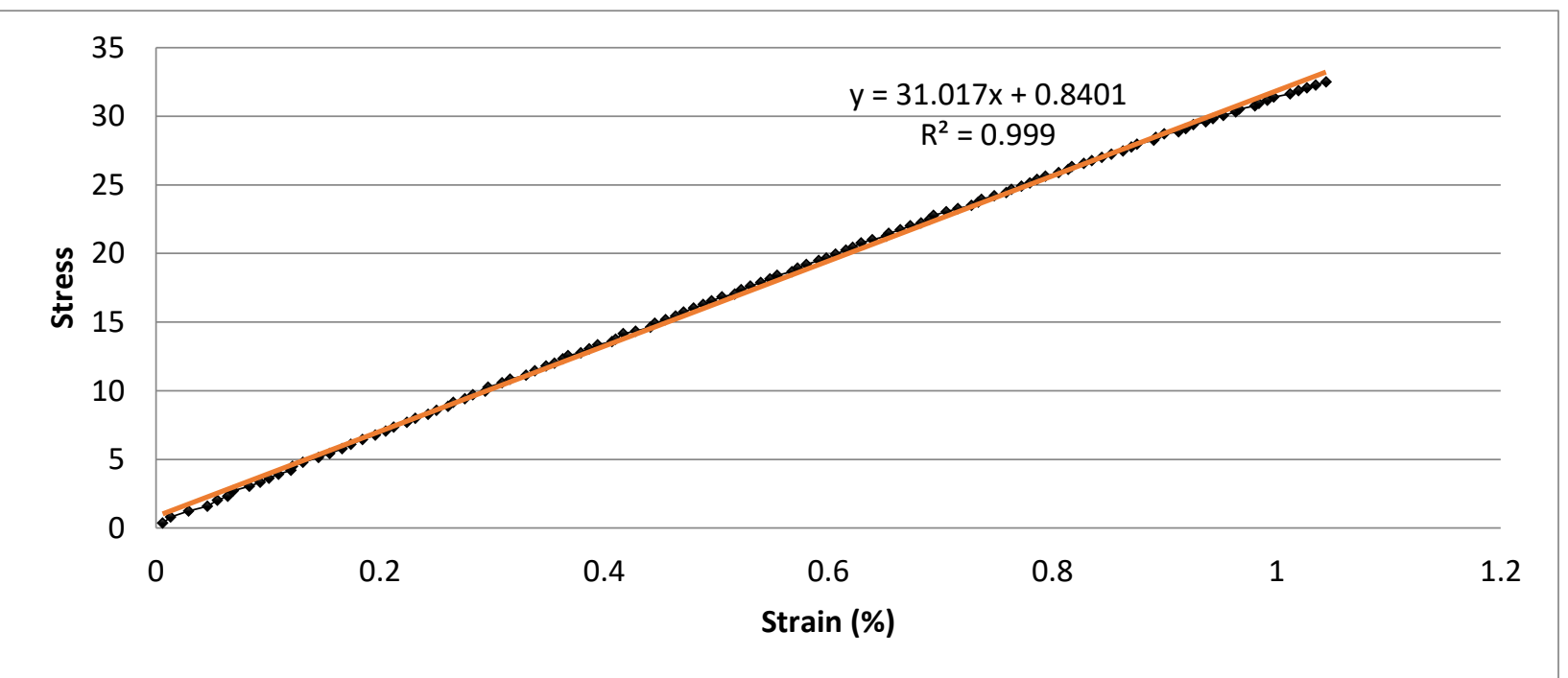

Figure 79: Stress-strain curve coupon D-3 (linear segment) 


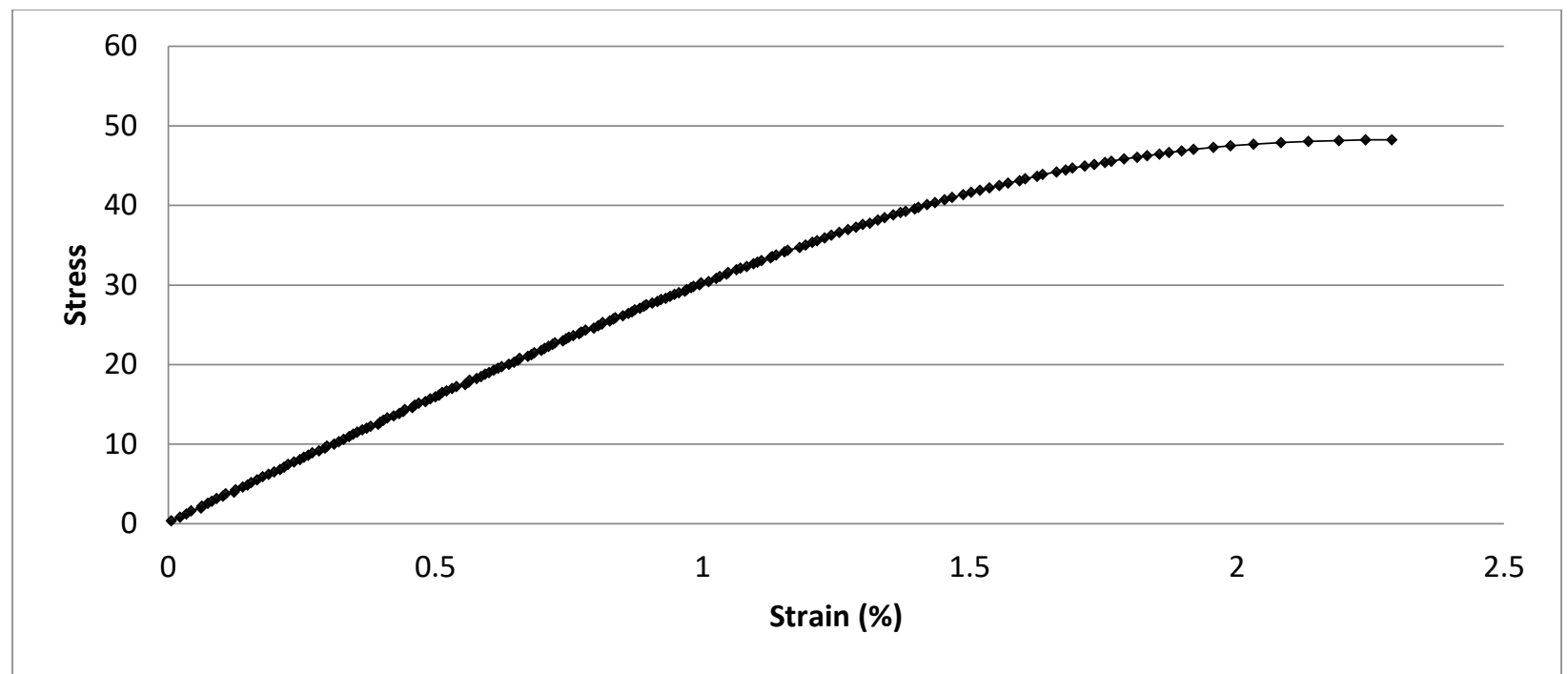

Figure 80: Stress-strain curve coupon D-4

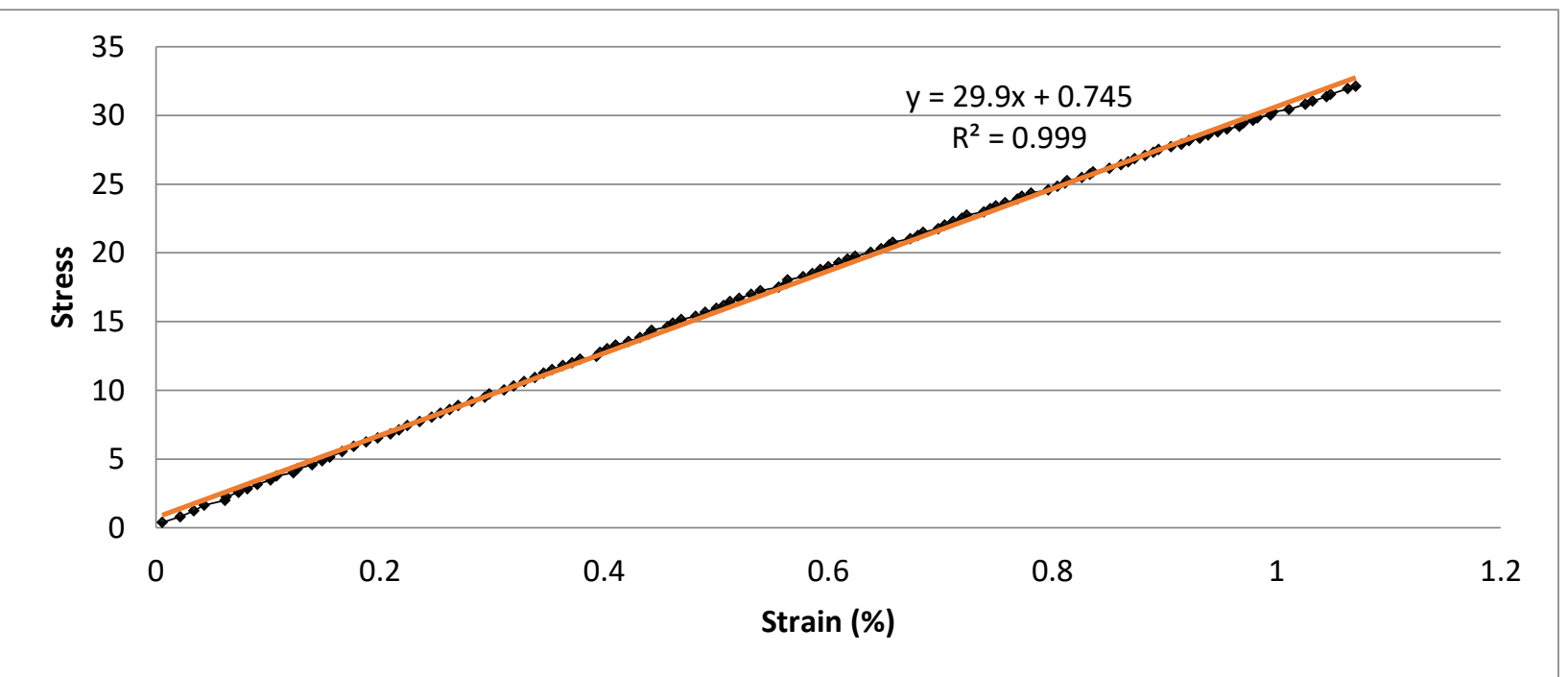

Figure 81: Stress-strain curve coupon D-4 (linear segment) 


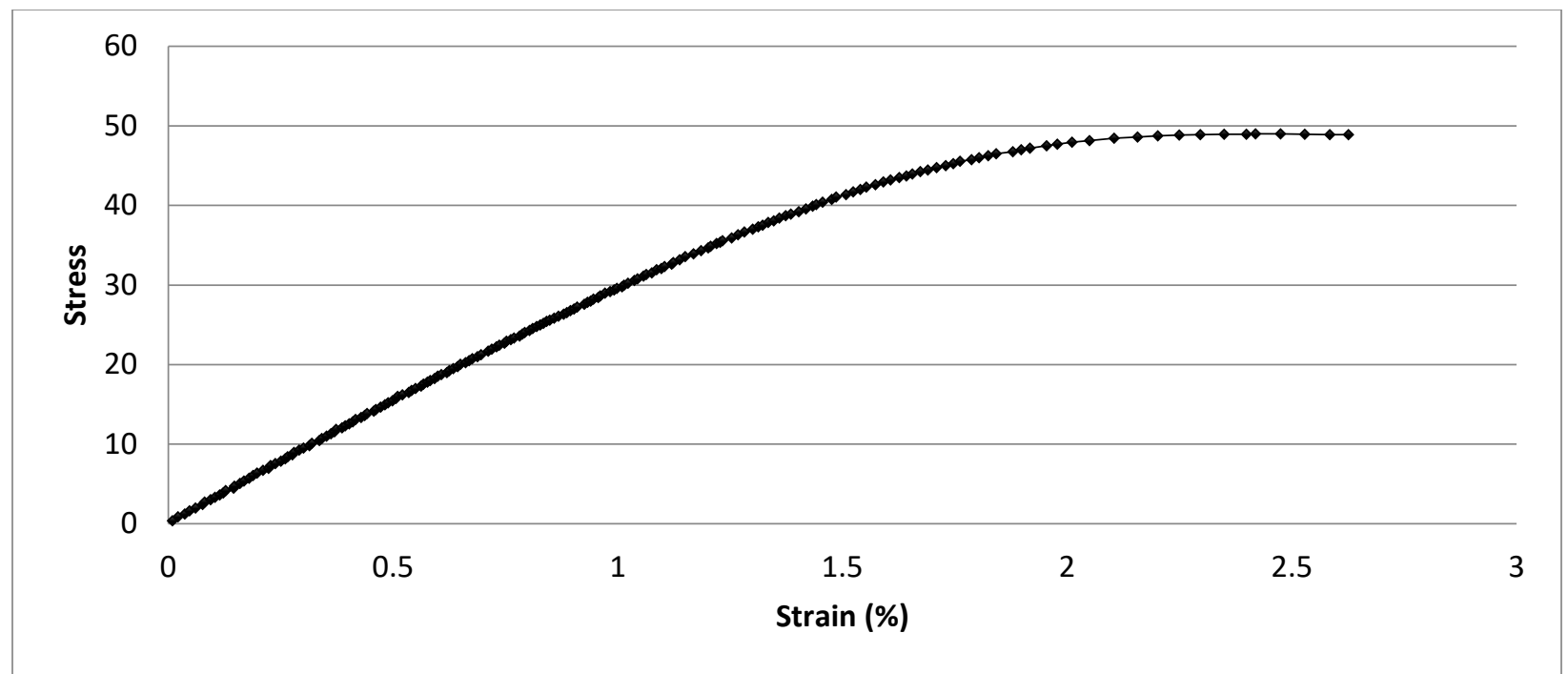

Figure 82: Stress-strain curve coupon D-5

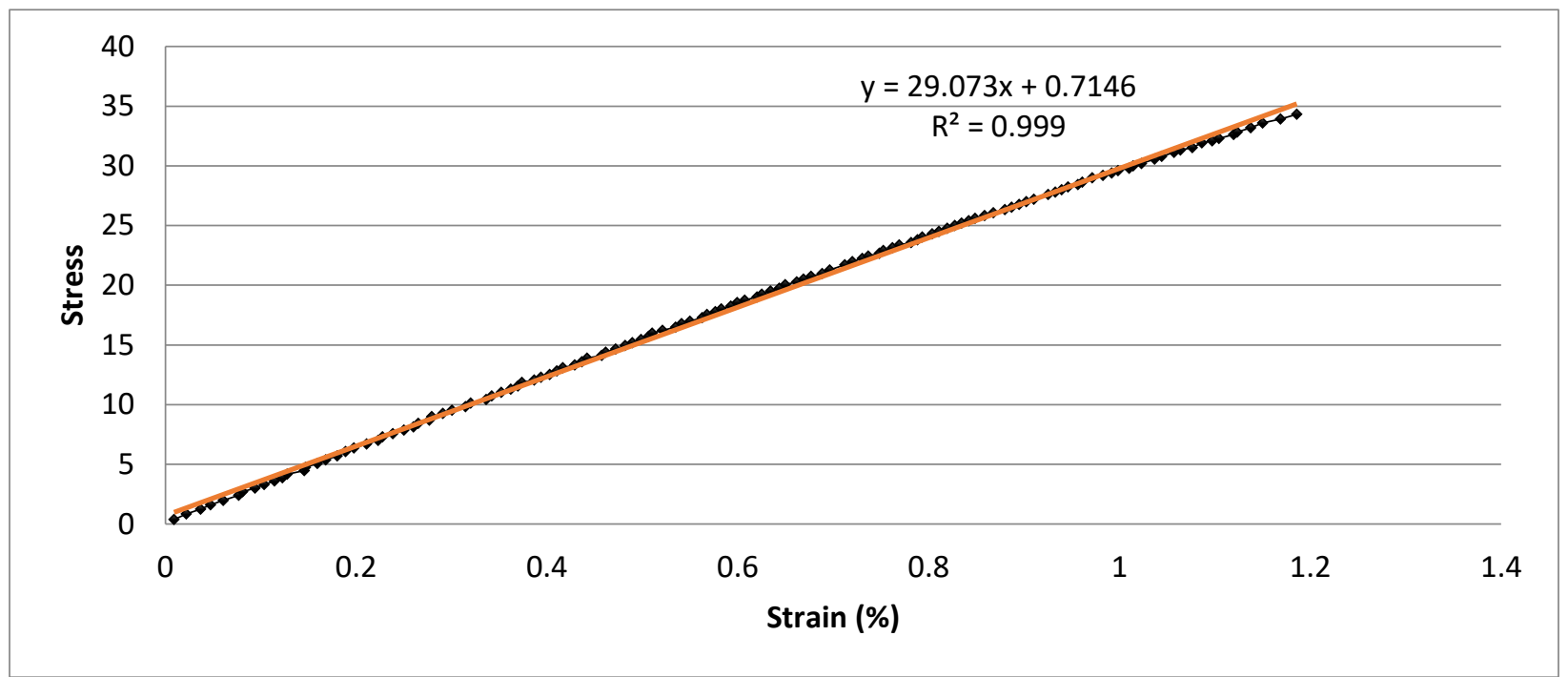

Figure 83: Stress-strain curve coupon D-5 (linear segment)

Table 18: Coupon E properties

\begin{tabular}{|c|c|c|c|c|c|c|c|}
\hline Coupon & $\begin{array}{c}\text { Maximum } \\
\text { force } \\
\text { (lbf) }\end{array}$ & $\begin{array}{c}\text { Cross section } \\
\left.\mathbf{( i n}^{\mathbf{2}}\right)\end{array}$ & $\begin{array}{c}\text { Width } \\
\text { (in) }\end{array}$ & $\begin{array}{c}\text { Thickness } \\
\text { (in) }\end{array}$ & $\begin{array}{c}\text { Failure } \\
\text { stress (Psi) }\end{array}$ & $\begin{array}{c}\text { Strength } \\
(\mathbf{M P a})\end{array}$ & $\begin{array}{c}\text { Modulus } \\
(\mathbf{G P a})\end{array}$ \\
\hline E-1 & 453.804 & 0.070 & 506 & 139 & 6463.382 & 44.6 & 2.90 \\
\hline E-2 & 451.663 & 0.071 & 508 & 141 & 6320.618 & 43.6 & 2.83 \\
\hline
\end{tabular}




\begin{tabular}{|c|c|c|c|c|c|c|c|}
\hline E-3 & 433.226 & 0.072 & 506 & 141 & 6053.877 & 41.7 & 2.77 \\
\hline E-4 & 448.173 & 0.072 & 507 & 142 & 6206.489 & 42.8 & 2.78 \\
\hline E-5 & 415.779 & 0.072 & 507 & 141 & 5798.620 & 40.0 & 2.76 \\
\hline
\end{tabular}

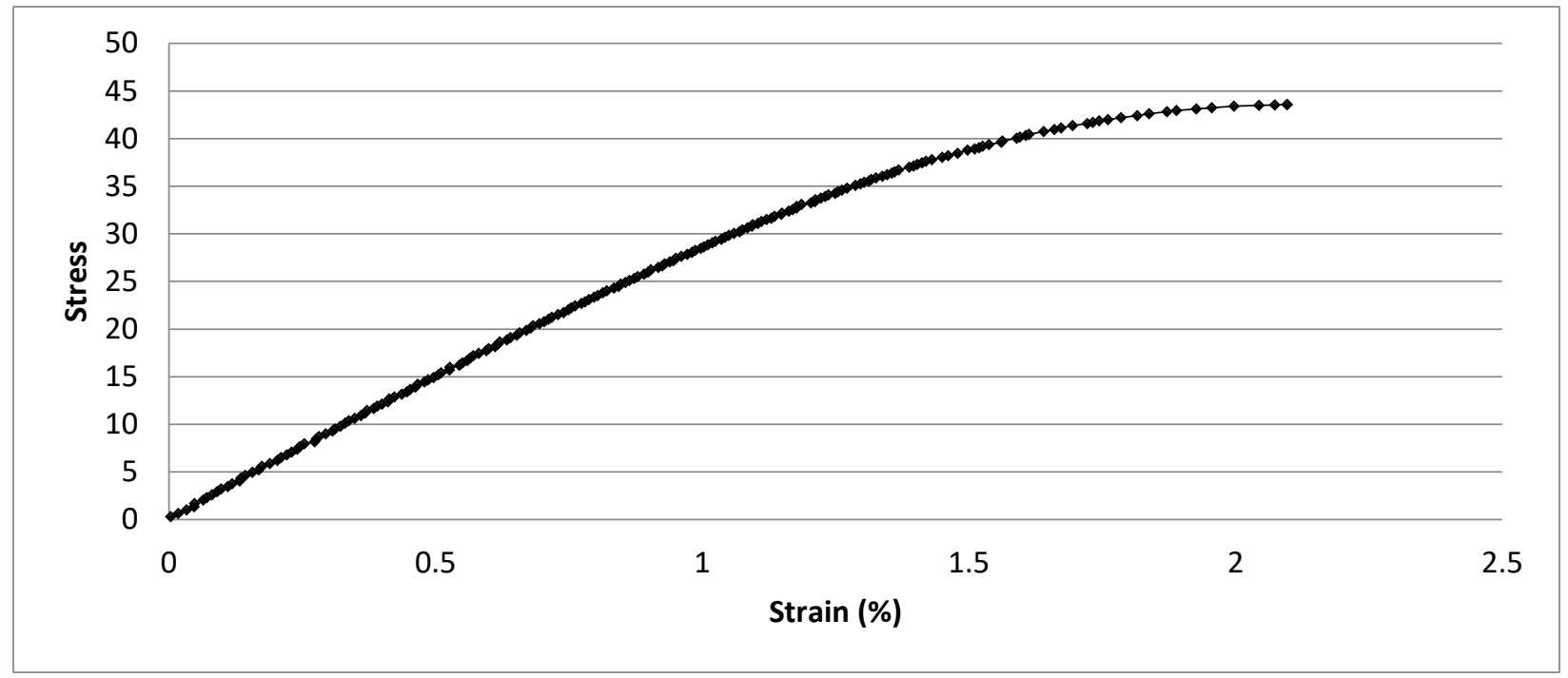

Figure 84: Stress-strain curve coupon E-2

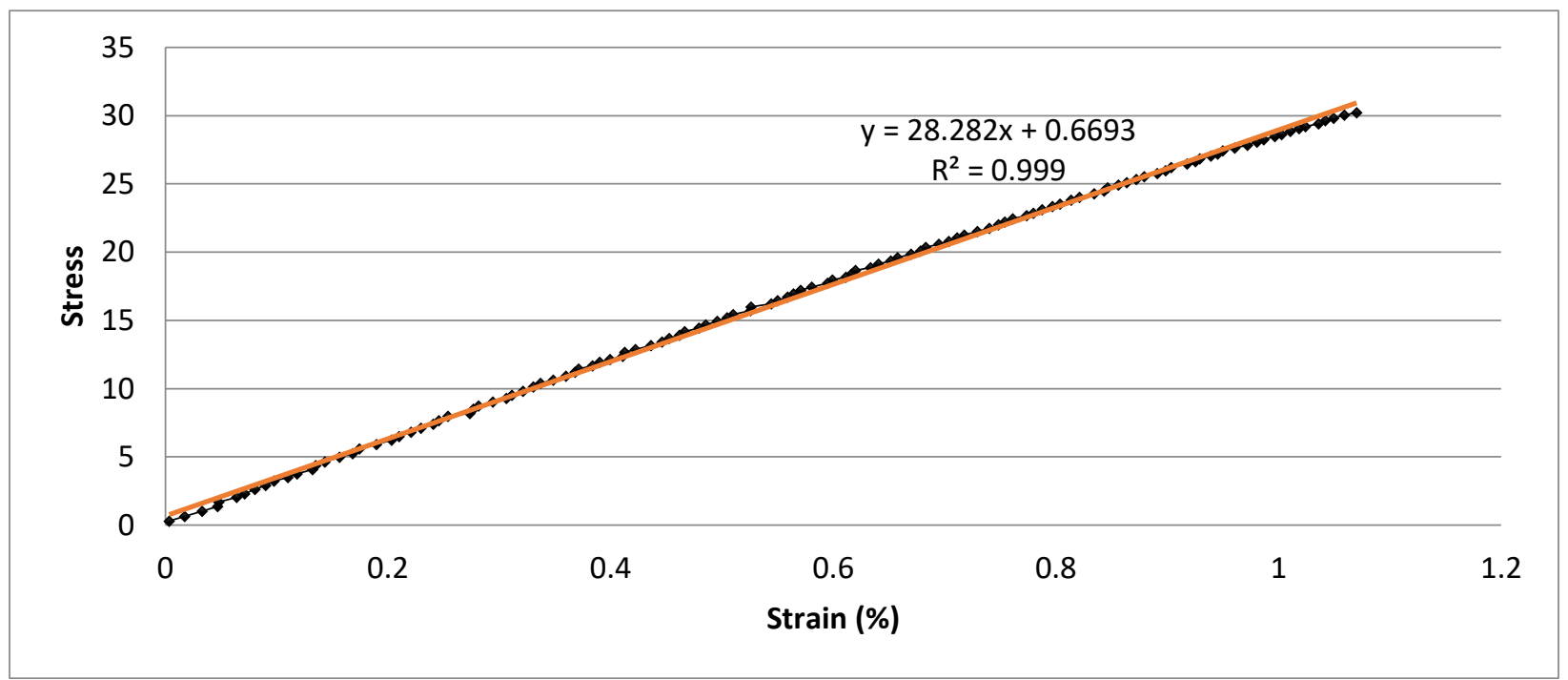

Figure 85: Stress-strain curve coupon E-2 (linear segment) 


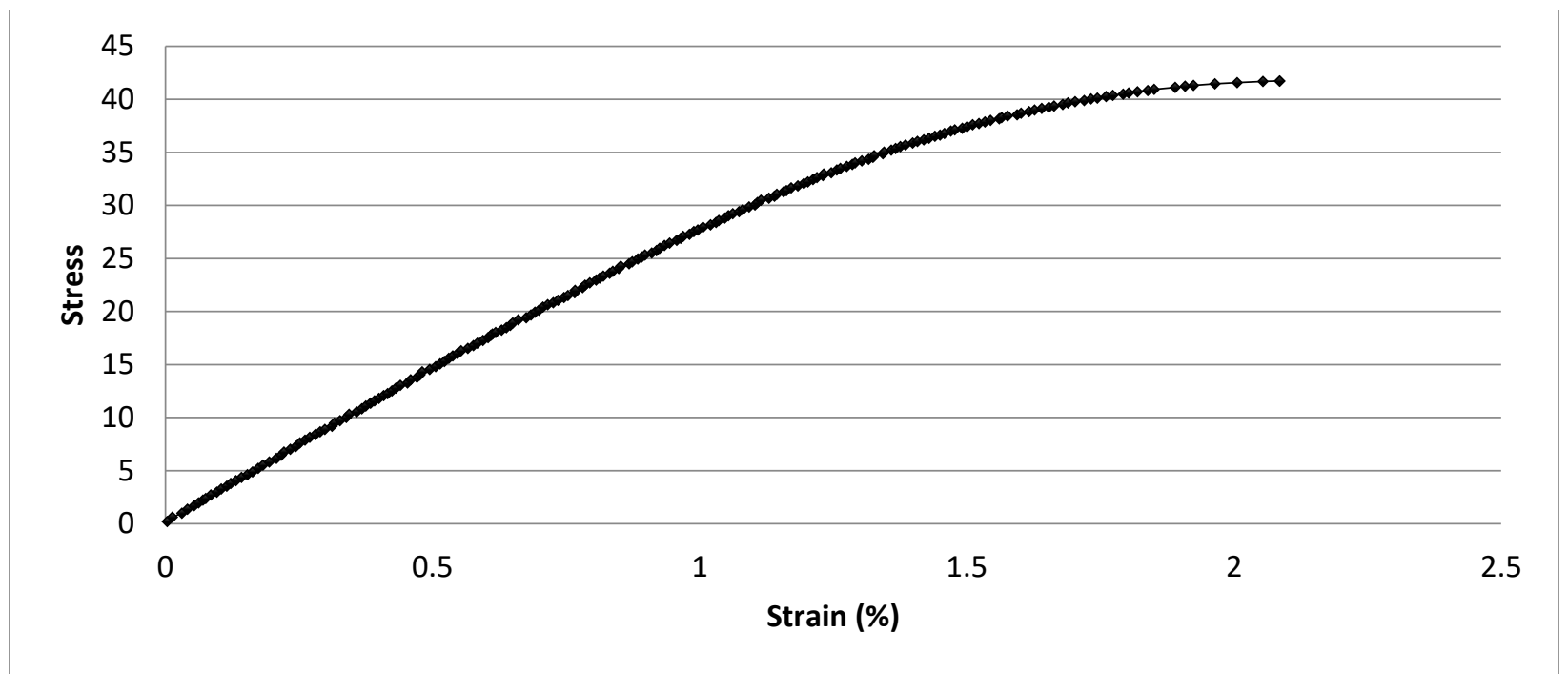

Figure 86: Stress-strain curve coupon E-3

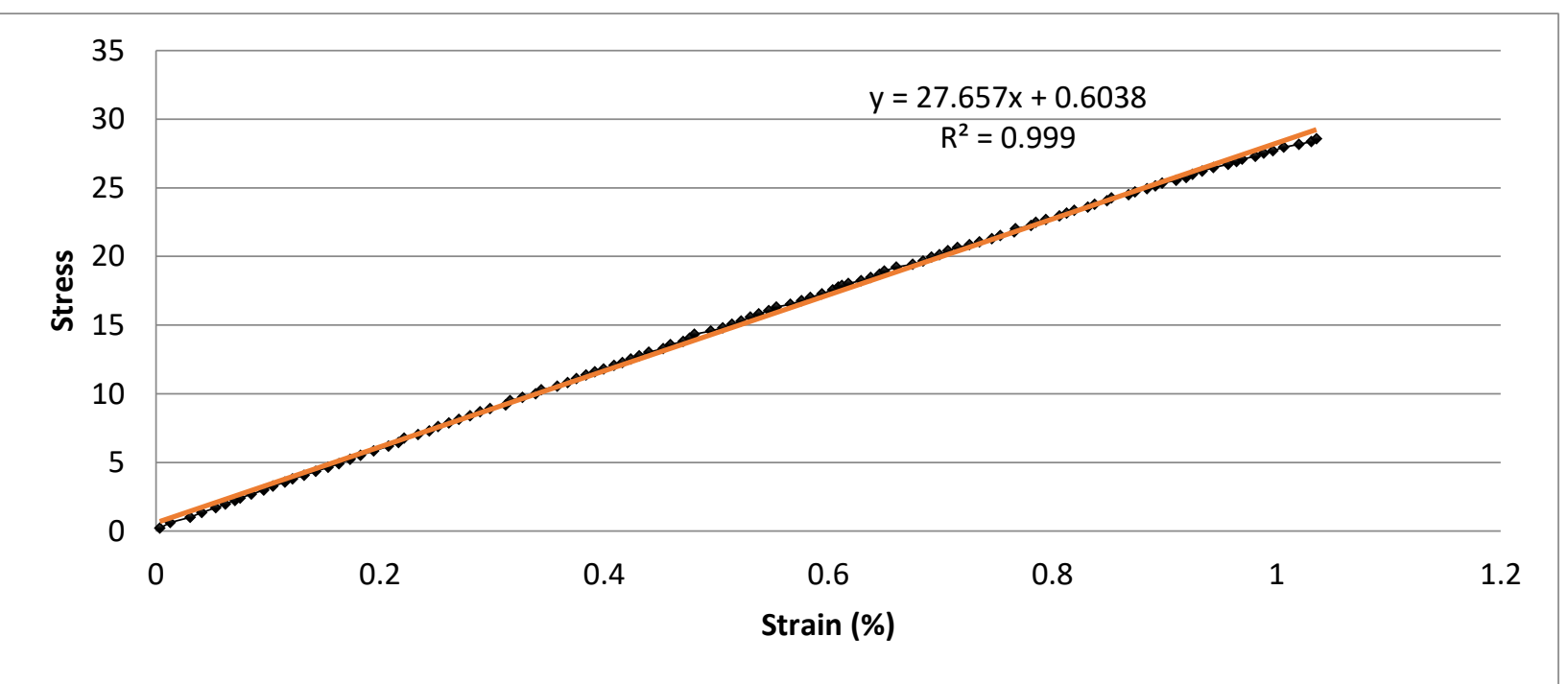

Figure 87: Stress-strain curve coupon E-3 (linear segment) 


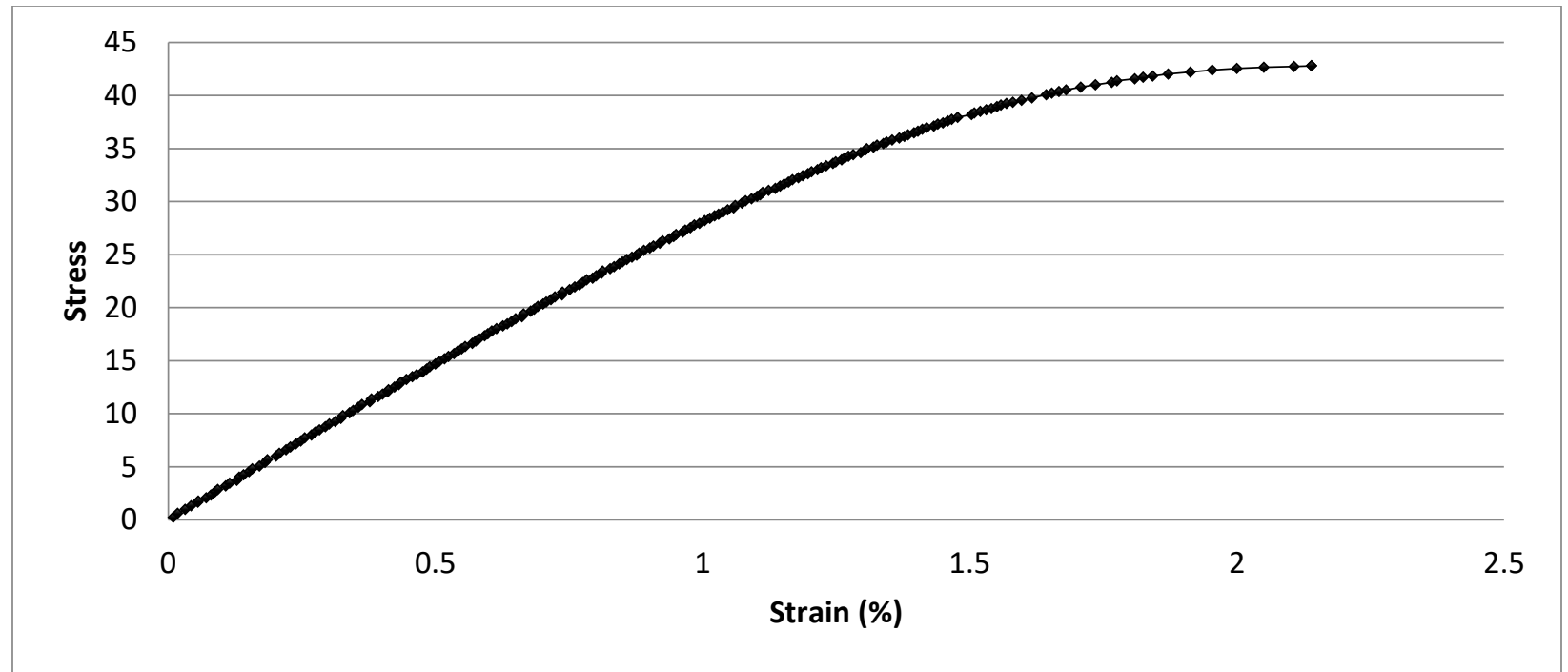

Figure 88: Stress-strain curve coupon E-4

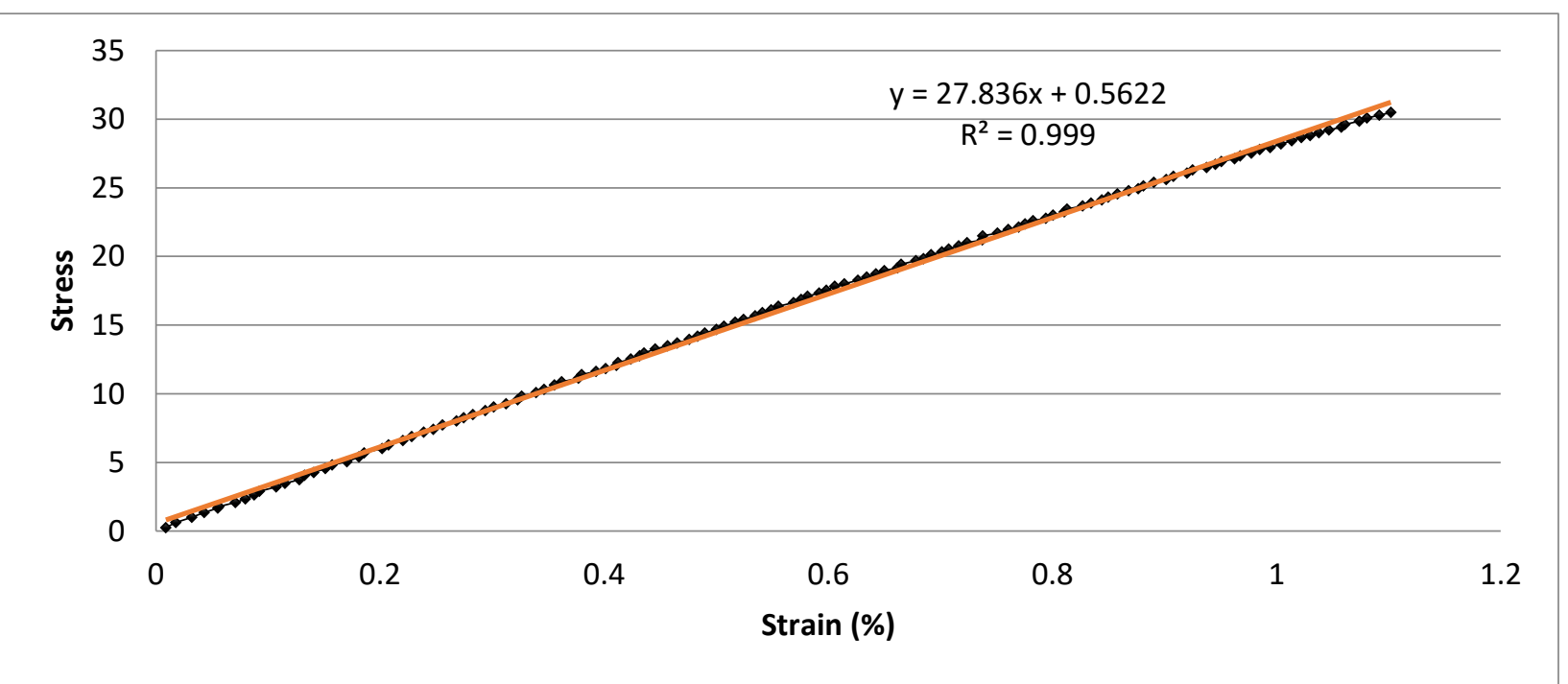

Figure 89: Stress-strain curve coupon E-4 (linear segment) 


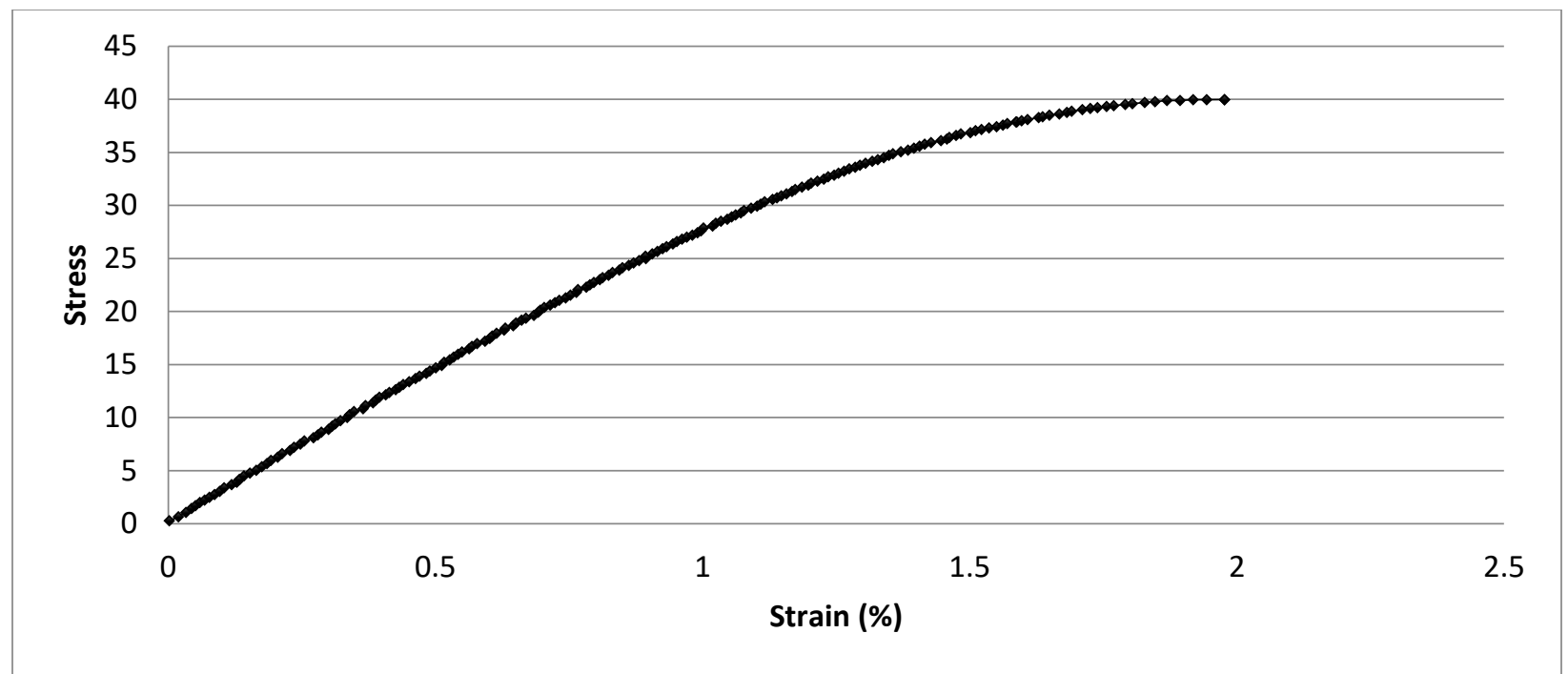

Figure 90: Stress-strain curve coupon E-5

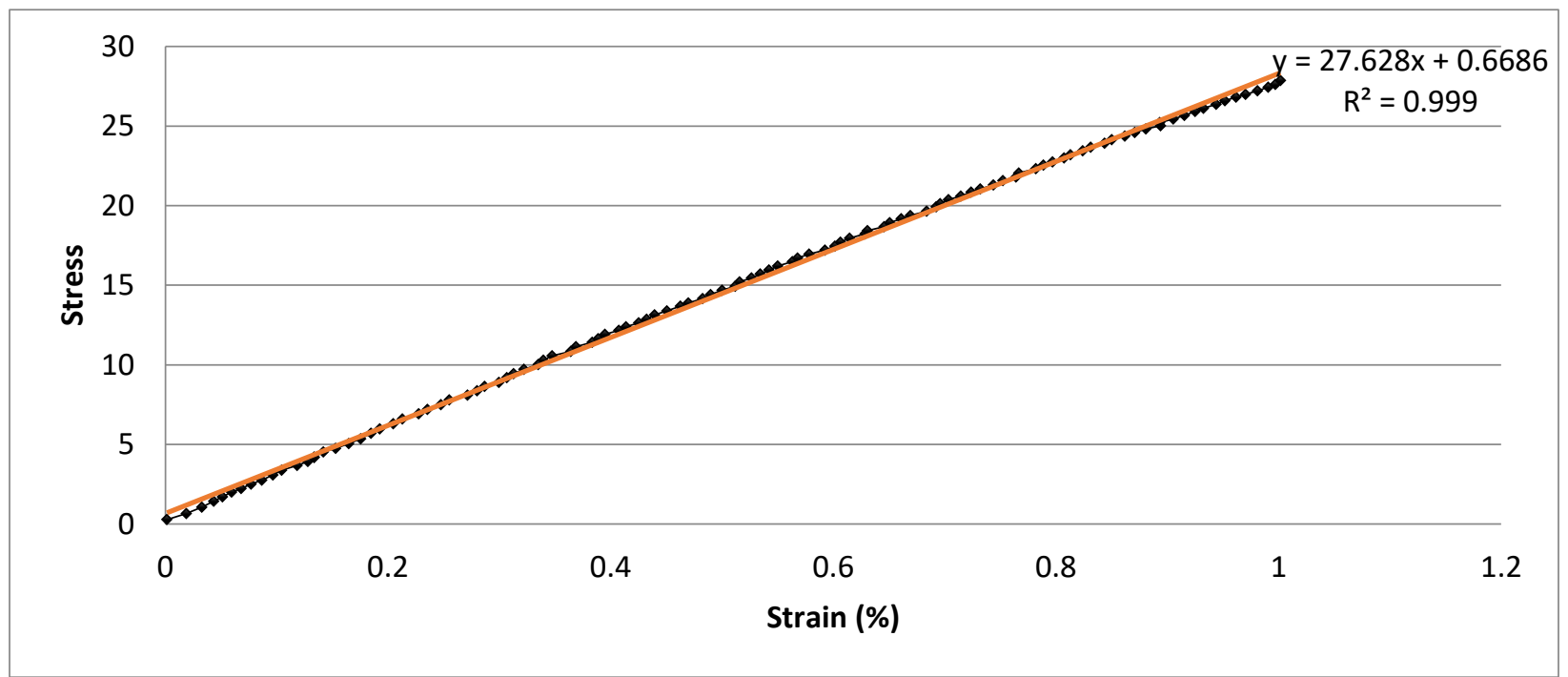

Figure 91: Stress-strain curve coupon E-5 (linear segment)

Table 19: Coupon F properties

\begin{tabular}{|c|c|c|c|c|c|c|c|}
\hline Coupon & $\begin{array}{c}\text { Maximum } \\
\text { force } \\
\text { (lbf) }\end{array}$ & $\begin{array}{c}\text { Cross section } \\
\left.\mathbf{( i n}^{\mathbf{2}}\right)\end{array}$ & $\begin{array}{c}\text { Width } \\
\text { (in) }\end{array}$ & $\begin{array}{c}\text { Thickness } \\
\text { (in) }\end{array}$ & $\begin{array}{c}\text { Failure } \\
\text { stress (Psi) }\end{array}$ & $\begin{array}{c}\text { Strength } \\
(\mathbf{M P a})\end{array}$ & $\begin{array}{c}\text { Modulus } \\
(\mathbf{G P a})\end{array}$ \\
\hline F-1 & 445.253 & 0.070 & 508 & 138 & 6331.857 & 43.7 & 2.88 \\
\hline F-2 & 440.510 & 0.071 & 508 & 139 & 6223.538 & 42.9 & 2.85 \\
\hline
\end{tabular}




\begin{tabular}{|c|c|c|c|c|c|c|c|}
\hline F-3 & 603.173 & 0.070 & 507 & 139 & 8564.559 & 59.1 & 3.10 \\
\hline F-4 & 435.376 & 0.071 & 508 & 140 & 6132.303 & 42.3 & 2.79 \\
\hline F-5 & 440.849 & 0.071 & 508 & 140 & 6187.996 & 42.7 & N/A \\
\hline
\end{tabular}

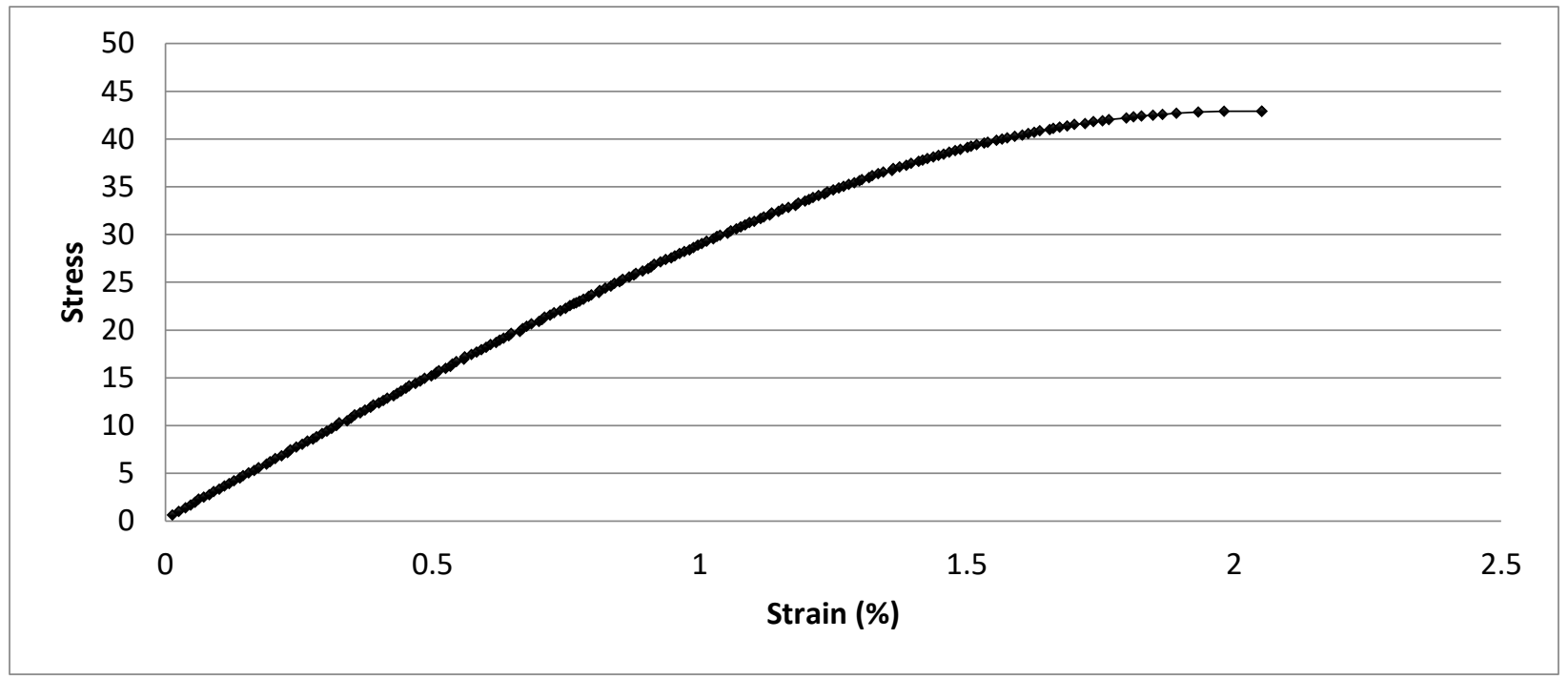

Figure 92: Stress-strain curve coupon F-2

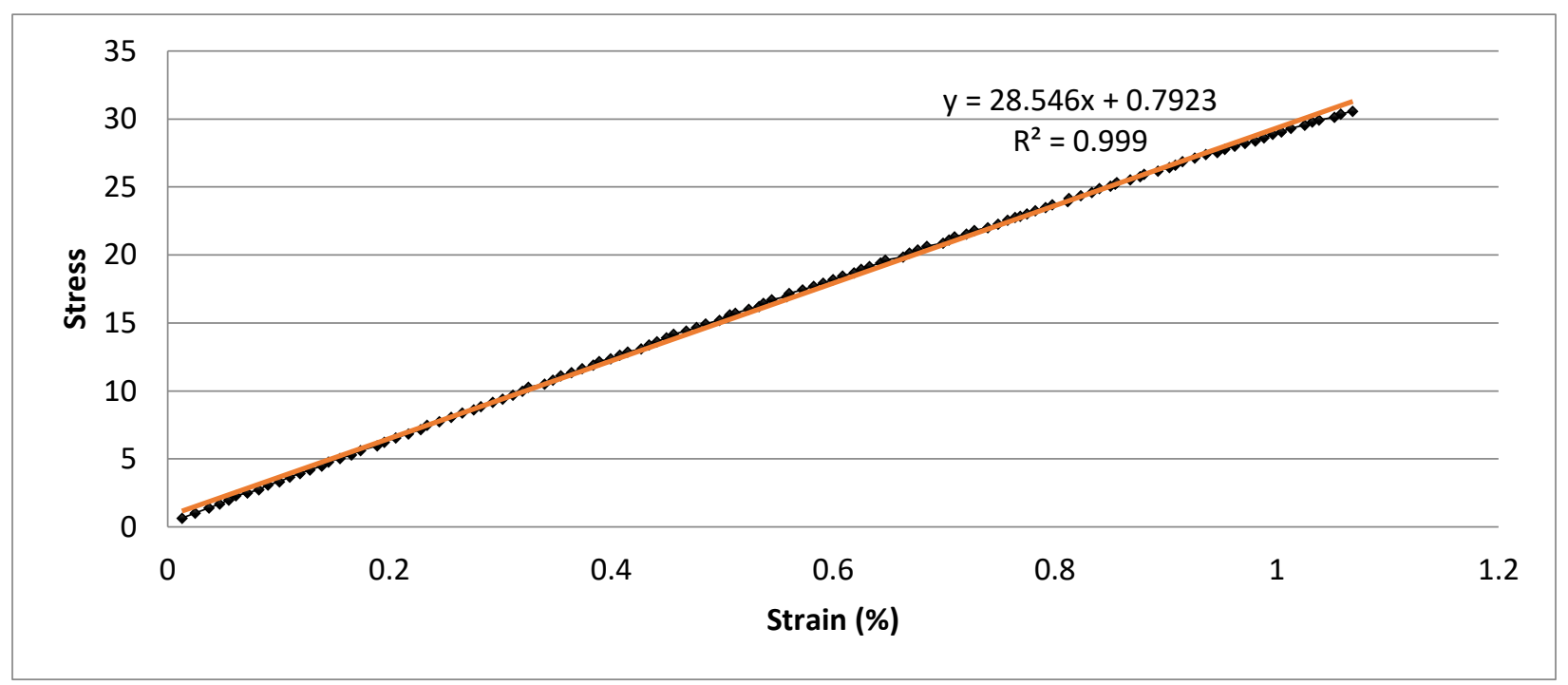

Figure 93: Stress-strain curve coupon F-2 (linear segment) 


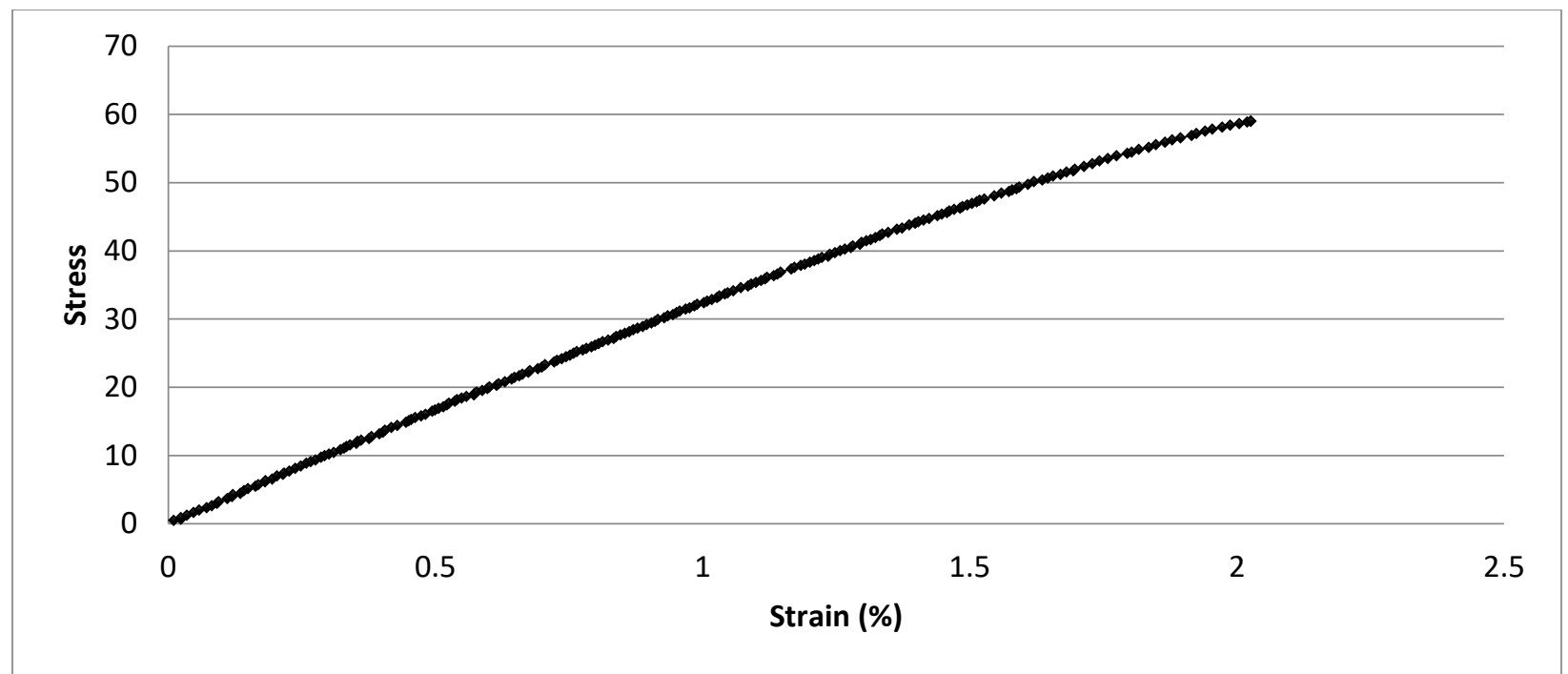

Figure 94: Stress-strain curve coupon F-3

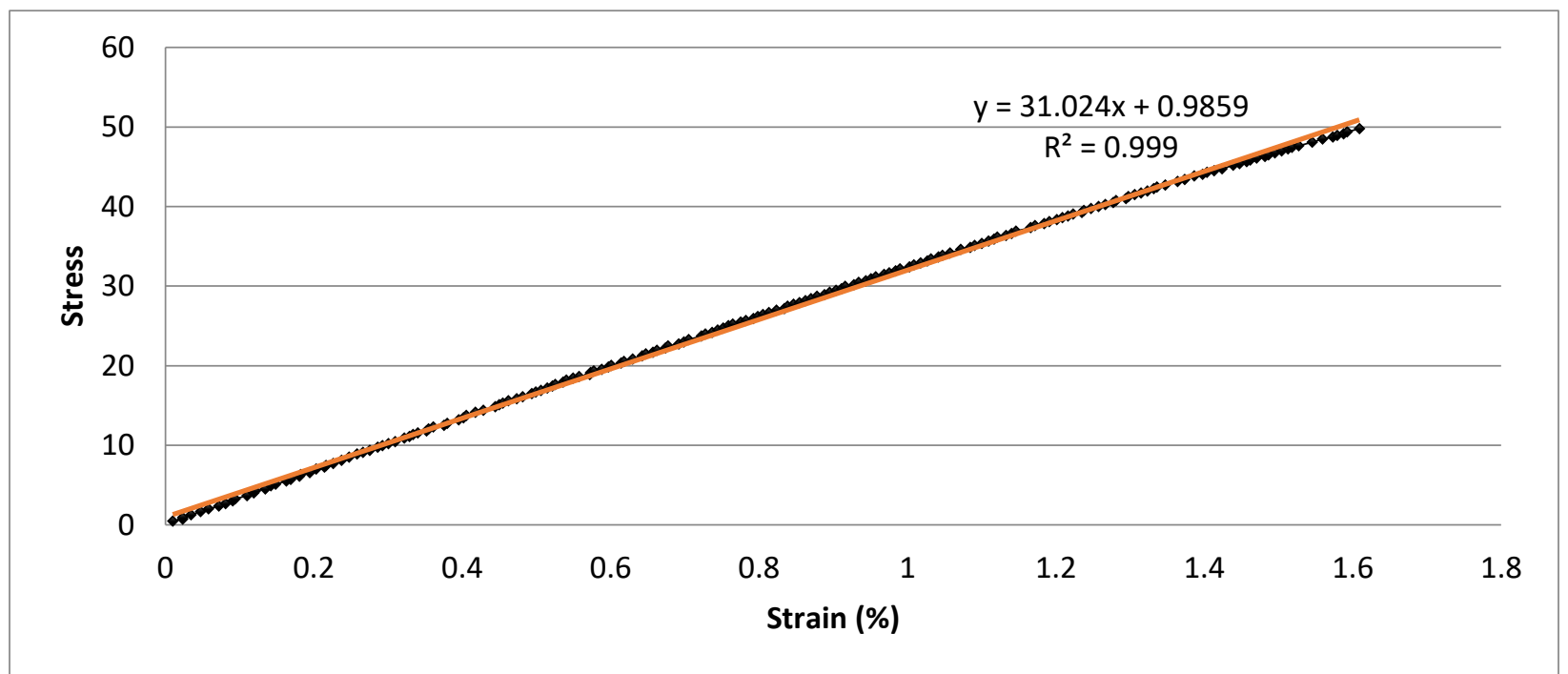

Figure 95: Stress-strain curve coupon F-3 (linear segment) 


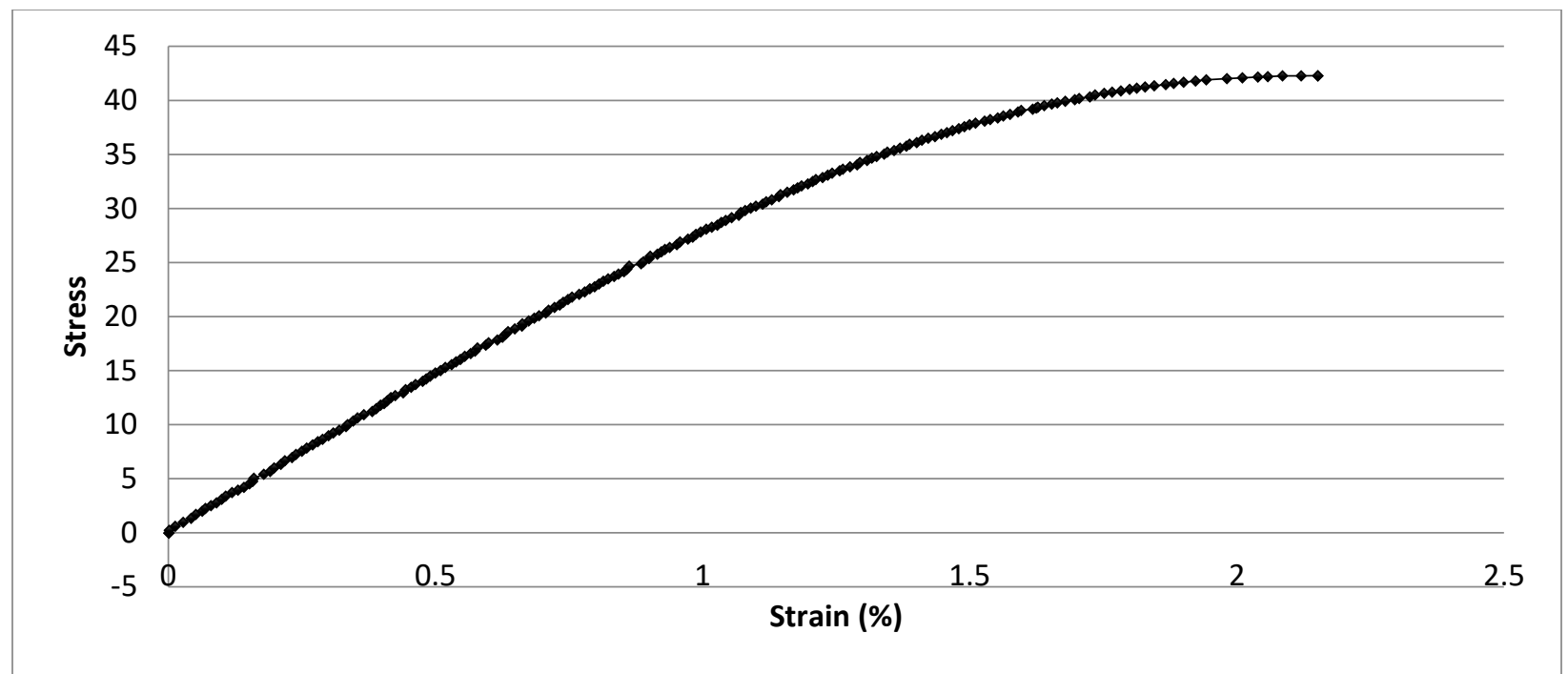

Figure 96: Stress-strain curve coupon F-4

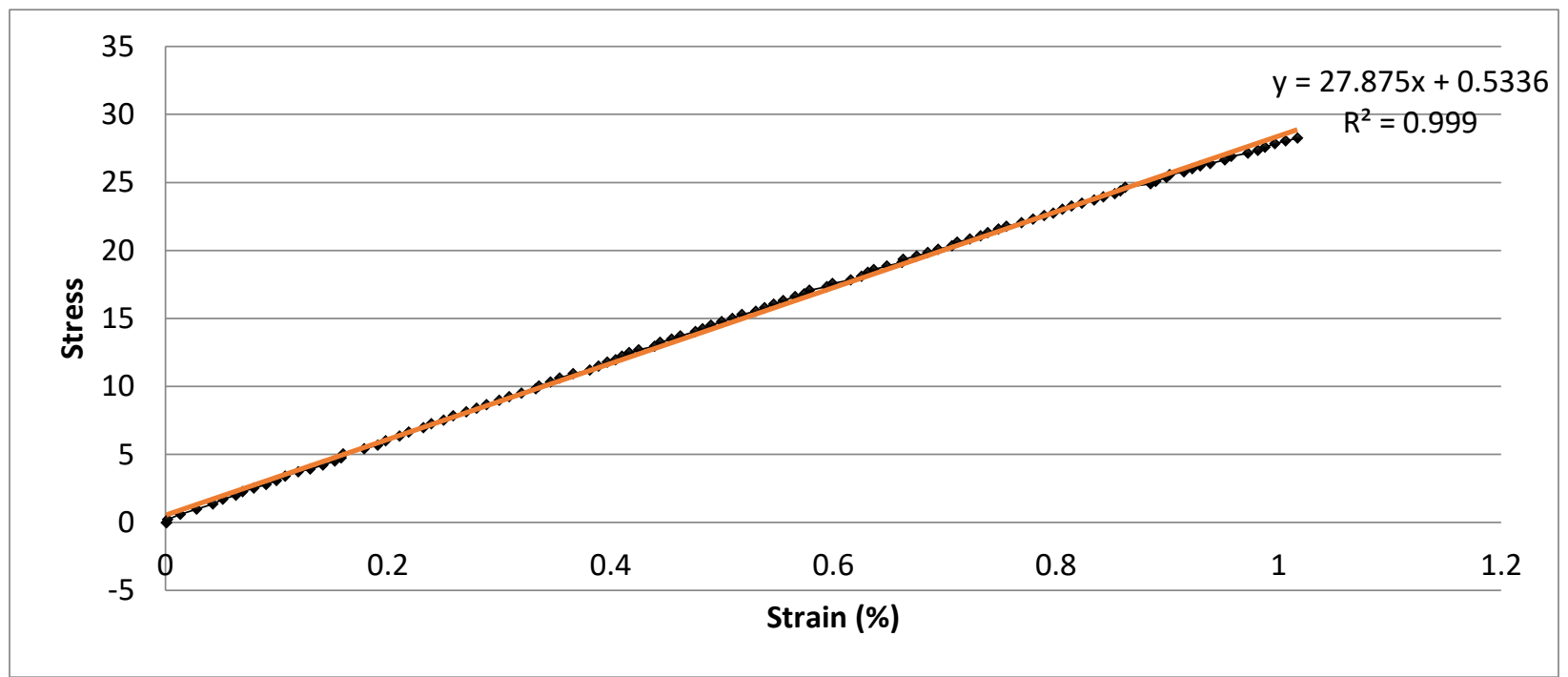

Figure 97: Stress-strain curve coupon F-4 (linear segment)

\section{REFERENCES}

1. Additive manufacturing of carbon fiber-reinforced plastic composites using fused deposition modeling: Effects of process parameters on tensile properties. Fuda Ning, Weilong Cong, Yingbin Hu and Hui Wang. 2017, JOURNAL NAME, pp. 451 - 462. 
2. Tensile and fatigue behavior of layered acrylonitrile butadiene styrene. Okwara, S. and Ziemain M. 2015, Rapid prototyping Journal, pp. 270 - 278.

3. 3D Printing of Carbon Fiber Composites With Preferentially Aligned Fibers. Ryan, S. and Cetinkaya J. K. 2015, Industrial and Systems Engineering Research Conference.

4. Fused deposition modeling with polypropylene. O.S. Carneiro, A.F. Silva and R. Gomes. 2015, Materials \& Design, pp. 768 - 776.

5. Failure Analysis and Anisotropy Evaluation of 3D-Printed Tensile Test Specimens of Different Geometries and Print Raster Patterns. Roberson, Angel R Torrado and David A. 2015, ASM International.

6. Additive manufacturing of PLA structures using fused deposition modelling: Effect of process parameters on mechanical properties and their optimal selection. Chacon, J.M., Caminero, A.M. and Garcia-Plaza, E. 2017, JOURNAL NAME, pp. 143-157.

7. Evaluating Mechanical Properties and Failure Mechanisms of Fused Deposition Modeling Acrylonitrile Butadiene Styrene Parts. M.S.Uddin, M.F.R. Sidek, M.A.Faizal, R.Ghommashchi, and A.Pramanik. 2017, JOURNAL NAME, pp. 081018-1 - 081018-12.

8. Improved Mechanical Properties of Fused Deposition Modeling-Manufactured Parts Through Build Parameter Modifications. M. S. Hossain, David Espalin, J. Ramos. 2014, JOURNAL NAME, pp. 061002-1 - 061002-12.

9. Influence of processing and orientation print effects on the mechanical and thermal behavior of 3D-Printed ULTEM® 9085 Material. R.J. Zaldivar, D.B. Witkin, T. McLouth, D.N. Patel, K. Schmitt, J.P. Nokes. 2016, JOURNAL NAME, pp. 71-80.

10. Structure and tensile properties evaluation of samples produced by fused deposition modeling. Slota, Ivan and Gajdos Jan. 2016, journal name, pp. 86-89.

11. Structural characteristics of fused deposition modeling polycarbonate material. Dean, W.C. and Smith R.W. 2013, Eslevier Ltd.

12. The ict of process parameters on mechanical properties of parts fabricated in PLA with an open-source 3-D printer. Antonio Lanzotti, Marzio Grasso, and Gabriele Staiano. 2015, Rapid Prototyping Journal, pp. 604 - 617.

13. Deposition direction-dependent failure criteria for fused deposition modeling polycarbonate. Haghi, N. Hill and M. 2014, Rapid prototyping journal, pp. 221 - 227. 
14. EVALUATION OF THE ICT OF PRODUCTION PARAMETERS ON THE FINAL PROPERTIES OF THE PART MADE OF NYLON 12 WITH RAPID PROTOTYPING TECHNOLOGY (FDM). Safka, Michal Ackermann and Jiri. 2016, pp. 956-959.

15. Fractographic analysis of tensile failure ofacrylonitrile-butadiene-styrene fabricated by fused deposition modeling. Riddick, Jaret C. and Haile, M.A. 2016, Additive Manufacturing journal.

16. Fatigue Behavior of FDM Parts Manufactured with Ultem 9085. From The Minerals. Fischer, Schoppner. 2016, Metals and Materials Society journal.

17. Mechanical Characterizing of parts fabricated using fused deposition modeling. Bellini, Anna and Guceri, Selcuk . 2003, Rapid Prototyping journal.

18. Anisotropic material properties of fused deposition modeling ABS. Odell, Dan. 2002, Rapid prototyping journal.

19. Characterizing the effect of additives to ABS on the mechanical property anisotropy of specimens fabricated by material extrusion 3D printing. Torrado, Angel R. 2015, Sience Direct.

20. Fused Deposition Modelling Parts Tensile Strength Characterisation. VIDAKIS, N. and VAIRIS , A. 2016.

21. An insight to the failure of FDM parts under tensile loading: finite element analysis and experimental study. Garg, A. and Bhattacharya, A. 2017, pp. 225 - 236.

22. Highly oriented carbon fiber-polymer composites via additive Manufacturing. L.T, Halil, K., Vlastimil and George, M. 2014, Composites Science and Technology, pp. 144-150.

23. Enhansment of Anisortopic Strength of Fused Deposited ABD parts by genetic Algorithm. Chockalingam, A., Jawahar, N and Praveen, J. 2016, Material and Manufacturing processes journal, pp. 2001-2010.

24. The mechanical characteristics of $3 D$ printed parts according to the build orientation. Zeleny, Petr and Šafka, Jiri. Switzerland : Trans Tech Publications, 2014, Vol. 474. 381 - 386.

25. 3-D printing and characterization of polymer composites with different reinforcements. Advanced processing and manufacturing for nanostructured and multifunctional materials II. Anton, S, Singh, M and C.H, Michael. 2016.

26. Parametric appraisal of mechanical property of fused deposition modeling processed parts. Kumar, A., Ohdar, R.K and Mahapatra, S.S. 2010, Materials and Design, pp. 278 - 295. 
27. Mechanical behavior of ABS: An experimental study using FDM and injection moulding techniques. Dewoud, Michael, Taha, Iman and Ebeid, Samy J. 2016, Manufacturing Processes, pp. $39-45$.

28. Investigating the influence of infill percentage on the mechanical properties of fused deposition modelled ABS parts. L, Kenny and C, Alvarez. 2016, pp. 110 - 116.

29. On the Strain Rate Sensitivity of ABS and ABS-Plus Fused Deposition Modeling Parts. Vairis, A, Petousis, M and Savvaki, K. 2016, pp. 3558 - 3565.

30. The importance of carbon fiber to polymer additive manufacturing. Love, Lonnie J., et al. 2014.

31. Mechanical and thermal properties of ABS/ montmorillonite nanocomposites for fused deposition modeling 3D printing. Weng, Z, Wang, J and Senthil, T. 2016, pp. 276 - 283.

32. Characterization of $3 D$ printed polymers for fiber reinforced polymers processing. Türk, Daniel-Alexander and Brenni, Franco. 2017, pp. 256 - 265.

33. Fatigue of injection molded and 3D printed polycarbonate urethane in solution. Miller, A.T and Safranski , D.L. 2017, pp. 121 - 134.

34. Experimental characterization and analytical modelling of the mechanical behaviour of fused deposition processed parts made of ABS-M30. A., Croccolo. 2013, Computational Materials Journal, pp. 506 - 518 .

35. Tensile and Harness characterisation of rapid prototyped, ABS prototypes. Sathyaseelan, $\mathbf{P}$ and Thamaraikannan, M. 2017, pp. $499-510$. 